Detecção de novidade com aplicação a fluxos contínuos de dados 



\title{
Detecção de novidade com aplicação a fluxos contínuos de dados
}

\author{
Eduardo Jaques Spinosa
}

Orientador: Prof. Dr. André Carlos Ponce de Leon Ferreira de Carvalho

Co-Orientador: Prof. Dr. João Manuel Portela da Gama

Tese apresentada ao Instituto de Ciências Matemáticas e de Computação - ICMC-USP, como parte dos requisitos para obtenção do título de Doutor em Ciências - Ciências de Computação e Matemática Computacional. 



\section{Agradecimentos}

Minha gratidão às pessoas com as quais tive a sorte de trabalhar nesses quatro anos vai além do que as palavras podem expressar.

Ao Professor André Carvalho, obrigado por ter estado sempre presente e por ter proporcionado as condições para que este trabalho pudesse ser desenvolvido. Suas idéias, sua

dedicação e seu entusiasmo foram essenciais. Obrigado pelos conselhos, pela paciência, e pela generosidade em todos os momentos, e em cada um.

Ao Professor João Gama, obrigado por ter aceito o convite para me co-orientar neste projeto, pela atenção durante o estágio, e pelas contribuições que tanto enriqueceram este trabalho.

À Professora Carolina Monard, obrigado pelas orientações, pelos ensinamentos, e pelo privilégio da convivência.

Aos professores, obrigado por compartilharem suas experiências e conhecimento.

Aos colegas, obrigado pelo companheirismo.

Aos funcionários do ICMC, parabéns pela competência e dedicação, qualidades que se refletem em um ambiente de trabalho produtivo e agradável.

Ao CNPq e à CAPES, obrigado pelo apoio. 


\section{Resumo}

Neste trabalho a detecção de novidade é tratada como o problema de identificação de conceitos emergentes em dados que podem ser apresentados em um fluxo contínuo. Considerando a relação intrínseca entre tempo e novidade e os desafios impostos por fluxos de dados, uma nova abordagem é proposta. OLINDDA (OnLIne Novelty and Drift Detection Algorithm) vai além da classificação com uma classe e concentra-se no aprendizado contínuo não-supervisionado de novos conceitos. Tendo aprendido uma descrição inicial de um conceito normal, prossegue à análise de novos dados, tratando-os como um fluxo contínuo em que novos conceitos podem aparecer a qualquer momento. Com o uso de técnicas de agrupamento, OLINDDA pode empregar diversos critérios de validação para avaliar grupos em termos de sua coesão e representatividade. Grupos considerados válidos produzem conceitos que podem sofrer fusão, e cujo conhecimento é continuamente incorporado. A técnica é avaliada experimentalmente com dados artificiais e reais. O módulo de classificação com uma classe é comparado a outras técnicas de detecção de novidade, e a abordagem como um todo é analisada sob vários aspectos por meio da evolução temporal de diversas métricas. Os resultados reforçam a importância da detecção contínua de novos conceitos, assim como as dificuldades e desafios do aprendizado não-supervisionado de novos conceitos em fluxos de dados. 


\section{Abstract}

In this work novelty detection is treated as the problem of identifying emerging concepts in data that may be presented in a continuous flow. Considering the intrinsic relationship between time and novelty and the challenges imposed by data streams, a novel approach is proposed. OLINDDA, an OnLIne Novelty and Drift Detection Algorithm, goes beyond one-class classification and focuses on the unsupervised continuous learning of novel concepts. Having learned an initial description of a normal concept, it proceeds to the analysis of new data, treating them as a continuous flow where novel concepts may appear at any time. By the use of clustering techniques, OLINDDA may employ several validation criteria to evaluate clusters in terms of their cohesiveness and representativeness. Clusters considered valid produce concepts that may be merged, and whose knowledge is continuously incorporated. The technique is experimentally evaluated with artificial and real data. The one-class classification module is compared to other novelty detection techniques, and the whole approach is analyzed from various aspects through the temporal evolution of several metrics. Results reinforce the importance of continuous detection of novel concepts, as well as the difficulties and challenges of the unsupervised learning of novel concepts in data streams. 


\section{Sumário}

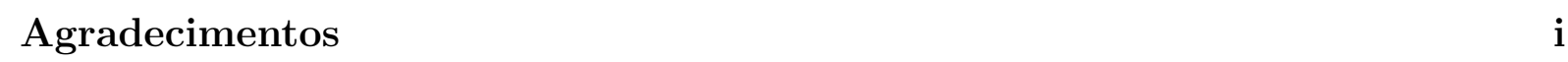

Resumo iii

\begin{tabular}{lll}
\hline Abstract & v
\end{tabular}

Lista de abreviaturas $\quad$ xi

Lista de símbolos $\quad$ xiii

Lista de figuras $\quad$ xvi

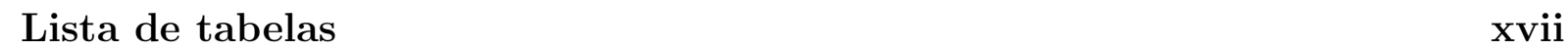

$\begin{array}{lll}\mathbf{1} & \text { Introdução } & \mathbf{1}\end{array}$

1.1 Aprendizado e novidade . . . . . . . . . . . . . . . . . . 1

1.2 Motivação . . . . . . . . . . . . . . . . . . . . . . . . . . . 1

$1.2 .1 \quad$ Detecção de novidade . . . . . . . . . . . . . . . . . . . . 2

$1.2 .2 \quad$ Aplicações envolvendo fluxos contínuos de dados . . . . . . . . . . . 3

1.3 Objetivos . . . . . . . . . . . . . . . . . . . . . . 4

1.4 Organização do texto . . . . . . . . . . . . . . . . . . . 5

$\begin{array}{|lll|}2 & \text { Detecção de novidade, aplicações e abordagens relacionadas } & 7\end{array}$

2.1 Contexto . . . . . . . . . . . . . . . . . . . . . . 7

2.2 Detecção de novidade como um problema de classificação com uma classe . 9

2.3 Definições de novidade e conceitos relacionados $\ldots \ldots \ldots$. . . . . . . . . . . . 9

2.4 Aplicações exploradas neste trabalho . . . . . . . . . . . . . . . . . . . . . 11

2.4 .1 Análise de expressão gênica . . . . . . . . . . . . . . . . . 11

$2.4 .2 \quad$ Fluxos contínuos de dados . . . . . . . . . . . . . . . . . . . . . 13

2.5 Técnicas para detecção de novidade . . . . . . . . . . . . . . . . . . . . 14

2.5 .1 Técnicas estatísticas . . . . . . . . . . . . . . . . . . . . 14

2.5 .2 Técnicas baseadas em redes neurais artificiais . . . . . . . . . . . 16

2.5 .3 Técnicas baseadas em máquinas de vetores suporte . . . . . . . . . 20 
2.5 .4 Técnicas de classificação com uma classe baseadas em agrupamento 22

2.6 Técnicas para detecção de eventos em fluxos de dados . . . . . . . . . . . . 22

2.6 .1 Baseadas em similaridade . . . . . . . . . . . . . . . . 23

2.6 .2 Baseadas em freqüência . . . . . . . . . . . . . . . . . . 24

2.6 .3 Baseadas na estrutura de decisão . . . . . . . . . . . . . 25

2.6 .4 Baseadas em agrupamento . . . . . . . . . . . . . . . . . 25

2.7 Técnicas de agrupamento incremental . . . . . . . . . . . . . . . . . 26

2.8 Discussão $\ldots \ldots \ldots \ldots \ldots \ldots$

3 Experimentos preliminares em bioinformática 29

3.1 Detecção de novidade com máquinas de vetores suporte . . . . . . . . . . . 29

3.1 .1 Motivação e objetivos . . . . . . . . . . . . . . . . . . . . 29

3.1 .2 Metodologia e conjuntos de dados . . . . . . . . . . . . . . . . 30

3.1 .3 Análise dos resultados . . . . . . . . . . . . . . . . . . . . . . 30

3.1 .4 Conclusões . . . . . . . . . . . . . . . . . . . . . . . . . . . . 32

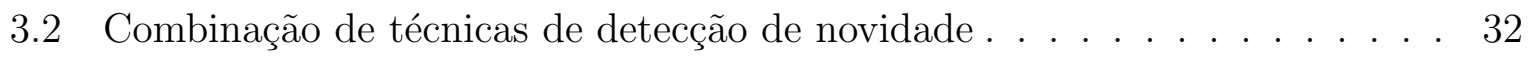

3.2 .1 Motivação e objetivos . . . . . . . . . . . . . . . . . . . . . . 32

3.2 .2 Metodologia e conjuntos de dados . . . . . . . . . . . . . . 33

3.2 .3 Análise dos resultados . . . . . . . . . . . . . . . . . . . . . 33

3.2 .4 Conclusões . . . . . . . . . . . . . . . . . . . . . . . . . 39

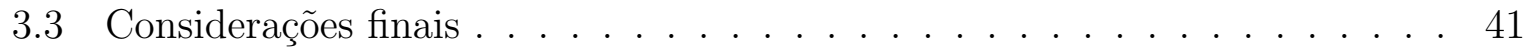

$\begin{array}{lll}4 & \text { Abordagem proposta } & 43\end{array}$

4.1 Detecção de novidade a partir da classificação com uma classe . . . . . . . 43

4.2 Detecção de novidade como parte de um processo de aprendizado contínuo 44

4.3 Grupos, conceitos, modelos e classes . . . . . . . . . . . . . . . . . . . . . 44

4.4 Visão geral do funcionamento de OLINDDA . . . . . . . . . . . . . . . . 45

4.5 Fase inicial de aprendizado supervisionado do conceito normal . . . . . . . 46

$4.6 \quad$ Fase de aprendizado contínuo não-supervisionado de novos conceitos . . . . 47

4.6 .1 Busca por novos conceitos … . . . . . . . . . . . . . . 47

4.6 .2 Critérios de validação . . . . . . . . . . . . . . . . . . . . 48

4.6 .3 Distinção entre conceitos de novidade e extensão . . . . . . . . . . . 49

4.6 .4 Atualização dos modelos e fusão de conceitos . . . . . . . . . . . . 50

4.6 .5 Adaptação automática do número de grupos . . . . . . . . . . . . . 51

4.7 Influência dos parâmetros . . . . . . . . . . . . . . . . . 51

4.8 Complexidade . . . . . . . . . . . . . . . . . . . . . . . . . . . . . 52

4.9 Considerações finais . . . . . . . . . . . . . . . . . . . . . . . . . . . 53 
5 Avaliação experimental de OLINDDA

5.1 Conjuntos de dados . . . . . . . . . . . . . . . . . . . . 55

5.2 Metodologia . . . . . . . . . . . . . . . . . . . 55

5.3 Métricas . . . . . . . . . . . . . . . . . . . . . . 57

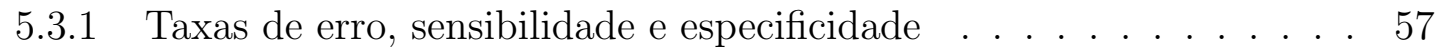

5.3 .2 Curva ROC . . . . . . . . . . . . . . . . . . . . . . . . 59

5.3 .3 Pureza média dos conceitos . . . . . . . . . . . . . . . . . . . . . . 59

5.3 .4 Número de grupos válidos e número de conceitos . . . . . . . . . . 60

5.3 .5 Uso da memória temporária de perfis desconhecidos . . . . . . . . . 60

5.3 .6 Número de grupos . . . . . . . . . . . . . . . . . . 60

5.3 .7 Tempo médio de processamento . . . . . . . . . . . . . . . . . . 60

5.3 .8 Distribuições de classes . . . . . . . . . . . . . . . . . . . . . . . . 61

5.4 Análise dos resultados . . . . . . . . . . . . . . . . . . . . . . . 62

5.4 .1 Distinção entre o conceito normal e perfis desconhecidos . . . . . . 62

5.4 .2 Comparação com outras técnicas de C1C . . . . . . . . . . . . . . . 62

5.4 .3 Descoberta de novos conceitos . . . . . . . . . . . . . . . 67

5.4 .4 Robustez à presença de outliers . . . . . . . . . . . . . . . . . . 72

5.4 .5 Pureza dos conceitos . . . . . . . . . . . . . . . 76

5.4 .6 Complexidade dos modelos e fusão de conceitos . . . . . . . . . . . 80

5.4 .7 Custo computacional . . . . . . . . . . . . . . . . 84

5.4 .8 Influência do algoritmo de agrupamento . . . . . . . . . . . . . 87

5.4 .9 Influência do critério de validação . . . . . . . . . . . . . . . . . 89

5.4 .10 Influência da adaptação automática do número de grupos . . . . . . 91

5.5 Considerações finais . . . . . . . . . . . . . . . . . . . . 92

\begin{tabular}{lll}
\hline 6 & Conclusão & 93
\end{tabular}

6.1 Aspectos gerais da abordagem proposta . . . . . . . . . . . . . . . . . . 93

6.2 Contribuições . . . . . . . . . . . . . . . . . . . . . 94

6.3 Limitações e trabalho futuro . . . . . . . . . . . . . . . . . . . . . . . 95

\begin{tabular}{ll}
\hline Referências bibliográficas & 99
\end{tabular} 


\section{Lista de abreviaturas}

$\mathrm{AM}$

ANN

Aprendizado de Máquina

AEG

Redes neurais artificiais, do Inglês Artificial Neural Networks 16

CD-EBF

Análise de Expressão Gênica

CD-RBF

Class Dependent Elliptical Basis Function

17

CLARA

Class Dependent Radial Basis Function

$\mathrm{C} 1 \mathrm{C}$

Clustering Large Applications

DCS

Classificação com 1 Classe, em Inglês one class classification

DN

Dynamic Cell Structure

FCD

Detecção de Novidade, em Inglês novelty detection

GCS

Fluxos Contínuos de Dados, em Inglês data streams ...

GMLP

Growing Cell Structure

GNG

Multi-Layer Perceptron com função de ativação Gaussiana ....

GNGU

Growing Neural Gas

GRBF

Growing Neural Gas with Utility

GWR

Generalized Radial Basis Function

17

KNN

$\mathrm{KM}$

Grow When Required

K vizinhos mais próximos, do Inglês $K$ Nearest Neighbors

K-Médias

17

MLP

Multi-Layer Perceptron

PAM

PCA

$\mathrm{PW}$

Partitioning Around Medoids

Análise de comp. principais, do Inglês Principal Components Analysis ..33

$\mathrm{RBF}$

$\mathrm{ROC}$

Janelas de Parzen, do Inglês Parzen Windows

Radial Basis Function

$\mathrm{SOM}$

Receiver Operating Characteristic

Mapa auto-organizável, do Inglês Self-Organizing Map

$\nu$-SVC

$\nu$-Support Vector Classifier

SVDD

Support Vector Data Description

SVM

Máquinas de vetores suporte, do Inglês Support Vector Machines 


\section{Lista de símbolos}

\begin{tabular}{|c|c|}
\hline$c$ & Grupo, em Inglês cluster \\
\hline dens & Densidade \\
\hline$e_{F N e g}$ & Taxa de erro falso-negativo \\
\hline$e_{F P o s}$ & Taxa de erro falso-positivo \\
\hline$k$ & Número de grupos \\
\hline$k_{i n i}$ & Número de grupos para a geração do modelo normal \\
\hline minexcl & Número mínimo de exemplos em um novo grupo \\
\hline MsPorEx & Tempo médio por exemplo desde o início do processo \\
\hline MsPorEx $5 p c$ & Tempo médio por exemplo em cada etapa de $5 \%$ isoladamente \\
\hline$\mu$ & Centróide \\
\hline$m$ & Dimensão, número de atributos \\
\hline$n$ & Número de exemplos . \\
\hline$n c$ & Número de grupos .. \\
\hline NumConc & Número de conceitos ..... \\
\hline NumExDes & Número de exemplos na memória temp. de perfis desconhecidos \\
\hline NumGrVal & Número de grupos válidos \\
\hline$p$ & Densidade de probabilidade \\
\hline$r$ & Raio \\
\hline PurConc & Pureza média dos conceitos \\
\hline PurConcDescob & Pureza média dos conceitos no momento da descoberta \\
\hline vol & Volume \\
\hline$w$ & Estado . . \\
\hline
\end{tabular}




\section{Lista de figuras}

2.1 Processo de expressão gênica. $\ldots \ldots \ldots \ldots$. . . . . . . . . . . . . 12

3.1 Resultados com o conjunto leukemia com ALL-T como novidade. . . . . . 31

3.2 Resultados com o conjunto lymphoma com germinal center como novidade. 32

3.3 Formato em que os resultados são apresentados. . . . . . . . . . . . . . . . 34

3.4 Mudanças com a redução de atributos para colon. . . . . . . . . . . . . . . 34

3.5 Mudanças com a redução de atributos para lymphoma. . . . . . . . . . . . 35

3.6 Mudanças com a redução de 5 para 3 classificadores para breast. . . . . . . 36

3.7 Mudanças com a redução de 5 para 3 classificadores para colon. . . . . . . 36

3.8 Mudanças com a redução de 5 para 3 classificadores para leukemia. . . . . 36

3.9 Mudanças com a redução de 5 para 3 classificadores para lymphoma. . . . . 37

3.10 Mudanças com um conjunto diferente de 3 classificadores para breast. . . . 37

3.11 Mudanças com um conjunto diferente de 3 classificadores para colon. . . . 38

3.12 Mudanças com um conjunto diferente de 3 classificadores para leukemia. $\quad 38$

3.13 Mudanças com um conjunto diferente de 3 classificadores para lymphoma. . 38

3.14 Erros cometidos por cada técnica para breast. . . . . . . . . . . . . 39

3.15 Erros cometidos por cada técnica para colon. . . . . . . . . . . . . . . 40

3.16 Erros cometidos por cada técnica para leukemia. . . . . . . . . . . . . . 40

3.17 Erros cometidos por cada técnica para lymphoma. . . . . . . . . . . . . . 40

4.1 Fluxograma de OLINDDA. . . . . . . . . . . . . . . . . . 46

5.1 Interpretação gráfica de sensibilidade e especificidade. . . . . . . . . . . . . 59

5.2 Exemplos de curvas ROC. . . . . . . . . . . . . . . . . . . 59

5.3 Curvas ROC para diversos conjuntos de dados. . . . . . . . . . . . . 63

5.4 Curvas ROC para diversos conjuntos de dados. . . . . . . . . . . . . . 63

5.5 Comparação com outras técnicas de C1C. . . . . . . . . . . . . . . 65

$5.6 \quad$ Distribuição de classes padrão para o conjunto de dados iris. . . . . . . . . . 68

5.7 Conjunto de dados outliers1. . . . . . . . . . . . . . . . 72

5.8 Distribuição de classes padrão para o conjunto de dados outliers1. . . . . . 73

5.9 Exemplo de descrição produzida por OLINDDA para o conjunto outliers1. 74

5.10 Conjunto de dados outliers2. . . . . . . . . . . . . . . . . 75 
5.11 Distribuição de classes padrão para o conjunto de dados outliers2. . . . . . 75

5.12 Exemplo de descrição produzida por OLINDDA para o conjunto outliers2. 76

5.13 Evolução de diversas métricas ao longo do tempo para breastwisconsin, com minexcl=3. . . . . . . . . . . . . . . . . . 81

5.14 Evolução de diversas métricas ao longo do tempo para $k d d c u p \_p c 10_{-} c 5$ com minexcl=5. . . . . . . . . . . . . . . . . . 82

5.15 Evolução de diversas métricas ao longo do tempo para kddcup_pc10 com minexcl=5. . . . . . . . . . . . . . . . . 83

5.16 Evolução de diversas métricas ao longo do tempo para $k d d c u p \_p c 10_{-} c 5$ com minexcl=10. . . . . . . . . . . . . . . . . 85

5.17 Exemplo de fusão de conceitos para o conjunto de dados iris. . . . . . . . 86

5.18 Influência da adaptação automática do parâmetro número de grupos. .. 92 


\section{Lista de tabelas}

3.1 Conjuntos de dados utilizados nos experimentos preliminares. . . . . . . . 30

5.1 Conjuntos de dados utilizados na avaliação experimental de OLINDDA. . . 56

5.2 Matriz de confusão com a nomenclatura adotada neste trabalho. . . . . . . 58

5.3 Legenda da distribuição de classes padrão. . . . . . . . . . . . . . . . . . . 61

5.4 Comparação com outras técnicas de C1C. . . . . . . . . . . . . . 66

5.5 Distribuição de classes padrão para diversos conjuntos de dados. . . . . . . 69

5.6 Taxas de erro e distribuição de classes resumida para $k d d c u p \_p c 10 \_c 5$. . . . 71

5.7 Taxas de erro e distribuição de classes resumida para $k d d c u p \_p c 10$. . . . . . 71

5.8 Valores finais de diversas métricas para diversos conjuntos de dados e parâmetros, parte 1 de 3. . . . . . . . . . . . . . . . . 77

5.9 Valores finais de diversas métricas para diversos conjuntos de dados e

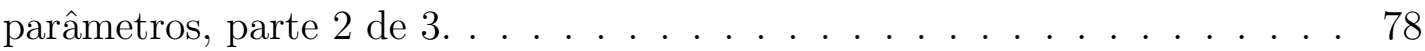

5.10 Valores finais de diversas métricas para diversos conjuntos de dados e parâmetros, parte 3 de 3. . . . . . . . . . . . . . . . . . . 79

5.11 Influência do algoritmo de agrupamento sobre a distribuição de classes. . 88

5.12 Influência do algoritmo de agrupamento sobre diversas métricas. . . . . . . 89

5.13 Influência do critério de validação sobre a distribuição de classes. . . . . . . 90

5.14 Influência do critério de validação sobre diversas métricas. . . . . . . . . . 91 


\section{Capítulo 1}

\section{Introdução}

Neste trabalho propõe-se uma nova abordagem ao problema da deteç̧ão de novidade, capaz de identificar de maneira não-supervisionada o aparecimento de novos conceitos em dados que podem ser apresentados sob a forma de um fluxo contínuo.

\subsection{Aprendizado e novidade}

Michalski et al. (1986) definem aprendizado de uma maneira clara e sucinta: "Learning is constructing or modifying representations of what is being experienced".

Além da capacidade de construir uma representação de algo que se experimenta, aprender é também modificar ou atualizar essa representação com o passar tempo e à medida que o que se experimenta tenha se modificado. Assim, o aprendizado é, em geral, um processo essencialmente contínuo.

O que mantém esse processo em atividade é a introdução de algo novo. Assim, aprendizado e novidade são conceitos intrinsecamente relacionados. Somente algo que introduza características até então desconhecidas é capaz de motivar um novo ciclo de aprendizado.

A capacidade de identificar o novo é, portanto, essencial para que, em geral, o aprendizado se dê de maneira efetiva. E essa capacidade apóia-se, basicamente, em dois elementos: uma descrição do que é usual, conhecido ou normal, e uma ação contínua de verificação de compatibilidade entre características que se apresentem com o passar do tempo e essa descrição do que é conhecido.

\subsection{Motivação}

Técnicas de Aprendizado de Máquina (AM) têm sido cada vez mais empregadas em problemas reais envolvendo a análise automática de uma grande quantidade de dados. Nessas aplicações, para que o aprendizado seja feito de maneira contínua, diversos desafios precisam ser enfrentados. Entre eles, um dos mais importantes é o da identificação de 
novos conceitos.

\subsubsection{Detecção de novidade}

Em AM, o termo Detecção de Novidade (DN), em Inglês novelty detection, pode ser usado para fazer referência a abordagens essencialmente distintas, dependendo, entre outros aspectos, da comunidade de pesquisa em que o trabalho se insere. No contexto deste trabalho, DN é a capacidade de identificar novos conceitos à medida que dados adicionais são recebidos. Esses conceitos podem representar classes reais, e a possibilidade de identificá-los pode contribuir para tratar uma série de problemas em AM.

Entre as diversas aplicações de técnicas de DN, estão:

- Detecção de falhas em máquinas. Com base em informações de sensores capturadas durante o funcionamento normal de uma máquina, identificar pequenas variações nesses valores que possam indicar alguma situação inesperada. A identificação prematura de uma falha pode permitir a intervenção para o desligamento da máquina antes que se danifique.

- Detecção de novos tópicos em textos. Com o aumento da quantidade de informação textual produzida nas mais diversas formas, incluindo, por exemplos, artigos de notícias e artigos científicos, detectar novos tópicos ou assuntos de maneira automática passa a ser um problema cada vez mais importante e desafiador, a ponto de haver uma área de pesquisa especificamente dedicada a ele, denominada topic detection and tracking.

- Detecção de invasões em redes de computadores. A análise do tráfego em redes de computadores pode permitir a identificação de tentativas de ataque. Com base no aprendizado feito a partir de dados referentes ao tráfego normal na rede, uma técnica de DN pode alertar para o aparecimento de características inesperadas, possibilitando a identificação de novos tipos de ataques.

- Detecção de regiões de interesse em imagens médicas. Com o aumento na quantidade de exames médicos por imagem, a análise dessas informações por um especialista torna-se cada vez mais cara. Além disso, dependendo do tipo de exame, pode ser difícil detectar visualmente alterações muito sutis. Técnicas de DN são úteis, por exemplo, em uma fase de triagem, auxiliando o especialista nessa tarefa.

- Detecção de mudanças em um ambiente. A DN é uma característica importante no uso de robôs em ambientes pouco conhecidos, como na exploração espacial, ou nos quais mudanças possam representar situações de risco. 
- Detecção de estouros (bursts) em séries temporais. Em fluxos contínuos de dados, a análise de agregados estatísticos permite, por exemplo, identificar variações de tendência. As áreas de aplicação variam da análise do volume de transações em bolsas de valores ao monitoramento de fótons capturados por um telescópio astronômico em busca de explosões de raios gama.

- Detecção de novos perfis de expressão gênica. Neste trabalho apresenta-se uma aplicação da DN à bioinformática cujo objetivo é o de tentar identificar novos perfis de expressão gênica.

Essas e outras aplicações nas mais diversas áreas têm motivando nos últimos anos o desenvolvimento de uma série de algoritmos para DN. Enquanto alguns são desenvolvidos especificamente para uma determinada aplicação, outros são adaptações de técnicas tradicionais de AM, com um caráter mais genérico.

Uma importante área de pesquisa na qual algoritmos de DN podem oferecer uma relevante contribuição é a relacionada ao estudo dos fluxos contínuos de dados.

\subsubsection{Aplicações envolvendo fluxos contínuos de dados}

Com o avanço tecnológico, alguns problemas, anteriormente tratados com técnicas tradicionais de AM e mineração de dados, passaram a envolver uma grande quantidade de dados gerados continuamente. À medida que deixa de ser possível armazenar os dados, surge uma série de novos desafios. Pesquisas nessa área passam a ser desenvolvidas segundo um novo paradigma, que encara os dados não mais como conjuntos limitados e estáticos, mas sob a forma de fluxos contínuos e potencialmente ilimitados, denominados Fluxos Contínuos de Dados (FCD), em Inglês data streams (Gama and Gaber, 2007).

Entre os domínios nos quais técnicas de AM em FCD têm sido aplicadas, estão:

- Redes de sensores. Redes de sensores podem, por exemplo, fornecer continuamente informações a respeito do nível de congestionamento nas vias de uma cidade. À medida que os dados provenientes desses diversos sensores distribuídos no espaço precisam ser continuamente analisados, técnicas de AM capazes de lidar com múltiplos FCD passam a ser empregadas.

- Serviços $\boldsymbol{w e b}$. Grandes sítios ou portais monitoram continuamente informações relativas ao seu uso para atividades como a personalização de conteúdo e o monitoramento de desempenho de seus equipamentos.

- Mercado financeiro. Dados do mercado financeiro, como os das bolsas de valores, por exemplo, precisam ser analisados à medida que são recebidos para produzir informações relevantes ao usuário, considerando que nesse contexto a relevância está diretamente relacionada ao fator tempo. 
- Redes de computadores. O aumento nas velocidades dessas redes tornam o processo de análise dos dados cada vez mais desafiador, especialmente nos equipamentos que agregam conexões de diversas redes. Como mencionado anteriormente, uma das aplicações de DN nesse domínio é a da detecção de intrusão.

Aplicações como essas representaram um importante incentivo para o desenvolvimento deste trabalho, uma vez que, em cada uma delas há a possibilidade de identificar o aparecimento de novos conceitos, fornecendo informações relevantes ao usuário, alertando para situações inesperadas que requeiram sua atenção imediata, ou identificando mudanças de regime, cujo conhecimento agregue valor à atividade em questão.

\subsection{Objetivos}

O objetivo central deste trabalho é propor uma nova abordagem ao problema da detecção de novidade, capaz de identificar de maneira não-supervisionada o aparecimento de novos conceitos em dados que podem ser apresentados sob a forma de um fluxo contínuo.

A abordagem proposta pretende ir além da visão da DN como um problema estático de classificação como uma classe. Aqui, a novidade é vista como um novo conceito em um cenário essencialmente dinâmico, em que o algoritmo deve ser capaz de distinguir, a qualquer instante, elementos associados a conceitos conhecidos de outros que possam potencialmente indicar a presença de novos conceitos. Para evidenciar o aparecimento de um novo conceito, propõem-se critérios de validação que avaliem aspectos como coesão e representatividade. Essa estratégia permite a caracterização de novidade e outliers como elementos distintos, o que não é possível somente com a classificação com uma classe.

Além disso, a abordagem proposta pretende permitir a extensão do conceito aprendido inicialmente e a fusão de conceitos descobertos ao longo do tempo, enfatizando novamente o caráter contínuo do processo de aprendizado, em que novos conceitos podem surgir e conceitos existentes podem modificar-se com o passar do tempo.

Propõe-se ainda uma metodologia experimental e um conjunto de métricas para avaliar, sob diversos pontos de vista, o desempenho de técnicas de DN.

Em uma fase inicial, também fizeram parte dos objetivos deste doutoramento a avaliação do uso de técnicas de DN em bioinformática, especificamente para identificar novos perfis de expressão gênica. Esses estudos envolveram a aplicação de uma técnica baseada em máquinas de vetores suporte e a combinação de algumas técnicas de DN para extrair melhores resultados. 


\subsection{Organização do texto}

No Capítulo 2 são tratados os conceitos relacionados com a DN, duas das aplicações exploradas neste trabalho, e as principais abordagens relacionadas descritas na literatura. Inicialmente apresenta-se o contexto envolvendo a DN e a classificação com uma classe. Em seguida, discute-se algumas definições de novidade e conceitos relacionados presentes na literatura, assim como a perspectiva deste trabalho. Em uma segunda parte desse capítulo são apresentadas duas das aplicações exploradas neste trabalho: a análise de expressão gênica e o aprendizado em FCD. Em seguida, são apresentadas algumas das principais técnicas envolvendo DN, detecção de eventos em FCD e agrupamento incremental, procurando construir um panorama geral das pesquisas realizadas nessas áreas. O capítulo termina com uma discussão acerca das técnicas mais diretamente relacionadas com este trabalho.

No Capítulo 3 são analisados os resultados de experimentos preliminares envolvendo DN em bioinformática, no contexto da análise de expressão gênica. Uma primeira série de experimentos avalia o uso de máquinas de vetores suporte para esse fim. Numa segunda série, os experimentos se concentram na combinação de técnicas de DN.

No Capítulo 4 descreve-se a abordagem proposta neste trabalho, implementada pelo algoritmo OLINDDA. Inicialmente são apresentadas duas idéias fundamentais em seu desenvolvimento: a da DN a partir da classificação com uma classe, aprofundando a discussão iniciada no Capítulo 2, e a da DN como parte de um processo de aprendizado contínuo. A nomenclatura adotada e a estrutura geral do algoritmo são então apresentadas, seguidas de uma descrição detalhada de seu funcionamento. No fim desse capítulo são discutidas a influência dos parâmetros e a complexidade.

No Capítulo 5 são analisados resultados de experimentos que avaliam a abordagem proposta sob diferentes pontos de vista. Inicialmente são descritos os conjuntos de dados, metodologia e métricas utilizadas. Em seguida, a análise dos resultados é dividida em uma série de seções, cada uma enfatizando um aspecto ou conjunto de aspectos considerados importantes no contexto da detecção de novos conceitos em FCD.

No Capítulo 6, são discutidas as principais conclusões e contribuições deste trabalho, assim como suas limitações e desafios futuros. 


\section{Capítulo 2}

\section{Detecção de novidade, aplicações e abordagens relacionadas}

O tema DN tem atraído crescente interesse em diversas áreas de pesquisa relacionadas com AM, percebendo-se um sensível aumento no número de trabalhos publicados (Markou and Singh, 2003a b). Em cada um, dependendo do contexto e da aplicação, diferentes termos podem ser utilizados para fazer referência a idéias essencialmente semelhantes. Este capítulo procura fornecer uma visão ampla do problema da DN, incluindo trabalhos de diversas áreas relacionadas.

Inicialmente, são apresentados o contexto geral de AM e a DN como um problema de classificação com uma classe. O conceito de novidade é discutido e estabelece-se sua definição no contexto deste trabalho. Em uma segunda parte deste capítulo, são apresentadas as duas principais aplicações exploradas: a análise de expressão gênica e o aprendizado em FCD. Em seguida, são apresentadas as principais técnicas descritas na literatura no âmbito da DN, da detecção de eventos em FCD e das técnicas de agrupamento incremental. O capítulo termina com uma discussão envolvendo as técnicas mais relevantes no contexto deste trabalho.

\subsection{Contexto}

O AM pode ser realizado de maneira supervisionada, se os exemplos possuirem informação relativa à sua classe real; não-supervisionada, se esses rótulos não estiverem disponíveis; ou semi-supervisionada, se tanto exemplos rotulados quanto não-rotulados forem utilizados. Em muitas aplicações reais, a obtenção dos rótulos de todos os exemplos pode não ser possível, uma vez que isso implica a análise manual dos dados por um especialista. Algoritmos de agrupamento (clustering), por exemplo, são capazes de aprender de maneira não-supervisionada.

No contexto do AM supervisionado, uma importante tarefa é a da classificação, que 
consiste em, com base em exemplos para os quais a classe é conhecida, induzir, em uma fase de treino, um classificador capaz de predizer, em uma fase de teste, a que classe pertence cada novo exemplo apresentado.

Em problemas convencionais de classificação, o classificador induzido sempre atribui cada novo exemplo a uma das classes conhecidas, o que pode ser uma decisão inadequada se o modelo obtido a partir dos exemplos do conjunto de treino não representar bem a distribuição dos dados no momento da classificação. Isso pode ser ocasionado, entre outros fatores, por:

- Mudança na distribuição dos dados. Se a distribuição dos dados tiver sofrido alterações após a fase de treino, é possível que novos conceitos tenham aparecido e que as características de conceitos antigos tenham se modificado (concept drift) (Klinkenberg, 2004). Essa é uma situação freqüente em diversas aplicações reais.

- Conjunto de treino pouco representativo. É possível que algum conceito sempre tenha existido, mas que apenas não fizesse parte do modelo por não estar bem representado na fase de treino. Obter um bom conjunto de treino, em que todos os conceitos estejam bem representados, normalmente não é uma tarefa simples.

- Impraticável obter exemplos que permitam descrever algumas classes. Em algumas aplicações é impraticável obter exemplos de todas as possíveis condições relacionadas a uma determinada classe. Em um problema de detecção de falhas em máquinas, por exemplo, é caro ou impraticável simular todas as possíveis condições de falha e, portanto, não é possível obter uma boa descrição para a classe que representa a falha.

- Presença de outliers. Exemplos esparsos que não representam nenhum conceito não deveriam ser atribuídos a nenhuma classe.

Nessas situações, a classificação tradicional será inadequada, porque falha a pressuposição de que o classificador induzido na fase de treino seja competente para julgar qualquer novo exemplo que lhe seja apresentado posteriormente. Uma alternativa é impedir que a classificação seja feita nos casos em que não haja um grau de confiança suficiente. Na literatura, classificadores que consideram a opção de rejeitar ou deixar de classificar exemplos são denominados reject-option classifiers (Landgrebe et al., 2006) e abstaining classifiers (Pietraszek, 2007). Entretanto, simplesmente impedir a classificação não permite a identificação de mudanças ou de novos conceitos, e o classificador continuará inadequado à classificação de novos exemplos. 


\subsection{Detecção de novidade como um problema de clas- sificação com uma classe}

Em classificação binária e com múltiplas classes, o aprendizado é feito com base em um conjunto de exemplos de treino que inclui representantes de todas as classes que compõem o problema.

Um tipo especial de classificação em que, na fase de treino, somente existe informação a respeito de uma única classe, é denominado Classificação com 1 Classe (C1C), em Inglês one class classification ou single class classification (Tax, 2001). A C1C caracteriza-se pelo aprendizado de um único conceito-alvo a partir apenas de exemplos desse conceito. Como na classificação binária esses exemplos seriam denominados positivos, a $\mathrm{C} 1 \mathrm{C}$ também pode ser vista como um tipo de aprendizado realizado com base apenas em exemplos positivos (learning from positive-only examples) (Valiant, 1984).

O maior desafio da C1C está em obter o grau adequado de generalização na descrição do conceito-alvo. Isso ocorre porque a ausência de contra-exemplos dificulta o posicionamento das fronteiras de decisão, isto é, a especialização do classificador.

Um classificador do tipo $\mathrm{C} 1 \mathrm{C}$ é capaz de identificar exemplos que não pertençam ao conceito-alvo que foi aprendido. Assim, além de ser capaz de impedir classificações inadequadas nos casos descritos anteriormente, a C1C aplica-se a situações nas quais só há informação a respeito de um único conceito, como naquelas em que é impraticável obter exemplos que permitam descrever algumas classes. Por esse motivo, o problema de $\mathrm{DN}$ é freqüentemente tratado ou referido na literatura como um problema de C1C.

Neste trabalho, contudo, propõe-se uma perspectiva diferente para o problema da DN, que a distingue da tarefa de $\mathrm{C} 1 \mathrm{C}$ e pretende estabelecer claramente que um exemplo que não pertença a um conceito-alvo não necessariamente é uma novidade, no sentido de representar um novo conceito.

\subsection{Definições de novidade e conceitos relacionados}

Em AM, a DN pode ser definida como a identificação de entradas que diferem de alguma maneira do que normalmente se espera (Marsland, 2003). Detecção de anomalia (anomaly detection) também é um termo utilizado com o mesmo sentido, normalmente fazendo referência a uma aplicação em que a novidade representa uma condição indesejável no domínio que está sendo analisado. Alguns outros termos, como surprising events ou bursts no contexto do estudo de séries temporais, também são usados em trabalhos relacionados com DN. A definição exata desses termos varia de um trabalho para outro, e fica mais clara com a análise de cada trabalho individualmente, apresentada na Seção 2.5 .

A definição de novidade como entradas que diferem do que normalmente se espera 
(Marsland, 2003) pode, entretanto, gerar confusão com o conceito de outlier. Uma recente pesquisa (survey) das abordagens à detecção de outliers (Hodge and Austin, 2004) considera a DN como uma delas. Embora não esteja em desacordo com a noção estatística de outlier, que identifica uma observação ou um sub-conjunto de observações que aparenta ser inconsistente em relação ao restante do conjunto de dados (Barnett and Lewis, 1995), a perspectiva de tratar novidades e outliers indistintamente pode não ser a mais apropriada. Outliers podem ser vistos como elementos contaminantes, que interferem negativamente na representação de uma população. Novidades, por outro lado, induzem naturalmente à idéia de novos conceitos, cujo aprendizado pode contribuir positivamente para a tarefa de classificação.

Neste trabalho pretende-se estabelecer claramente a distinção entre novidade e outlier. No contexto deste estudo, novidade é considerada um conceito, isto é, uma abstração de instâncias ou exemplos que compartilham um conjunto de características. Do ponto de vista da distribuição dos exemplos no espaço, um conceito é um grupo coeso e representativo de exemplos. Assim, uma novidade é um novo conceito, ou seja, um conceito cujas características diferem daquelas dos demais conceitos até então identificados. Outliers, por outro lado, são entendidos como exemplos isolados, não representativos, distribuídos de maneira esparsa, que, portanto, não compartilham características com os demais.

Se as características de um novo conceito forem semelhantes às do conceito aprendido inicialmente, denominado conceito normal, usa-se neste trabalho o termo extensão em vez de novidade, para indicar uma possível extensão ao conceito normal em vez de um conceito realmente distinto. Esse tipo de situação pode estar relacionada a uma mudança de conceito (concept drift) (Tsymbal, 2004). Entretanto, é importante ressaltar que o estudo das técnicas para identificação e tratamento de concept drift envolve uma série de considerações que fogem ao escopo deste trabalho.

Algumas técnicas de DN utilizam ainda o conceito de habituação (habituation), inspirado na habilidade natural que têm os seres vivos de detectarem rapidamente mudanças no meio ambiente (Marsland, 2003). Essa capacidade é vital em um cotidiano de permanente luta pela sobrevivência e pela propagação de seu material genético, além de um importante fator de estímulo ao aprendizado, uma vez que o desafio imposto pela novidade motiva o desenvolvimento de novas habilidades.

A idéia central da habituação é a de que cada nova resposta a um estímulo que se repete sem causar efeitos nocivos, tende a ser menos intensa do que a anterior Thompson and Spencer, 1966). Isto é, de maneira gradual, sensações inicialmente consideradas novas vão sendo incorporadas ao conceito de normalidade. Do ponto de vista de AM, o ser vivo está constantemente modificando seu modelo de ambiente, o que computacionalmente pode corresponder a uma atividade bastante complexa.

A habituação é reversível, isto é, se um dado estímulo ao qual o ser vivo tenha se habituado desaparecer e somente voltar a ocorrer após um certo tempo de repouso, a 
resposta voltará a ser alta. Essa e outras características da habituação já há muito tempo vêm sendo estudadas por Biólogos. O conhecimento do processo de habituação e desabituação nos seres vivos pode inspirar o desenvolvimento de métodos computacionais de DN mais complexos. Em particular, essa influência pode ser observada em alguns tipos de redes neurais artificiais auto-organizáveis, apresentadas na Seção 2.5 .

\subsection{Aplicações exploradas neste trabalho}

Na Seção 1.2.1 foram identificadas algumas aplicações às quais técnicas de DN podem ser úteis. Esta seção apresenta mais detalhes sobre as duas aplicações mais profundamente estudadas ao longo do desenvolvimento deste trabalho.

Em primeiro lugar, descreve-se a análise de expressão gênica, um problema de bioinformática. Os principais resultados experimentais dos estudos relativos à DN em bioinformática são apresentados no Capítulo 3. Em seguida, descreve-se o problema da AM em FCD, importante fator incentivador ao desenvolvimento da abordagem proposta, apresentada no Capítulo 4 e avaliada no Capítulo 5.

\subsubsection{Análise de expressão gênica}

Avanços na tecnologia de seqüenciamento do DNA alavancaram as pesquisas na área da biologia molecular, levando a um crescimento exponencial na quantidade de dados armazenados e disponíveis para serem analisados (Baldi and Brunak, 2001). O alto custo da análise laboratorial tradicional motivou o desenvolvimento de uma série de ferramentas computacionais e deu origem a uma nova área interdisciplinar de pesquisa, a bioinformática ou biologia computacional (Meidanis and Setúbal, 1994).

Com a finalização do seqüenciamento genético de diversas espécies, o objetivo das pesquisas na área da biologia molecular voltou-se para o entendimento das funções de cada gene e da maneira como eles interagem. Acredita-se que esse conhecimento possa levar a uma abordagem promissora para o diagnóstico e o tratamento de doenças, permitindo, por exemplo, o desenvolvimento de drogas cuja ação seja direcionada especificamente a um determinado conjunto de genes.

Um dos diversos problemas de biologia molecular que vêm sendo tratados computacionalmente com o uso de técnicas de AM é o da Análise de Expressão Gênica (AEG).

A expressão gênica, representada na Figura 2.1, é o processo pelo qual as informações codificadas nos genes são expressas nas estruturas e funções presentes nas células. Em uma primeira fase, o DNA é transcrito para o RNA mensageiro (mRNA). Em seguida, ocorre a tradução do mRNA e a síntese efetiva de moléculas de proteína. Trata-se de um processo muito importante, pois nele são definidas as intensidades com as quais as proteínas atuarão nas células, o que tem influência sobre o funcionamento de todo o 


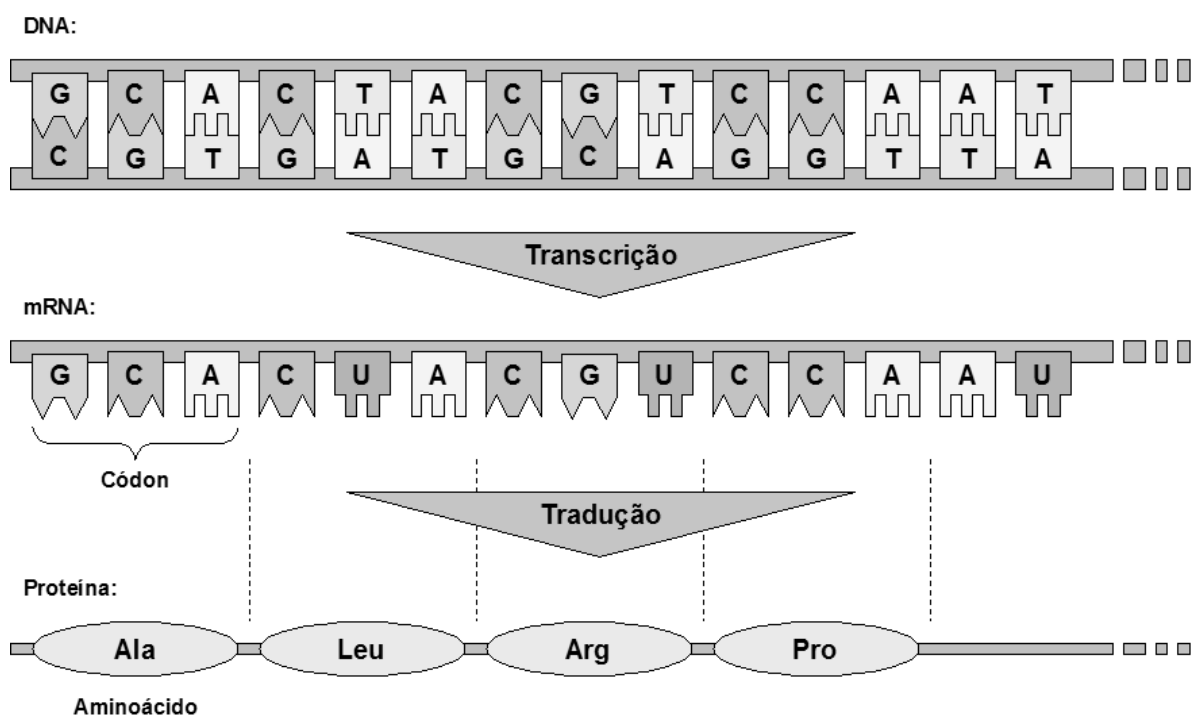

Figura 2.1: Processo de expressão gênica.

organismo.

Diversos métodos podem ser utilizados para medir a expressão dos genes, entre os quais Massively Parallel Signature Sequence (Brenner et al., 2000), Serial Analysis of Gene Expression (Velculescu et al., 1995), Reverse-Transcription Polymerase Chain Reaction (Freeman et al., 1999) e Microarray de DNA (Harrington et al., 2000). Por meio da aplicação de um desses processos sobre uma amostra de tecido, são coletados os valores individuais da expressão de cada gene. Esses valores podem ser armazenados sob a forma de uma tabela em que cada linha refere-se a uma amostra de tecido (exemplo), e cada coluna contém o valor da expressão de um determinado gene (atributo). Na maioria das vezes há também a informação, obtida por meio de técnicas tradicionais de citologia e microscopia eletrônica, que indica se a amostra apresenta ou não uma determinada alteração ou doença (classe).

Sabe-se que mudanças na fisiologia de um ser vivo estão normalmente relacionadas a variações na expressão de determinado conjunto de genes (Alberts et al., 1997). Espera-se que resultados obtidos em processos computacionais de AEG possam identificar relações importantes entre a intensidade com a qual um determinado gene ou conjunto de genes está expresso e alterações de natureza fisiológica, como um determinado tipo ou sub-tipo de doença.

Do ponto de vista de AM, o problema de AEG consiste na busca por relações entre os valores de expressão dos genes (atributos) e uma determinada característica biológica verificada na amostra (classe). Técnicas de AM utilizadas para AEG incluem máquinas de vetores suporte (Brown et al., 2000; Furey et al., 2000), redes neurais artificiais (Khan et al. 2001; Xu et al., 2002) e diversas outras (Shipp et al., 2002). Os resultados indicam ser possível descobrir de maneira automática quais genes estão relacionados a uma determinada fisiologia ou doença. 
Analisando o problema da AEG sob a ótica da DN, acredita-se que esse tipo de técnica possa contribuir para, por exemplo, identificar novos perfis de expressão gênica que possam estar relacionados a uma determinada manifestação fisiológica até então desconhecida. No Capítulo 3 são apresentados resultados de experimentos preliminares envolvendo técnicas de DN para AEG.

Uma característica intrínseca aos dados de expressão gênica que representa um grande desafio do ponto de vista de AM é a grande quantidade de genes (atributos), da ordem de milhares, em contraposição à pequena quantidade de amostras (exemplos), da ordem de dezenas. A influência desse aspecto será analisada no Capítulo 3.

Outra característica dos dados de expressão gênica a ser considerada é a presença do chamado ruído biológico. Como os valores de expressão gênica dependem de interações complexas, fatores intracelulares, relacionados ao estado da célula no ciclo celular, e extracelulares, decorrentes de interações entre as células que estão sendo analisadas na amostra, podem gerar oscilações indesejáveis nos valores de expressão de genes obtidos experimentalmente. Do ponto de vista da DN, a presença de ruído nos dados iniciais pode dificultar a geração de um modelo que descreva adequadamente os dados.

\subsubsection{Fluxos contínuos de dados}

Em uma série de domínios, entre eles os descritos na Seção 1.2.2, os dados assumem a forma de um fluxo contínuo. No contexto de muitas dessas aplicações, a DN é uma tarefa importante, uma vez que permite a identificação de novos conceitos potencialmente interessantes.

O modelo dos FCD caracteriza-se essencialmente pelos seguintes pontos Babcock et al., 2002):

- Os elementos que compõem os dados são recebidos de maneira contínua.

- O sistema não tem controle sobre a ordem em que os elementos são recebidos.

- FCD são potencialmente ilimitados.

- Uma vez que um elemento do fluxo tenha sido processado, deve ser descartado ou arquivado, não podendo ser recuperado facilmente a não ser que seja explicitamente armazenado na memória, que é pequena quando comparada ao fluxo.

Essas características impõem uma série de novos desafios aos algoritmos de AM. Em primeiro lugar, como os dados não podem ser armazenados, o algoritmo deve ser capaz de tratar cada exemplo individualmente ou em pequenos conjuntos. O aprendizado precisa ser feito de maneira que, em geral, os exemplos possam ser descartados após terem sido tratados. 
Além disso, como a idéia de fluxo está intrinsecamente ligada ao fator tempo, o algoritmo deve ser capaz de aprender continuamente. Isso significa, entre outras coisas, que o modelo que descreve os dados deve ser capaz de representar adequadamente o conhecimento a qualquer instante. Sua estrutura deve ser flexível e simples, para que ocupe pouco espaço em memória e seja facilmente atualizável, por exemplo, na inclusão ou modificação de um conceito.

Finalmente, a grande quantidade de dados presente nos FCD impõe restrições adicionais com respeito à eficiência. O algoritmo deve ser capaz de tratar os dados pelo menos na mesma velocidade do fluxo, e seu custo computacional não deve, em nenhuma circunstância, ultrapassar esse limite.

Essas e outras características têm motivado o desenvolvimento de técnicas de AM específicas para FCD. Os trabalhos relacionados com a detecção de eventos em FCD serão tratados na Seção 2.6 .

A próxima seção apresenta algumas das principais técnicas para DN.

\subsection{Técnicas para detecção de novidade}

Diversas abordagens ao problema da DN têm sido propostas nos últimos anos. A pesquisa (survey) mais abrangente que apresenta as principais iniciativas nesse campo está dividida em duas partes: abordagens estatísticas (Markou and Singh, 2003a) e baseadas em redes neurais artificiais (Markou and Singh, 2003b). Esta última inclui também as abordagens baseadas em máquinas de vetores suporte e as que utilizam o conceito de habituação, apresentado na Seção 2.3 .

Esta seção apresenta um panorama geral das técnicas para DN, incluindo as linhas de pesquisa mais importantes e destacando os principais trabalhos e o estado da arte em cada uma. Inicialmente, são apresentadas as técnicas estatísticas de estimação de densidade, seguidas das redes neurais artificiais e das máquinas de vetores suporte. Depois, são tratadas as técnicas de $\mathrm{C} 1 \mathrm{C}$ baseadas em algoritmos de agrupamento, tendo em vista o uso de algoritmos de agrupamento na abordagem proposta neste trabalho.

\subsubsection{Técnicas estatísticas}

Para detectar novidade é preciso conhecer a distribuição dos dados, o que pode ser feito por meio da função densidade de probabilidade. Técnicas estatísticas paramétricas consideram modelos previamente estabelecidos de distribuição e calculam os parâmetros necessários para adequar esses modelos aos dados. Entretanto, a pressuposição feita a respeito da forma de distribuição dos dados pode não se verificar, especialmente em distribuições multimodais. Essa dificuldade pode ser superada com o uso de técnicas nãoparamétricas, em que a estimação da função densidade de probabilidade é feita apenas 
com base nos exemplos do conjunto de treino. Entre elas, duas têm sido utilizadas para DN: a das janelas de Parzen e a dos k vizinhos mais próximos.

\section{Janelas de Parzen}

A técnica das janelas de Parzen (PW, do Inglês Parzen Windows) (Parzen, 1962) é uma extensão do modelo de mistura de Gaussianas (Duda and Hart, 2001), que consiste em uma combinação linear de distribuições normais. Sua estratégia baseia-se na criação de hipercubos de aresta $h_{n}$ centrados em cada um dos exemplos. A partir do número de exemplos localizados no interior de cada hipercubo e de seu volume é possível calcular a função densidade de probabilidade A largura da janela $h_{n}$ é o parâmetro que determina o grau de generalização.

As PW foram utilizadas inicialmente para DN em imagens obtidas de exames de mamografia (Tarassenko et al. 1995). A abordagem proposta foi capaz de identificar corretamente as regiões de interesse relacionadas à presença de massas cancerígenas. A taxa de erro aproximou-se do equivalente a 1 elemento falso-positivo por imagem, em média.

Em um trabalho mais recente, PW foram utilizadas para DN em redes de computadores (Yeung and Chow, 2002). Por meio da análise do formato e do conteúdo dos pacotes que trafegavam na rede, o sistema foi capaz de identificar possíveis ataques internos e externos à rede, atingindo resultados superiores aos de uma abordagem anterior baseada em árvores de decisão. Uma das principais vantagens enfatizadas pelos autores é que, com técnicas não-paramétricas como PW, o modelo pode ser facilmente modificado para incorporar mudanças nos dados, não havendo necessidade de realizar uma nova fase de treino.

\section{K vizinhos mais próximos}

Outra importante abordagem estatística não-paramétrica é a dos k vizinhos mais próximos (KNN, do Inglês K Nearest Neighbors) (Cover and Hart, 1967). A principal diferença com relação a PW está no fato de que KNN não utiliza uma largura de janela fixa $h_{n}$. Em vez disso, cada janela com centro em um exemplo cresce até o momento em que nela estiverem contidos $k$ exemplos. A classe de um novo exemplo $x$ será aquela a que pertencerem a maior parte dos $k$ exemplos mais próximos de $x$. Assim, nas regiões em que a densidade dos dados for maior, o tamanho das janelas será menor. Esse comportamento gera fronteiras de decisão que assumem o formato de células de Voronoi.

A principal desvantagem de KNN está no seu alto custo para classificação e no fato de que todos os exemplos precisam ser armazenados. Em aplicações que envolvam um grande número de exemplos, especialmente em FCD, sua aplicação torna-se inviável. Ainda assim, é possível encontrar trabalhos que utilizam KNN para DN em aplicações 
reais, como para a identificação de veículos em imagens (Munroe and Madden, 2005) e para a detecção de falhas em motores (Casimir et al., 2006).

\subsubsection{Técnicas baseadas em redes neurais artificiais}

As redes neurais artificiais (ANN, do Inglês Artificial Neural Networks) (Haykin, 1998) são uma técnica de AM inspirada no funcionamento do cérebro. Assim como neurônios biológicos ligam-se uns aos outros para receber, processar e transportar sinais através de uma rede complexa, o neurônio artificial, unidade fundamental das ANN, também é responsável por receber um conjunto de sinais, processá-los e emitir um sinal de saída. O modelo inicial de neurônio artificial, proposto por McCulloch and Pitts (McCulloch and Pitts, 1943), realiza uma operação de soma ponderada sobre uma série de sinais de entrada, aplicando o resultado desse estímulo a uma função de ativação que irá produzir um valor de saída, a ser transmitido para o próximo neurônio. Os pesos de cada sinal de entrada são definidos na fase de treino de acordo com uma determinada regra de aprendizado. Apesar da simplicidade do cálculo envolvido em cada unidade fundamental, a combinação de neurônios artificiais em camadas possibilita a construção de redes com diversas arquiteturas capazes de desempenhar tarefas de aprendizado complexas.

As ANN têm sido amplamente utilizada para a DN, com aplicações a problemas reais nos mais variados domínios (Markou and Singh, 2003b). Entre as diversas abordagens de ANN utilizadas para esse fim, destacam-se as redes RBF e as redes auto-organizáveis e construtivas, especialmente a rede GWR.

\section{Redes RBF e técnicas similares}

As redes Radial Basis Function (RBF) são capazes de modelar qualquer função nãolinear com uma única camada escondida. Assim, não existe o problema da determinação do número de camadas que a rede precisa possuir. Além disso, como a camada de saída pode ser otimizada com técnicas lineares, o tempo de treino é reduzido e evita-se o problema de ótimos locais.

Em um estudo comparativo envolvendo redes dos tipos Multi-Layer Perceptron (MLP), Multi-Layer Perceptron com função de ativação Gaussiana (GMLP) e RBF (Vasconcelos et al., 1995), comprovou-se, com relação à capacidade de rejeição, que Redes RBF são mais adequadas à tarefa de DN em aplicações reais do que as MLP ou GMLP. A principal razão está nas suas fronteiras de decisão circulares em torno dos centros que representam os padrões conhecidos. A resposta da rede depende da distância da entrada aos centros, e decresce à medida que a entrada se afasta dos mesmos, identificando claramente entradas diferentes dos padrões conhecidos.

Roberts and Penny (1996) reforçam a importância de monitorar o grau de confiança de cada decisão tomada pela rede na tarefa de classificação. Naquele trabalho, isso é feito 
por meio de um comitê de redes RBF. O modelo proposto é aplicado a um problema de regressão e a um problema de classificação envolvendo tremor muscular, no qual o objetivo é verificar se os movimentos do braço são normais ou se existe alguma anomalia. Os resultados mostram que o comitê de redes com monitoramento de confiabilidade foi capaz de classificar até $80 \%$ dos dados com $90 \%$ de exatidão, enquanto a abordagem tradicional permitia a classificação de apenas $20 \%$ com a mesma exatidão.

Redes do tipo Class Dependent Radial Basis Function (CD-RBF) foram utilizadas para detectar anomalias em aeronaves militares de combate (Brotherton and Johnson, 2001). Na primeira etapa da fase de treino, os dados foram agrupados utilizando a técnica de K-Médias (KM) (Duda and Hart, 2001). Em seguida, os pesos das saídas das unidades radiais foram determinados pelo método dos mínimos quadrados. Os resultados mostram que a rede é capaz de identificar falhas em diversos sinais extraídos de dois subsistemas da aeronave, com poucos alarmes falsos.

Outra abordagem propõe uma mudança na função de ativação dos neurônios, fazendo uma normalização em nível global (Albrecht et al., 2000). A função permanece em torno de um centro mas assume uma forma mais complexa e, por esse motivo, recebe o nome de Generalized Radial Basis Function (GRBF). São acrescentadas à rede algumas conexões que partem da camada de saída e voltam à camada central. Com isso, pretende-se fazer com que a rede se auto-organize. Para permitir a DN, os autores inspiraram-se no comportamento dos neurônios do córtex cerebral. O classificador foi aplicado ao reconhecimento de padrões de fala e os resultados mostraram que o desempenho do classificador melhora com o passar do tempo, à medida que a rede se auto-organiza.

Li et al. (2002) estudam o impacto do valor de um limiar aplicado à saída de uma rede RBF para a identificação de falhas desconhecidas. Propõe-se o uso de dois valores para esse limiar: um para a situação em que as falhas desconhecidas possam ocorrer e outro quando elas já tenham sido detectadas.

Redes do tipo Class Dependent Elliptical Basis Function (CD-EBF), nas quais as classes são representadas por conjuntos de unidades elípticas semelhantes às unidades radiais das Redes RBF, também foram utilizadas para DN, reforçando a vantagem desse tipo de arquitetura (Brotherton et al. 1998). O sistema obteve bons resultados na classificação de sinais eletromagnéticos.

Em um outro trabalho, redes de função elíptica foram utilizadas para a detecção de falhas em sistemas de medição automobilísticos (Jakubek and Strasser, 2002). Nesse caso, propõe-se o uso de análise de componentes principais para determinar as áreas onde se concentram os dados. A DN é feita verificando se o padrão de entrada está localizado em um dos grupos do conjunto de treino, sendo a função de distribuição dos dados estimada por meio de técnicas de regressão (kernel regression). São propostas modificações ao algoritmo de treino com o objetivo de minimizar o número de funções elípticas, reduzindo o custo computacional. 
Outra abordagem de ANN à DN, especialmente útil em problemas de aprendizado contínuo, é apresentada pelas redes auto-organizáveis e construtivas.

\section{Redes auto-organizáveis e construtivas}

Uma das primeiras iniciativas no âmbito das ANN auto-organizáveis para obter uma representação da distribuição de um conjunto de dados foi proposta por Teuvo Kohonen, o mapa auto-organizável (SOM, do Inglês Self-Organizing Map) (Kohonen, 2001). Apesar de suas qualidades, a rede SOM precisa ser corretamente dimensionada para cada tipo de distribuição. Se sua arquitetura for insuficiente, seu desempenho na obtenção de uma boa representação é prejudicado. Além disso, uma vez definida, a arquitetura permanece estática, o que impede que a rede se adapte a eventuais mudanças na distribuição dos dados.

A busca por um modelo mais adequado a problemas não-estacionários motivou o desenvolvimento das ANN construtivas, capazes de adicionar nós, adaptando sua arquitetura a mudanças na distribuição dos dados. Uma das primeiras redes construtivas foi apresentada por Bernd Fritzke: a Growing Cell Structure (GCS) (Fritzke, 1994). Naquela abordagem, a cada $\lambda$ iterações, nós são acrescentados próximo ao nó que tenha acumulado o maior erro, com o objetivo de melhorar o desempenho da rede. A rede cresce até que um critério de parada previamente estabelecido seja atingido. A rede GCS motivou o desenvolvimento de abordagens semelhantes, como a Dynamic Cell Structure (DCS) (Bruske and Sommer, 1995) e a Probabilistic GCS (Vlassis et al., 1997).

Fritzke propôs também a rede Growing Neural Gas (GNG) (Fritzke, 1995). Como na rede GCS, nós são adicionados a cada $\lambda$ iterações de acordo com o nó que acumulou o maior erro. Entretanto, a GNG introduz uma ligação entre os dois nós mais ativos para cada entrada, o que proporciona uma maior liberdade à rede na definição de sua arquitetura. Além disso, cada ligação possui um contador que determina sua idade, permitindo que ligações muito antigas, e que provavelmente não são mais necessárias, sejam removidas com o passar do tempo.

Melhorias ao modelo GNG ocorreram com a introdução do conceito de utilidade de um nó, dando origem à rede Growing Neural Gas with Utility (GNGU) (Fritzke, 1997). Esse conceito procura prever quanto o erro da rede aumentaria se cada nó fosse retirado, com o intuito de reduzir o tamanho da rede pela remoção de nós supérfluos.

Como a maior parte das redes constutivas adiciona nós a cada $\lambda$ iterações, a rede cresce a uma taxa constante, independentemente da taxa com que variam os dados. Assim, a rede pode levar muito tempo para incorporar mudanças rápidas ocorridas na distribuição dos dados. Esse atraso pode ser prejudicial, por exemplo, em tarefas que envolvam DN. Uma alternativa é oferecida pela rede GWR. 


\section{Rede GWR}

A principal vantagem oferecida pela rede Grow When Required (GWR) (Marsland, 2001; Marsland et al., 2002) é que sua estrutura só cresce à medida que seja necessário.

Ao contrário das redes construtivas tradicionais, a abordagem GWR estabelece outros critérios para adicionar e inicializar um novo nó. Nós são adicionados quando a entrada não casa com nenhum nó dentro de um limiar máximo de erro estipulado. Nesse caso, o novo nó tem seus pesos inicializados para representar a entrada em questão. Com isso, pretende-se que a rede pare de crescer quando estiver adequadamente dimensionada às entradas, voltando a crescer se a distribuição dos dados se modificar.

Os dois principais elementos da rede GWR são os nós e as arestas. Ambos podem ser adicionados e removidos ao longo do tempo. A adição de arestas é feita com base no aprendizado Hebbiano (Hebb, 1949), estabelecendo uma ligação entre os dois nós mais representativos para cada entrada: o nó vencedor e o segundo colocado. Sua remoção é feita pela idade, como na rede GNG.

Já para acrescentar nós, a rede GWR utiliza dois conceitos relativos a cada nó: atividade e disparo. A atividade do nó vencedor $a(s)$ é função da distância desse nó ao vetor de entrada, e mede o grau de semelhança entre o vetor de entrada e o vetor de pesos do nó. Um limiar de atividade $a_{T}$ é responsável por definir se o nó é ou não um bom representante da entrada. Caso a atividade do nó vencedor não seja suficientemente alta, novos nós podem ser adicionados à rede. Tal operação pode ser feita a qualquer momento, não apenas a cada $\lambda$ iterações como na rede GNG. O conceito de disparo completa a decisão de acrescentar ou não um nó. Disparo de um novo nó é uma função que mede quão freqüentemente o nó é utilizado, com decréscimo exponencial de 1 para 0. Se o valor do disparo do nó vencedor $h(s)$ estiver acima de um certo limiar $h_{T}$, o nó é considerado novo e ainda precisa ser treinado. Caso contrário, isso significa que o nó já foi suficientemente treinado; e é apenas nesse caso que a rede cresce.

O esquema a seguir resume as decisões tomadas pelo algoritmo da rede GWR, no momento em que ele analisa uma entrada $\mathbf{x}$ e o nó vencedor $s$ associado a ela.

- Analisar atividade $a(s)$ :

- Se $a(s) \geq a_{T} \rightarrow$ nó $s$ é um bom representante da entrada $\mathbf{x}$. Atualizar pesos de $s$ e sua vizinhança.

- Se $a(s)<a_{T} \rightarrow$ existe uma grande diferença entre o nó $s$ e a entrada $\mathbf{x}$. O nó pode ser novo ou inadequado. Analisar disparo $h(s)$ :

* Se $h(s) \geq h_{T} \rightarrow$ nó é novo. Treiná-lo um pouco mais e decrementar seu contador $h(s)$.

* Se $h(s)<h_{T} \rightarrow$ nó já foi treinado e, mesmo assim, não conseguiu representar bem a entrada $\mathbf{x}$. Criar um novo nó. 
Assim, o algoritmo GWR consegue determinar, de maneira confiável, em que situações a rede precisa realmente crescer, quando os nós precisam apenas de mais treino e quando nada precisa ser feito. Como resultado, tem-se uma rede eficiente e econômica, capaz de representar adequadamente conceitos que mudam com o tempo (Klinkenberg, 2004) sem crescer desnecessariamente.

A rede GWR foi utilizada por Marsland em uma série de experimentos envolvendo cenários estáticos e dinâmicos (Marsland et al., 2002). Em um problema artificial de múltiplas dimensões, por exemplo, demonstrou-se que a rede realmente para de crescer quando consegue descrever os dados, e que é capaz de representar adequadamente dados em diferentes dimensões. O problema real mais importante escolhido para demonstrar o desempenho da rede GWR na tarefa de DN envolveu a análise das informações fornecidas pelo sonar de um robô ao percorrer um corredor com várias portas e diferentes texturas de parede. Os resultados mostraram que a rede GWR respondeu rapidamente a mudanças, adicionando muitos nós quando foi necessário, e que parou de crescer assim que conseguiu obter uma boa representação, não permitindo a manutenção de estruturas desnecessárias. Essas características lhe conferem resultados muito bons em problemas de DN e em situações de aprendizado contínuo.

\subsubsection{Técnicas baseadas em máquinas de vetores suporte}

Máquinas de vetores suporte (SVM, do Inglês Support Vector Machines) são uma importante técnica de AM que baseia-se na teoria do aprendizado estatístico (Vapnik, 1995) para gerar classificadores de margens largas. Isso significa que exemplos de classes diferentes são separados maximizando-se as margens do classificador, ou seja, selecionando um hiperplano separador cuja distância ao exemplo mais próximo seja a máxima possível. Para tratar dados não separáveis linearmente, SVM promove uma transformação do espaço de entradas para um espaço de dimensão mais alta denominado espaço de atributos. A função que realiza essa transformação é denominada função kernel.

Apesar de ter sido proposta há relativamente pouco tempo se comparada com outras técnicas de AM, SVM tem despertado forte interesse, justificado por uma série de vantagens (Bennett and Campbell, 2000). Uma das mais importantes é o fato de a função otimizada pelo algoritmo ser convexa, o que evita a convergência a ótimos locais. Um segundo ponto positivo é sua boa capacidade de generalização, garantida pela maximização das margens. SVM são, portanto, pouco suscetíveis ao sobre-ajuste. Finalmente, um aspecto importante a ser destacado diz respeito ao caráter genérico e flexível das SVM (Bennett and Campbell, 2000), que tem proporcionado aplicações a diversos domínios, em tarefas de classificação e regressão.

As duas principais abordagens de SVM ao problema da DN são denominadas $\nu$-SVC e SVDD. Diversos trabalhos foram motivados a partir dessas duas técnicas, descritas a 
seguir.

\section{$\nu$-SVC}

A técnica $\nu$-Support Vector Classifier ( $\nu$-SVC) (Schölkopf et al., 1999) propõe isolar os dados por um hiperplano o mais distante possível da origem. Isso é conseguido a partir do cálculo de uma função binária que retorna positivo nas regiões em que os dados estão concentrados e negativo no restante do espaço de atributos. Em seguida, encontra-se o hiperplano com a maior margem em relação à origem. O parâmetro $\nu$ ajusta a flexibilidade da fronteira de decisão.

As primeiras aplicações da abordagem $\nu$-SVC foram a identificação de números escritos à mão em envelopes do correio (Schölkopf et al., 2000, 2001; Rätsch et al., 2002) e a análise de som para detecção de falhas em turbinas a jato (Hayton et al., 2000). Posteriormente, foi utilizada para diversas outras aplicações envolvendo DN, com bons resultados (Manevitz and Yousef, 2001; Davy et al., 2002; Desobry and Davy, 2003).

A crítica mais importante a essa abordagem está no fato de a origem ter um papel fundamental no posicionamento do hiperplano. Ao utilizar a origem como elemento repulsor para maximizar-se a margem do classificador, pressupõe-se indiretamente que elementos representantes de possíveis novos conceitos estejam localizados em torno da origem (Campbell and Bennett, 2001). Uma abordagem alternativa é descrita a seguir.

\section{SVDD e técnicas similares}

A técnica Support Vector Data Description (SVDD) (Tax and Duin, 1999a, b; Tax, 2001) descreve o domínio dos dados por meio de uma hiperesfera que contenha a maior parte dos exemplos de uma classe-alvo. Com a minimização do raio dessa hiperesfera, obtém-se a descrição mais perfeita, abrangendo o menor volume possível. Assim como na abordagem $\nu$-SVC, com a SVDD também é possível flexibilizar a descrição por meio do parâmetro de regulação $C$.

A SVDD foi inicialmente aplicada aos conjuntos de dados do UCI Machine Learning Dataset Repository (Asuncion and Newman, 2007, Tax, 2001) e ao reconhecimento de números escritos à mão (Tax and Duin, 2002).

Grande quantidade de trabalhos tem sido publicada, aplicando a abordagem SVDD para DN em diversos domínios, de ecologia (Sanchez-Hernandez et al., 2007; Drake et al., 2006) ao reconhecimento de face e objetos em imagens e vídeos (Abeni et al., 2006; Wang et al., 2004; Zeng et al., 2006; Tavakkoli et al., 2006). Várias modificações e extensões também têm sido propostas (Lee et al., 2007; Wang et al., 2006), algumas direcionadas, inclusive, ao aprendizado contínuo (Zhao et al., 2006, Jia et al., 2005). Esses aspectos fortalecem SVM, e especialmente a técnica SVDD, como uma das mais importantes abordagens para DN. 
Uma série de outras técnicas baseadas em SVM para DN são descritas na literatura (Ben-Hur et al., 2001; Beatty et al., 2000; Hoare et al., 2002; Davy et al., 2002; Davy and Godsill, 2002; Desobry and Davy, 2003; Campbell and Bennett, 2001; Manevitz and Yousef, 2001; Diehl and Hampshire II, 2002).

\subsubsection{Técnicas de classificação com uma classe baseadas em agru- pamento}

Alguns trabalhos desenvolvidos no contexto da $\mathrm{C} 1 \mathrm{C}$ utilizam algoritmos de agrupamento para DN.

O algoritmo k-médias foi usado para descrever o domínio dos dados de uma classe-alvo com o objetivo de identificar outliers ou novidade (Tax, 2001), conceitos que, naquele trabalho, são tratados indistintamente. A abordagem, denominada kmeansdd, utiliza como parâmetro uma taxa de rejeição que tem a função de obrigar que um certo percentual dos exemplos da classe-alvo permaneça fora das fronteiras de decisão. O número de grupos também é definido manualmente. Um trabalho mais recente estuda o ajuste da medida de distância (Tax et al., 2006).

Tarassenko et al. (1999) e Clifton et al. (2006) também utilizaram o algoritmo k-médias para descrever um conceito normal num espaço onde a distância Euclideana corresponde à distância Mahalanobis no espaço de atributos original. Assim como na abordagem anterior, o número de grupos é fixo e o modelo não é atualizado com o tempo.

Em outro trabalho, k-médias foi utilizado em conjunto com outras duas técnicas para DN com o objetivo de selecionar dados de maior interesse para minimizar o volume de informação a ser enviada pelo canal de comunicação e planejar os próximos comandos a serem enviados ao robô, em um cenário de exploração espacial geológica Castaño et al. 2004).

A principal desvantagem dessas técnicas para o aprendizado de novos conceitos, como proposto neste trabalho, está no fato de que a DN é vista apenas como uma tarefa de C1C. Conforme discutido nas Seções 2.2 e 2.3, esta abordagem ao problema não permite a caracterização de novidade como um novo conceito.

A próxima seção apresenta as principais técnicas desenvolvidas especificamente para a identificação de eventos em FCD.

\subsection{Técnicas para detecção de eventos em fluxos de dados}

A identificação de eventos em FCD é uma área de pesquisa em franco desenvolvimento, considerando-se o alto nível de interesse por esse tipo de informação em diversas aplicações, 
tais como a detecção de um repentino aumento no número de visitas em um serviço web, de mudanças em dados do mercado financeiro, e alterações bruscas nos valores obtidos por sensores distribuídos em uma rede.

Algumas técnicas desenvolvidas para séries temporais ou grandes bases de dados também foram incluídas neste estudo, tendo em vista a similaridade entre os desafios encontrados nessas áreas e os relacionados com FCD.

\subsubsection{Baseadas em similaridade}

A detecção de estouros (bursts) em séries temporais é um importante foco de pesquisa para aplicações envolvendo dados financeiros e em mineração de textos, por exemplo. Dada uma série temporal, a maneira mais simples de identificar esse tipo de evento é comparar seu valor a um limiar definido segundo algum critério.

Essa estratégia tem sido aplicada para a identificação de padrões de estouros correlacionados em múltiplas séries temporais (Vlachos et al., 2005). O fato de que condições anômalas estejam correlacionadas reforça a evidência de que um evento inesperado tenha ocorrido em um determinado intervalo de tempo. Nessa abordagem, diferentes valores para o limiar $\tau$, que determina a ocorrência de um estouro, são calculados para cada porção da série, considerando que os dados em cada porção mantenham uma distribuição exponencial, típica dos dados do mercado financeiro utilizados naquele trabalho. Uma vez que vários intervalos de estouro tenham sido identificados, procura-se identificar a ocorrência de sobreposição entre essas regiões. Para essa tarefa, uma estrutura de indexação eficiente foi adaptada a partir da noção de containment encoded intervals (CEI). A indexação baseada em CEI apresenta como vantagem o fato de que quase todas as operações podem ser realizadas por meio de somas inteiras e deslocamentos lógicos, tornando-a mais eficiente do que outras alternativas (Wu et al., 2004).

Com a expansão das redes de comunicação, a mineração de fluxos de texto surgiu como um importante área de pesquisa. Nesse cenário, a busca contínua pela identificação da primeira reportagem de um novo evento, denominada first story detection, pode ser abordada por meio de técnicas de DN.

O alto custo da comparação entre as características de cada novo documento e as dos que já existem motivou uma abordagem em 2 níveis denominada topic-conditioned novelty detection (Yang et al., 2002). Nela, novos documentos são inicialmente classificados em tópicos gerais, utilizando algoritmos de AM supervisionado. A DN em si acontece no segundo nível, onde um detector é construído para cada tópico. Ao receber um novo documento, o detector do tópico equivalente o compara com todos os documentos no histórico daquele tópico, encontra o seu vizinho mais próximo e calcula o valor da similaridade pela medida do cosseno. O limiar é definido empiricamente com base em validação cruzada. A abordagem em 2 níveis apresenta como vantagem a possibilidade de definir listas de 
remoção (stop lists) para cada tópico, e os resultados demonstram que essa abordagem melhorou sensivelmente o desempenho dos detectores.

\subsubsection{Baseadas em freqüência}

Uma maneira de tornar concreta a noção de surpresa na busca por exemplos incomuns é associá-la à freqüência. Nesse sentido, um padrão seria considerado surpreendente ou anômalo se a freqüência de sua ocorrência diferir substancialmente do que se espera ao acaso, considerando um conjunto de dados previamente analisado (Keogh et al., 2002). Essa definição se opõe à de motivos (motifs), que são padrões que aparecem muito freqüentemente, isto é, que estão sobre-representados.

Com essa perspectiva, o algoritmo TARZAN (Keogh et al., 2002) foi desenvolvido para descobrir padrões surpreendentes em séries temporais em tempo e espaço lineares. Dada uma série de teste $X$, TARZAN identifica sub-seqüências de $X$ que ocorram com uma freqüência acima da esperada, dada uma série de referência $R$. Inicialmente, ambas as séries são discretizadas utilizando um processo definido mais tarde como symbolic aggregate approximation (SAX) (Lin et al., 2003), resultando em duas seqüências $x$ e $r$. Então, para cada seqüência, são identificadas sub-seqüências, e suas respectivas freqüências são calculadas e armazenadas em duas árvores de sufixos $T_{x}$ e $T_{r}$, que podem ser acessadas eficientemente. Pela comparação direta entre essas árvores, uma medida de surpresa $z(w)$ é obtida para cada sub-seqüência $w$ de $T_{x}$, subtraindo-se o número de ocorrências esperado do número de ocorrências observado. As freqüências esperadas ou são obtidas de $T_{r}$, se $w$ existir em $T_{r}$, ou são estimadas por modelos de Markov. Finalmente, TARZAN identifica as sub-seqüências cujo valor de $z(w)$ excede um limiar definido pelo usuário.

TARZAN foi avaliado experimentalmente em dados artificiais e reais, envolvendo o gasto anual de energia de um estabelecimento de pesquisa. Seu desempenho foi comparado à técnica IMM, que utiliza uma estratégia baseada na seleção negativa que ocorre em sistemas imunológicos naturais (Dasgupta and Forrest, 1996), e à TSA-tree (Shahabi et al., 2000), um sistema baseado em wavelet desenvolvido para atender a consultas queries envolvendo surpresa e tendência em séries temporais. Considerando o problema proposto, de encontrar semanas em que o consumo de energia foi irregular, TARZAN obteve sucesso enquanto as técnicas IMM e TSA-tree falharam.

TARZAN foi desenvolvido no contexto de bancos de dados de séries temporais estáticos, obrigando o carregamento completo das séries antes do seu processamento. Em um cenário de FCD, em que as séries podem potencialmente ser infinitas, diversas restrições teriam que ser consideradas.

VizTree (Lin et al., 2004) utiliza a mesma abordagem de TARZAN, mas foca principalmente a visualização de padrões não-triviais. Essa técnica também aplica SAX para a discretização e representação, realçando o fato de que, quando comparado com outros 
esquemas de representação, SAX é tão bom quanto ou melhor na capacidade de representar similaridades, o que é um aspecto importante para os objetivos pretendidos. VizTree exibe a árvore de sub-seqüências utilizando a espessura dos ramos para representar a freqüência. Assim, o usuário pode identificar anomalias em uma única série explorando visualmente ramos menos freqüentes, ou, em duas séries, observando a árvore diferencial obtida conforme em TARZAN. VizTree foi testada em uma série temporal obtida a partir de imagens de posições de yoga, de informações de consumo energético, e dados de exames de eletrocardiograma.

\subsubsection{Baseadas na estrutura de decisão}

O problema da detecção de mudanças em FCD também pode ser encarado considerando que, em um problema de classificação tradicional com múltiplas classes, a contribuição de cada unidade decisória do classificador deve permanecer estável se não se observarem mudanças no processo que está sendo analisado. Uma alteração nas informações estatísticas relativas ao uso das unidades pode indicar que os conceitos envolvidos podem ter sofrido uma alteração.

Fan et al. (2004) avaliaram o uso de duas informações estatísticas em um classificador baseado em árvores de decisão, ambas obtidas nas folhas, para detectar mudanças em FCD. A primeira, denominada $P S$, calcula o número de exemplos classificados por cada folha e os compara com os respectivos valores obtidos na fase de treino. A segunda, denominada $L S$, é calculada comparando-se o erro obtido em um conjunto de validação à soma dos erros esperados em cada folha, considerando a proporção de exemplos classificados por cada uma. A avaliação experimental feita no problema de detecção de fraudes em cartões de crédito demonstrou que tanto $P S$ quanto $L S$ estão bem correlacionados com a intensidade da mudança no FCD. O fato de que essas medidas estatísticas não impõem a necessidade de dados rotulados é colocada como uma vantagem sobre trabalhos relacionados anteriores.

\subsubsection{Baseadas em agrupamento}

Pelo fato de serem técnicas de aprendizado não-supervisionado, algoritmos de agrupamento são particularmente adequados ao aprendizado contínuo, especialmente aos problemas envolvendo FCD. Além disso, modelos construídos com algoritmos de agrupamento são naturalmente atualizáveis de maneira incremental. Isso permite que novos conceitos sejam facilmente incorporados com o passar do tempo, embora nem todas as técnicas propostas considerem esse aspecto.

Gazen et al. (2005) propuseram ARGUS, uma técnica de DN capaz de trabalhar de maneira contínua em FCD que utiliza o algoritmo de agrupamento k-médias para melhorar a qualidade dos grupos gerados inicialmente por um algoritmo do tipo leader-follower. A 
DN é feita observando-se alterações que podem ocorrer na função de densidade de cada grupo. Diferentes interpretações são possíveis, à medida que diferentes tipos de eventos novos ou de crescimento produzem alterações que conferem diferentes formatos à função de densidade.

Uma técnica de agrupamento hierárquico e outra de agrupamento incremental foram comparadas em um estudo envolvendo o problema de Topic Detection and Tracking (TDT) em um fluxo de artigos de notícias (Yang et al., 1998). O algoritmo hierárquico (group average clustering) produziu uma floresta de árvores binárias, em que o número de árvores e o número de grupos são definidos manualmente. O algoritmo de agrupamento incremental processa os documentos seqüencialmente, adicionando cada um ao grupo mais similar se o grau de similaridade excede um limiar definido manualmente. A tarefa de DN consistiu em comparar cada documento com os últimos documentos em uma janela temporal cujo tamanho também é definido manualmente. Se todas as medidas de similaridade estiverem abaixo de um limiar previamente estabelecido, a notícia é considerada nova.

O algoritmo Gecko Salvador and Chan (2005) utiliza um algoritmo de agrupamento para gerar estados que são posteriormente traduzidos em regras lógicas, utilizadas para detectar anomalias em séries temporais. O número de grupos é definido automaticamente, utilizando um método proposto pelos próprios autores (Salvador and Chan, 2004).

\subsection{Técnicas de agrupamento incremental}

Algoritmos de agrupamento incremental constroem o modelo que descreve os dados à medida que os exemplos são recebidos, o que permite sua aplicação a problemas de aprendizado contínuo. Em geral, num algoritmo de agrupamento incremental típico, cada exemplo pode ser atribuído a um grupo existente ou criar seu próprio grupo (Jain et al. 1999).

Alguns algoritmos, como o COBWEB (Fisher, 1987) por exemplo, consideram ainda a divisão e a combinação de grupos. A estrutura em árvore gerada por COBWEB facilita a interpretação dos grupos gerados. Entretanto, sua sensibilidade à ordem em que os exemplos são tratados é uma desvantagem (Li et al., 2004).

Dos vários algoritmos de agrupamento incremental descritos na literatura, BIRCH (Balanced Iterative Reducing and Clustering using Hierarchies) (Zhang et al., 1997) destacase como um dos mais completos para lidar com grande quantidade de dados, considerando limitações de espaço de armazenamento e tempo de processamento como fatores que interferem no próprio processo de agrupamento. De acordo com os autores, BIRCH foi o primeiro algoritmo de agrupamento incremental a lidar com outliers. Entretanto, assim como COBWEB, BIRCH também é sensível à ordem de apresentação dos exemplos.

O algoritmo CURE (Guha et al., 1998) também trata o problema dos outliers, eliminando- 
os após uma fase de agrupamento inicial, e é capaz de identificar grupos não-esféricos. Ao contrário de BIRCH, em que todos os dados são pré-agrupados, CURE trabalha com uma amostra do conjunto de dados completo, assim como o algoritmo CLARA (Clustering Large Applications).

Os algoritmos CLARA e PAM (Partitioning Around Medoids) Kaufman and Rousseeuw, 1990) motivaram o desenvolvimento do algoritmo CLARANS (Clustering Large Applications based on RANdomized Search) (Ng and Han, 2002). CLARANS consegue ser mais eficiente que PAM e CLARA, apesar de trabalhar com o conjunto de dados completo. Isso é possível pois, ao contrário de PAM, CLARANS considera apenas um conjunto reduzido de possíveis substituições de medóides até que seja encontrada uma melhor configuração.

No contexto dos objetivos deste trabalho, os algoritmos de agrupamento incremental apresentam como principal vantagem a possibilidade de aprenderem continuamente à medida que os exemplos são recebidos. Por outro lado, como em geral todos os exemplos são agrupados, sua aplicação direta ao problema de DN é limitada.

\subsection{Discussão}

Este capítulo apresentou os principais aspectos conceituais relacionados à DN e à $\mathrm{C} 1 \mathrm{C}$, bem como a terminologia utilizada neste trabalho. Em seguida, foram apresentadas duas das aplicações exploradas neste trabalho, destacando os principais desafios na AEG, especialmente com relação à alta dimensão dos dados, e nos FCD, decorrentes da grande quantidade de dados recebidos ininterruptamente e da impossibilidade de mantê-los em memória.

Com o objetivo de construir um panorama geral das principais iniciativas no campo da DN, foram apresentadas as principais técnicas enfatizando quatro grandes linhas: a das técnicas estatísticas, das baseadas em ANN, em SVM, e dos algoritmos de agrupamento.

Nas técnicas estatísticas, destacam-se as não-paramétricas, mas sua limitação no tratamento de problemas com um grande número de dimensões ou de exemplos é vista como um obstáculo às aplicações pretendidas neste trabalho.

Das várias técnicas de ANN descritas, a rede GWR apresenta vantagens, especialmente pela sua capacidade de obter um modelo compacto e bom desempenho no tratamento de mudanças de conceito (concept drift).

As técnicas baseadas em SVM são consideradas abordagens promissoras para DN por uma série de trabalhos publicados nos últimos anos, especialmente $\nu$-SVC e SVDD.

As técnicas de $\mathrm{C} 1 \mathrm{C}$ que utilizam algoritmos de agrupamento para DN consideram qualquer novo exemplo que não seja identificado como membro da classe-alvo como novidade, e desconsideram o aspecto contínuo do aprendizado.

Nas aplicações envolvendo FCD, dado o caráter não-supervisionado do aprendizado, 
os algoritmos de agrupamento representam uma opção natural. Entre eles, destacam-se algoritmos tradicionais eficientes e algoritmos incrementais.

Os algoritmos de agrupamento incremental permitem o aprendizado contínuo; contudo, consideram que, em geral, todos os exemplos recebidos serão agrupados, ou num grupo existente ou num grupo a ser criado. Na perspectiva deste trabalho, da identificação de novos conceitos como grupos coesos de exemplos, entretanto, não há uma correspondência obrigatória entre os exemplos recebidos e os grupos gerados.

A abordagem proposta, que será apresentada no Capítulo 4, considera as vantagens e desvantagens das técnicas discutidas neste capítulo e as restrições impostas pelo aprendizado contínuo não-supervisionado em uma grande quantidade de dados.

No próximo capítulo são analisados resultados de experimentos preliminares de DN em bioinformática. 


\section{Capítulo 3}

\section{Experimentos preliminares em bioinformática}

A aplicação de técnicas de C1C para DN em bioinformática fez parte dos objetivos iniciais deste doutoramento, em particular no problema da AEG, descrito na Seção 2.4.1. Investigou-se, em primeiro lugar, o uso da técnica $\nu$-SVC, descrita na Seção 2.5.3, para a deteç̧ão de novos perfis de expressão gênica. Posteriormente, a combinação de técnicas de C1C foi avaliada em diversos conjuntos de dados de expressão gênica. Este capítulo apresenta os resultados obtidos nessas duas linhas de investigação iniciais.

\subsection{Detecção de novidade com máquinas de vetores suporte}

Nesta primeira série de experimentos avaliou-se o uso de uma técnica de DN baseada em SVM em dados de expressão gênica.

\subsubsection{Motivação e objetivos}

Considerando o interesse em investigar como a DN poderia contribuir para a solução de problemas de bioinformática, mais especificamente com referência ao processo de AEG, a escolha da técnica de AM a ser utilizada levou em conta o fato de os conjuntos de dados de expressão gênica serem de alta dimensão. Considerando os bons resultados que SVM vinha apresentando, especialmente em dados com uma grande quantidade de atributos e poucos exemplos, optou-se pela abordagem $\nu$-SVC (Schölkopf et al., 1999), apresentada na Seção 2.5.

O principal objetivo dos experimentos foi o de verificar se, obtida a descrição de um conceito considerado normal, o classificador $\nu$-SVC seria capaz de detectar como novidade elementos das demais classe. Além disso, pretendeu-se, ainda, estudar de que maneira esse 


\begin{tabular}{|c|c|c|c|c|c|}
\hline \multirow{2}{*}{ Denominação } & \multirow{2}{*}{ Origem } & \multirow{2}{*}{$\begin{array}{l}\text { Número de } \\
\text { atributos }\end{array}$} & \multirow{2}{*}{$\begin{array}{l}\text { Número de } \\
\text { exemplos }\end{array}$} & \multicolumn{2}{|c|}{ Classes } \\
\hline & & & & C1 & $\mathrm{C2}$ \\
\hline Breast & West et al., 2001 & 7129 & 44 & ER- & ER+ \\
\hline Colon & Alon et al., 1999 & 2000 & 62 & Tumor & Normal \\
\hline Leukemia & Golub et al., 1999 & 7129 & 72 & ALL & AML \\
\hline Lymphoma & Alizadeh et al., 2000 & 4026 & 47 & Germinal Center & Activated \\
\hline
\end{tabular}

Tabela 3.1: Conjuntos de dados utilizados nos experimentos preliminares.

comportamento é afetado pelo parâmetro $\nu$, responsável pela flexibilização da descrição.

\subsubsection{Metodologia e conjuntos de dados}

Foram utilizados os seguintes conjuntos de dados de expressão gênica, cujas características básicas são apresentadas na Tabela 3.1.

- leukemia. Identificação de três tipos de leucemia, ALL-B, ALL-T e AML, em que B e T são subtipos de ALL. (Golub et al., 1999).

- lymphoma. Distinção entre linfomas large B-cell dos tipos germinal center e activated diffuse (Alizadeh et al. 2000).

A separação em dados de treino e teste seguiu a divisão previamente estabelecida pelos trabalhos originais. Em cada experimento, o objetivo foi o de identificar uma das classes como novidade. O conjunto de treino utilizado foi composto pelos exemplos de todas as classes, exceto aquela que se desejava identificar como novidade, obtidos do conjunto de treino original. Os exemplos da classe novidade, pertencentes aos conjuntos de treino e de teste originais, passam a fazer parte do conjunto de teste para a novidade. O conjunto de teste utilizado para o conceito normal foi formado pelos exemplos de todas as classes, exceto a classe considerada novidade, obtidos do conjunto de teste original.

A metodologia adotada incluiu ainda uma etapa inicial de normalização dos dados. Ao parâmetro de controle do grau de flexibilidade $\nu$ foram atribuídos os valores de 0,05 a 0,95 com passos de 0,05. Para cada configuração, foram medidas as taxas de acerto do classificador (C1C) para normal e novidade, além da quantidade de vetores suporte (SV) necessária para se obter a descrição. A implementação fez uso da biblioteca LibSVM Chang and Lin, 2004). Kernel linear foi utilizado em todos os experimentos. Os resultados obtidos são analisados a seguir.

\subsubsection{Análise dos resultados}

Os resultados são apresentados sob a forma de gráficos, como o mostrado na Figura 3.1. O eixo horizontal indica a variação do parâmetro $\nu$. As curvas indicam as taxas de acerto, para as classes normal (círculos) e novidade (triângulos), cujos valores podem ser 


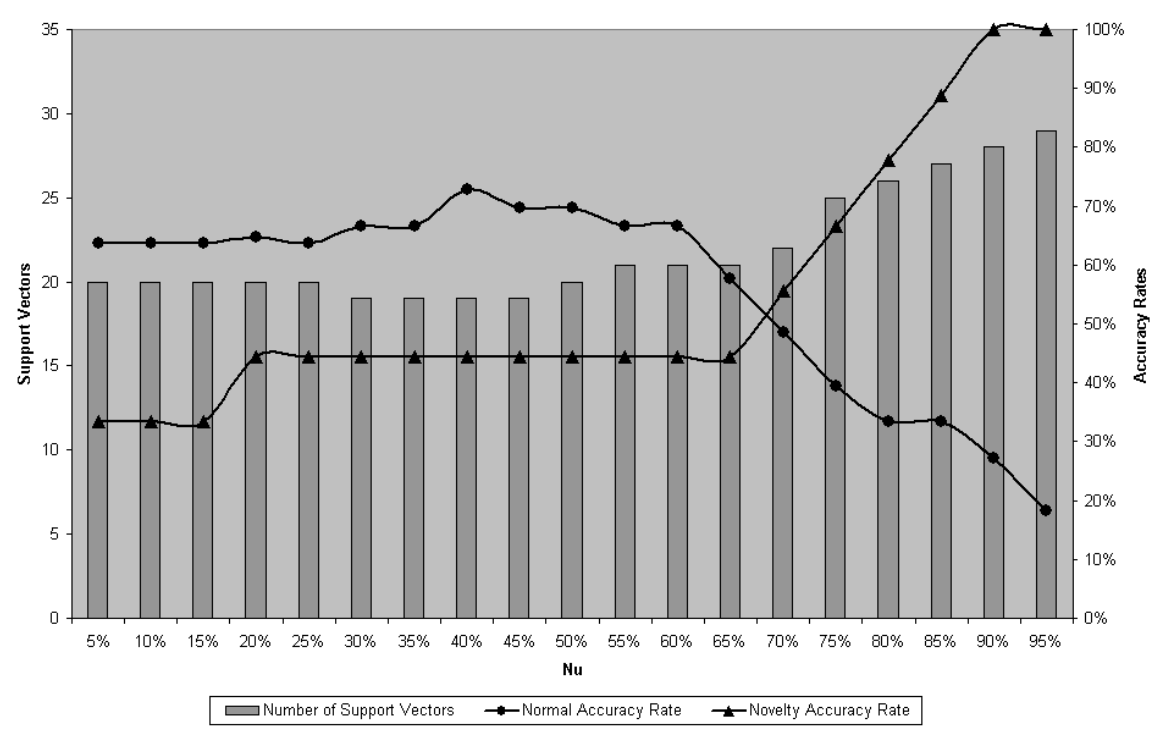

Figura 3.1: Resultados com o conjunto leukemia com ALL-T como novidade.

lidos na escala vertical à direita. As barras indicam o número de vetores suporte em cada situação, cujos valores estão no eixo vertical à esquerda.

Em primeiro lugar, é possível verificar que o aumento de $\nu$ implica tornar a descrição mais específica para os dados do conjunto de treino (conceito normal), e os resultados mostram que essa variação tem forte impacto sobre as taxas de acerto. Uma descrição cada vez mais específica, obtida com o aumento de $\nu$, torna mais difícil a identificação de exemplos normais, o que pode ser observado pela queda na sua taxa de acerto. Por outro lado, grande parte dos novos exemplos apresentados passa a ser considerada novidade, o que se demonstra pelo aumento na taxa de acerto da novidade. Analogamente, o comportamento contrário pode ser observado com a redução do valor de $\nu$. A oposição no comportamento das duas curvas pode ser observada nos outros experimentos, havendo ou não um ponto de cruzamento.

O aumento do valor de $\nu$ pode levar também ao crescimento no número de vetores suporte necessários para descrever os dados, uma vez que, à medida que se caminha para uma descrição mais específica, as fronteiras podem começar a coincidir com um número maior de exemplos. Assim, se a quantidade de vetores suporte começa a se aproximar muito do número de exemplos disponíveis para treino, isso indica a ocorrência de sobreajuste.

Com o segundo conjunto de dados, foram obtidos resultados semelhantes. Na Figura 3.1 é apresentado um dos gráficos obtidos.

Quanto aos valores das taxas de acerto, considerando a alta dimensão dos dados (dezenas de exemplos com milhares de atributos), os resultados foram considerados compatíveis. Entretanto, com a realização da segunda série de experimentos, verificou-se que o uso de uma técnica para reduzir o número de atributos pode contribuir fortemente para 


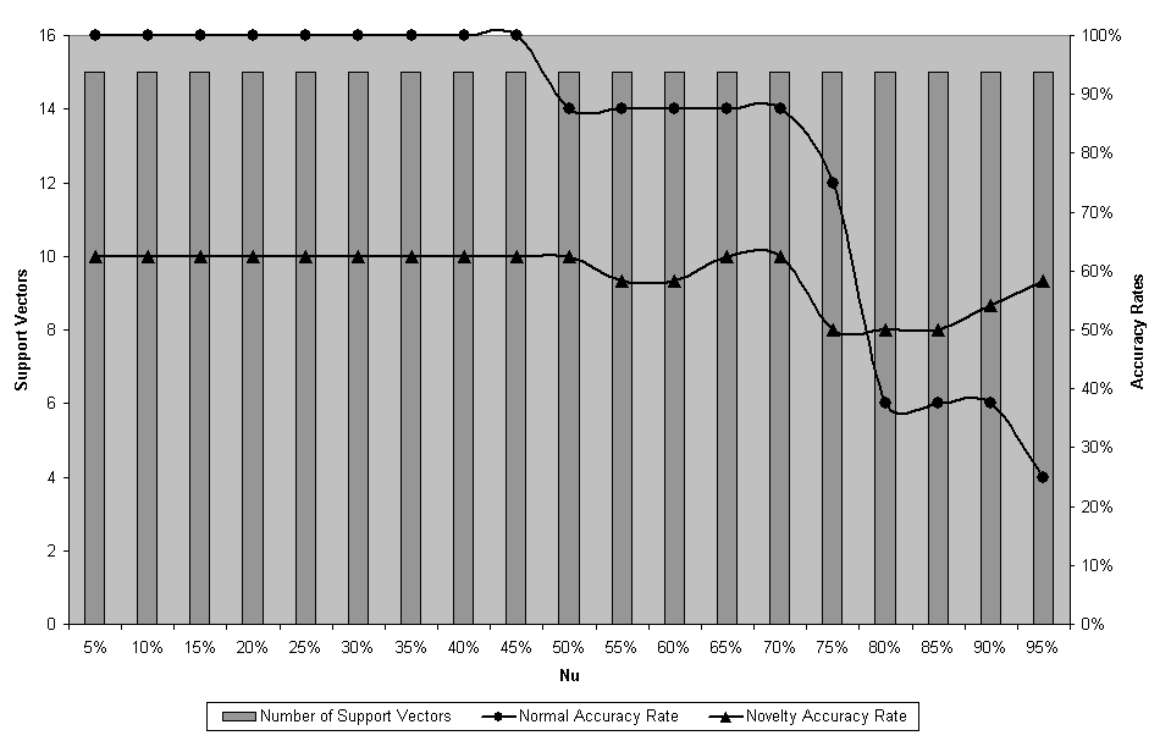

Figura 3.2: Resultados com o conjunto lymphoma com germinal center como novidade.

a melhoria desses resultados.

\subsubsection{Conclusões}

Com a primeira série de experimentos explorou-se o uso da DN em bioinformática. A abordagem escolhida conseguiu obter resultados razoáveis, considerando a alta dimensão dos dados e o fato de que em problemas de C1C o classificador é induzido com base apenas em exemplos do conceito normal.

Por outro lado, a forte influência do parâmetro $\nu$ na qualidade dos resultados foi um fator negativo, uma vez que em DN não basta atingir uma boa taxa de acerto para a novidade; é preciso também continuar a reconhecer elementos do conceito normal com um bom grau de confiança.

Mais informações sobre esta série de experimentos podem ser obtidas em Spinosa and de Carvalho (2004, 2005b).

\subsection{Combinação de técnicas de detecção de novidade}

Nesta segunda série de experimentos avaliou-se o uso de uma abordagem combinada de diversas técnicas de DN em dados de expressão gênica.

\subsubsection{Motivação e objetivos}

O fato de diferentes técnicas de AM mostrarem-se mais ou menos eficazes em diferentes domínios incentivou a investigação de uma abordagem combinada para a DN no problema de AEG. Considerando a opinião de um conjunto de classificadores em oposição 
à dependência de uma única abordagem, espera-se evitar o favorecimento de um conceito em detrimento de outros e, com isso, melhorar a robustez da tarefa de C1C.

\subsubsection{Metodologia e conjuntos de dados}

Cinco técnicas de AM para DN foram escolhidas para esse estudo: PW, KNN, KM, SOM e análise de componentes principais (PCA, do Inglês Principal Components Analysis). Para a classificação de cada novo exemplo, considerou-se a decisão da maioria do conjunto de classificadores, em uma votação com igual peso para cada um.

Inicialmente, todos os classificadores foram treinados com um conjunto de dados contendo apenas exemplos de um conceito considerado normal. Para cada conjunto de dados, cada classe foi considerada normal por vez, e os exemplos de outras classes foram rotulados como novidade e utilizados apenas para teste.

A avaliação dos resultados foi feita com base nas taxas de erro, denominadas taxa de erro normal, devida aos erros do tipo falso-novidade, e taxa de erro novidade, referente aos erros do tipo falso-normal.

Foram utilizados os seguintes conjuntos de dados de expressão gênica, cujas características constam da Tabela 3.1.

- breast. Classificação de amostras de câncer de mama em duas classes que indicam o estado do receptor de estrogênio: positivo e negativo (West et al., 2001).

- colon. Distinção entre amostras de tecido de cólon normais e com tumor Alon et al., 1999).

- leukemia. Identificação de dois tipos de leucemia (ALL e AML) (Golub et al., 1999).

- lymphoma. Distinção entre linfomas large B-cell dos tipos germinal center e activated diffuse (Alizadeh et al., 2000).

Utilizou-se validação cruzada estratificada com 10 partições. As mesmas partições foram usadas em todos os experimentos. A implementação fez uso do pacote DDtools (Tax, 2005).

Os resultados obtidos são analisados a seguir. Na apresentação desses resultados, as classes são referenciadas por números, de acordo com a associação mostrada na Tabela 3.1 .

\subsubsection{Análise dos resultados}

Os resultados são apresentados sob a forma de gráficos como o ilustrado na Figura 3.3. O título de cada gráfico fornece o nome do conjunto de dados, o número de atributos 


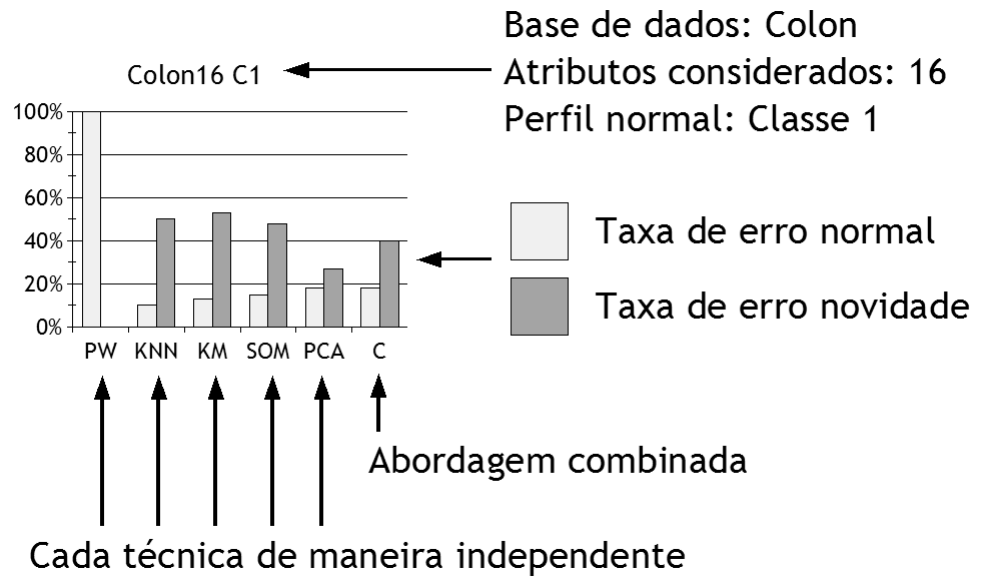

Figura 3.3: Formato em que os resultados são apresentados.

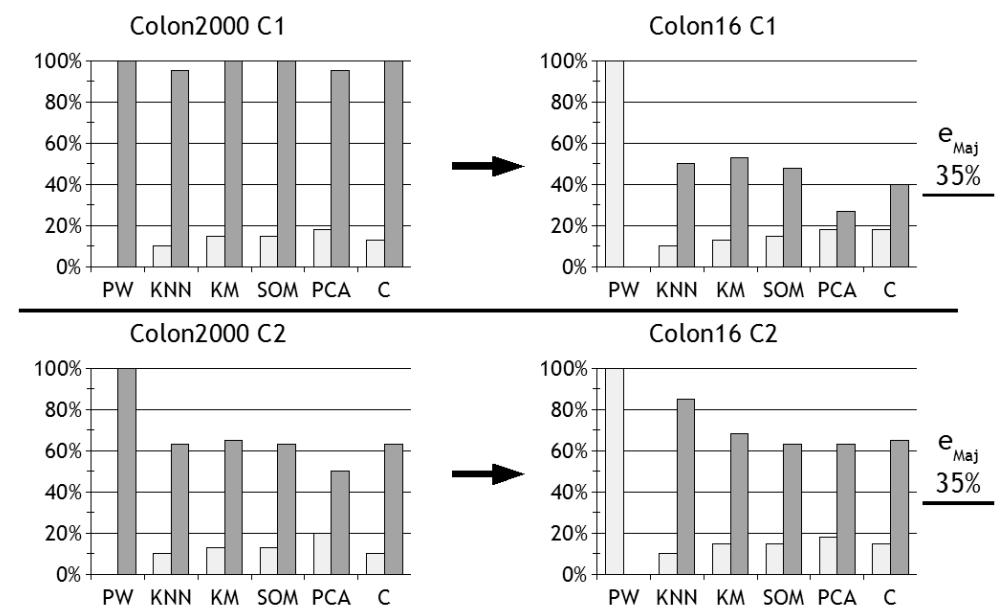

Figura 3.4: Mudanças com a redução de atributos para colon.

e a classe que foi considerada como o conceito normal. As barras claras indicam taxas de erro para o conceito normal e as escuras indicam a taxa de erro para novidade. Todos os resultados representam a média dos resultados obtidos nas 10 partições. Cada par de barras representa os resultados de uma técnica trabalhando de maneira independente. $\mathrm{O}$ último par corresponde aos resultados da abordagem combinada.

Inicialmente, foram considerados dois dos conjuntos de dados originais, com o número total de atributos: colon2000 e lymphoma4026. Os resultados não foram satisfatórios, como pode ser constatado pelos gráficos à esquerda nas Figuras 3.4 (conjunto colon2000) e 3.5 (conjunto lymphoma4026). Observa-se que grande parte das cinco técnicas obteve taxas de erro muito elevadas para novidade e muito baixas para o conceito normal, identificando a ocorrência de sub-ajuste (underfitting), ou seja, os classificadores foram incapazes de aprender que características determinam o conceito normal. A situação oposta, o sobre-ajuste (overfitting), ocorreu com a técnica SOM para o conjunto lymphoma4026. Considerando que o número de exemplos, 62 e 47, é extremamente baixo se comparado à quantidade de atributos, tal resultado se justifica. 


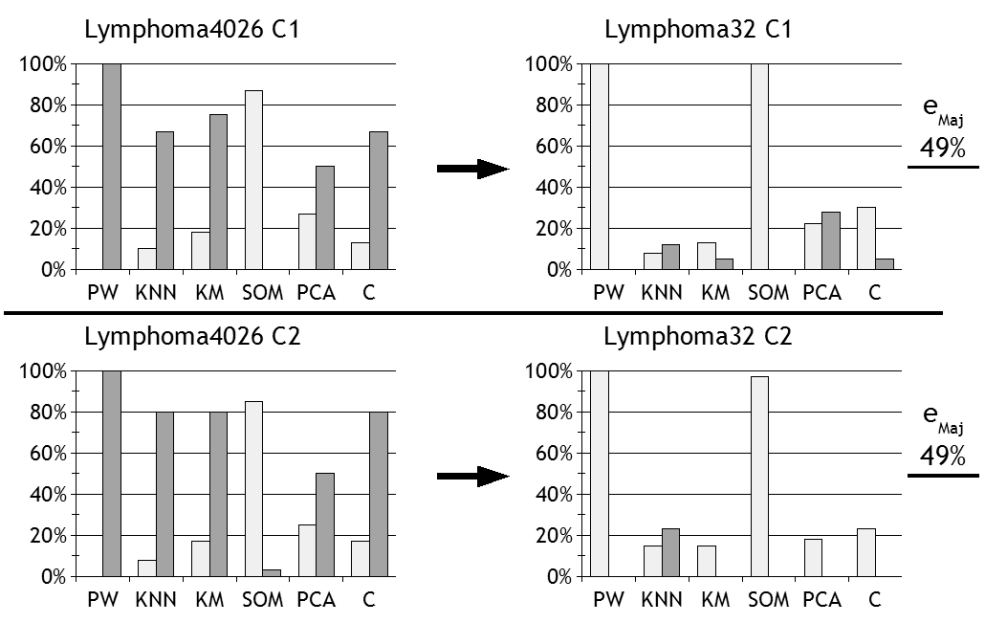

Figura 3.5: Mudanças com a redução de atributos para lymphoma.

Com o objetivo de verificar se esses problemas realmente estavam relacionados à alta dimensão dos dados, foram utilizados conjuntos de dados cedidos por Souza (2005), em que foi aplicada uma técnica de redução de atributos. Os resultados obtidos com os conjuntos reduzidos colon16 e lymphoma32 podem ser comparados com os resultados anteriores nas Figuras 3.4 e 3.5.

Observa-se que as situações de sub-ajuste foram resolvidas. Com o conjunto lymphoma32, grande parte das taxas de erro ficou abaixo do erro da classe majoritária, representado na figura por $e_{M a j}$. Para o conjunto colon16, apesar da grande redução, ainda se observam algumas taxas altas. As técnicas PW e SOM também apresentaram problemas de sobreajuste; entretanto, é interessante notar que esses problemas não influenciaram o resultado da abordagem combinada.

Como um efeito positivo, a redução na quantidade de atributos contribuiu para uma queda substancial no custo computacional. Esse aspecto fortalece ainda mais o argumento em favor do uso de técnicas de redução de atributos para aplicações em bioinformática, particularmente para AEG.

Considerando a vantagem da abordagem combinada, demonstrada pela combinação de classificadores induzidos por cinco técnicas de AM, o próximo objetivo foi investigar se a redução do número de classificadores para três afetaria o resultado final. Para essa análise, foram excluídas as técnicas SOM e PCA. Os resultados dessa mudança podem ser vistos nos gráficos das Figuras 3.6, 3.7, 3.8 e 3.9.

Mesmo após a redução de cinco para três classificadores, não se observou alteração significativa dos resultados para nenhum dos quatro conjuntos de dados. Apesar de a técnica PW continuar a apresentar sub-ajuste ou sobre-ajuste em todas as situações, constatou-se que uma abordagem combinada, ainda que com um pequeno conjunto de classificadores, apresentou vantagens sobre a escolha tradicional de apenas uma técnica.

Em uma última seqüência de experimentos, foi considerada uma outra combinação 


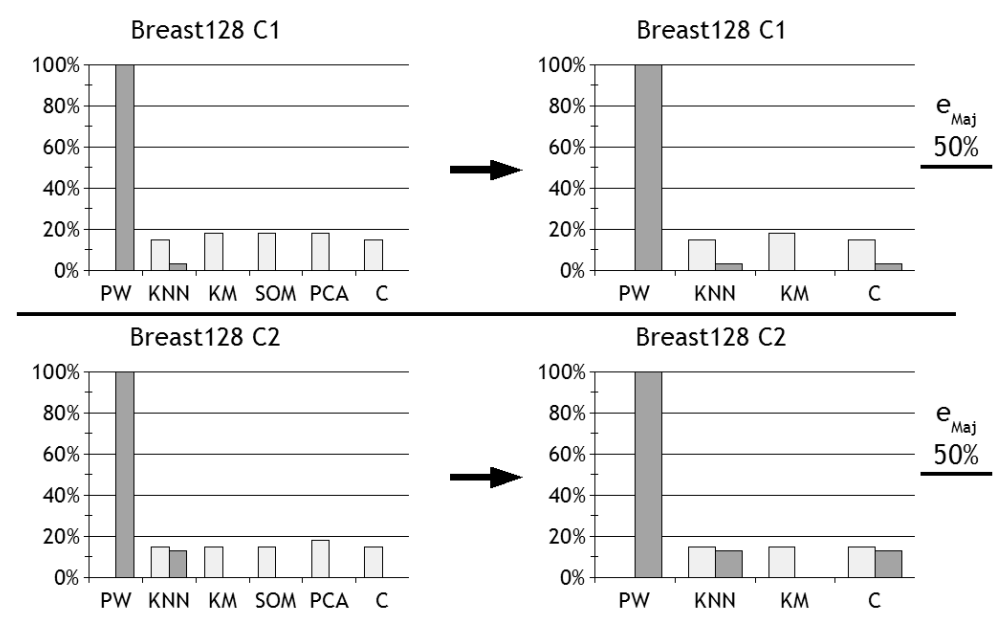

Figura 3.6: Mudanças com a redução de 5 para 3 classificadores para breast.

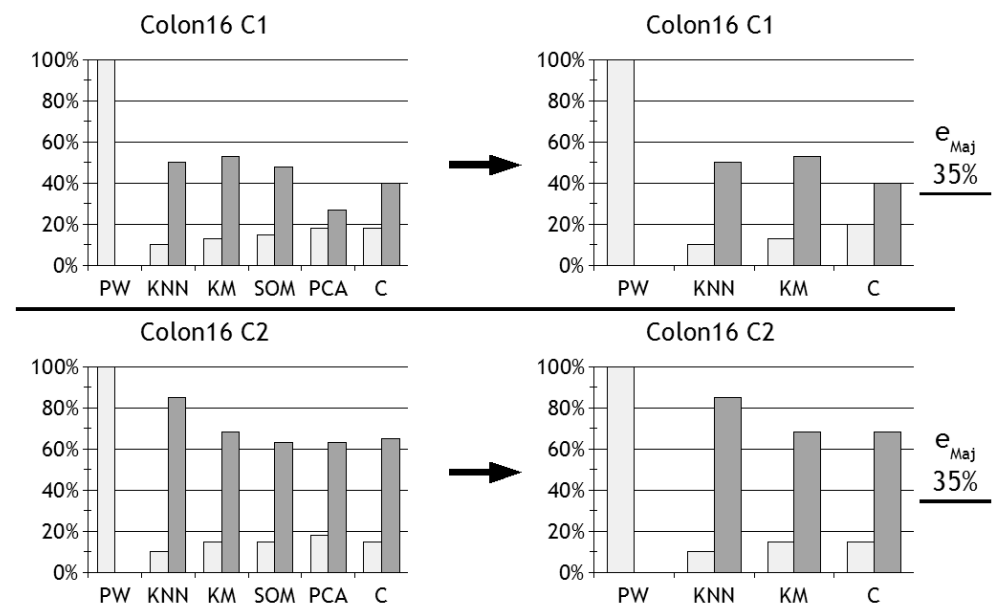

Figura 3.7: Mudanças com a redução de 5 para 3 classificadores para colon.

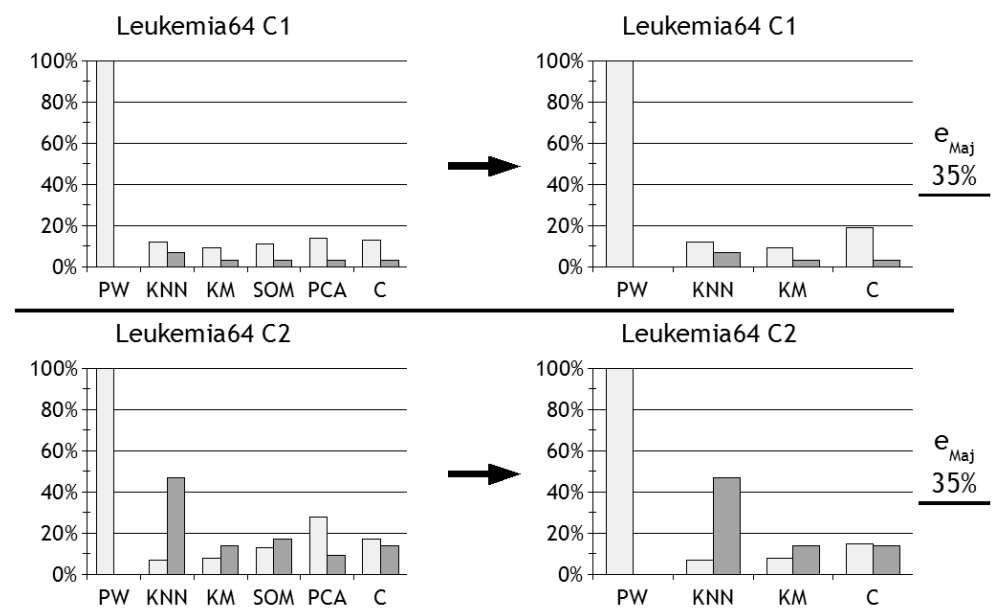

Figura 3.8: Mudanças com a redução de 5 para 3 classificadores para leukemia. 


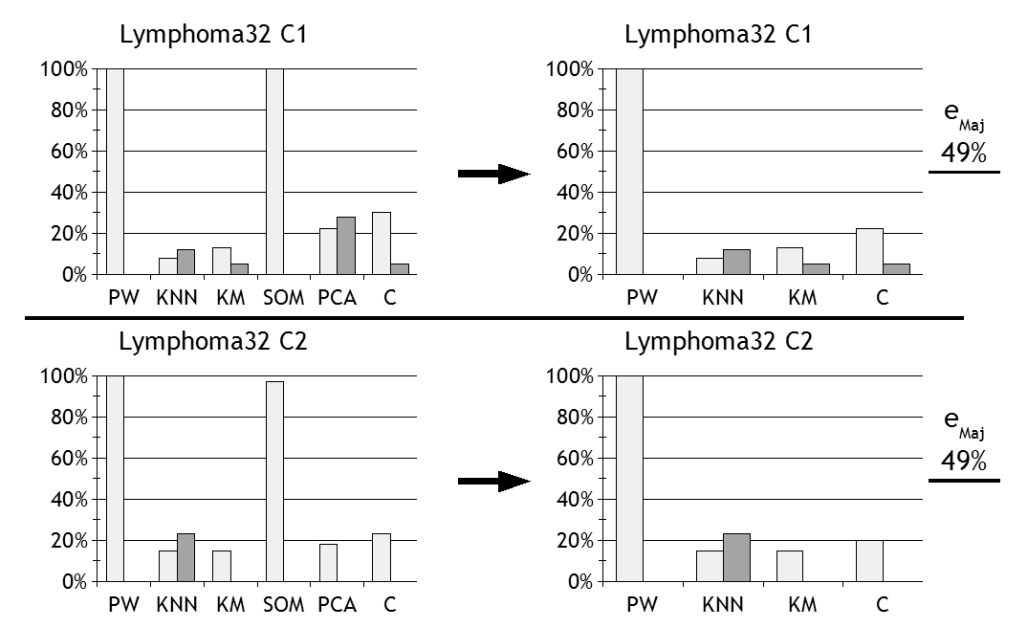

Figura 3.9: Mudanças com a redução de 5 para 3 classificadores para lymphoma.

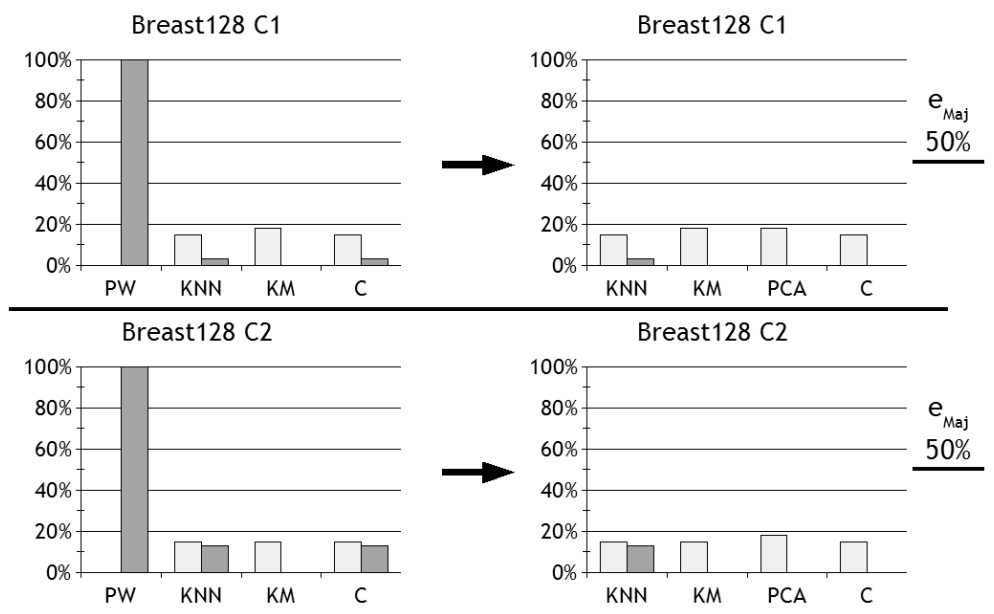

Figura 3.10: Mudanças com um conjunto diferente de 3 classificadores para breast.

de três classificadores, com a substituição de PW, que apresentou problemas em todos os casos, por PCA. As mudanças dos resultados obtidos com o conjunto anterior de três classificadores para o novo conjunto de classificadores são apresentadas nas Figuras 3.10. $3.11,3.12$ e 3.13 .

Com a substituição de PW por PCA, não foram verificadas diferenças relevantes nos resultados da abordagem combinada, ocorrendo apenas melhorias sutis de uma maneira geral. Isso reforça o fato de que o resultado da combinação é robusto, ou seja, a influência de uma mudança relevante no comportamento de uma das técnicas, mesmo em um pequeno conjunto de classificadores, não é suficiente para alterar substancialmente o resultado final.

Com o objetivo de analisar mais profundamente o funcionamento da abordagem combinada, todos os erros cometidos foram representados graficamente. Na Figura 3.14, em cada linha estão representados todos os 44 exemplos do conjunto breast128. Um quadrado branco mostra um acerto do classificador induzido com o uso da técnica identificada no 


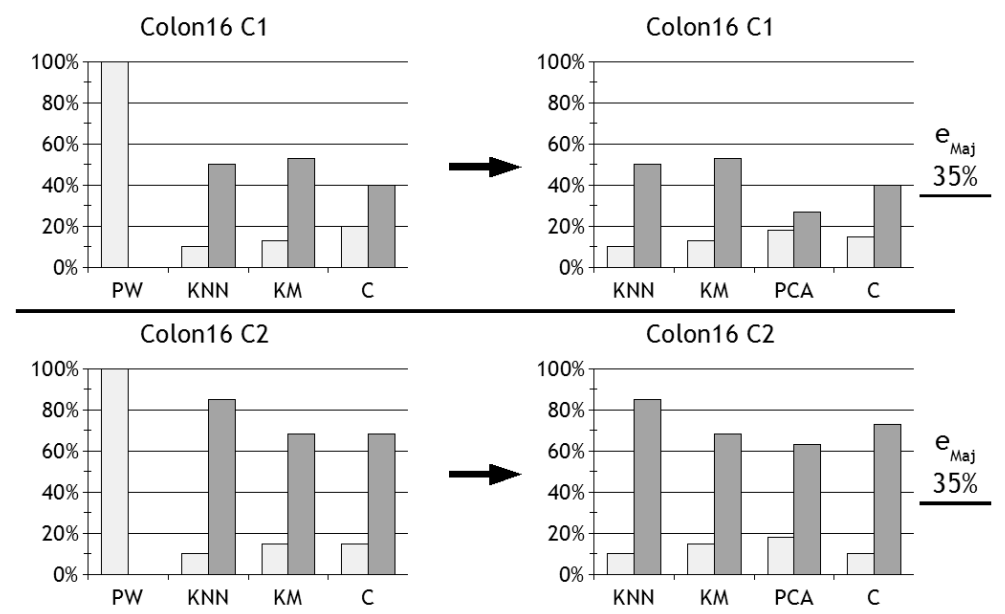

Figura 3.11: Mudanças com um conjunto diferente de 3 classificadores para colon.

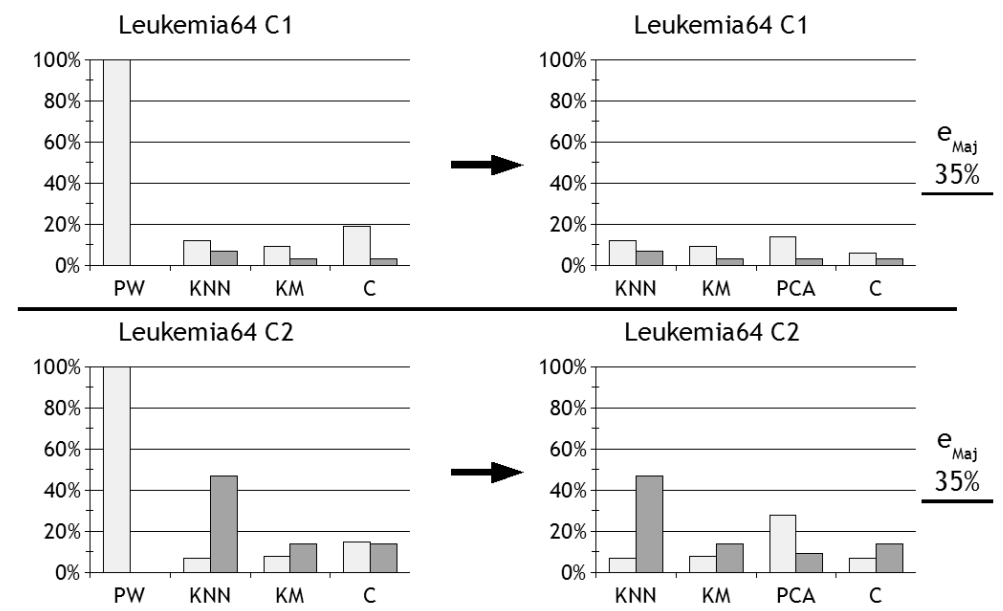

Figura 3.12: Mudanças com um conjunto diferente de 3 classificadores para leukemia.

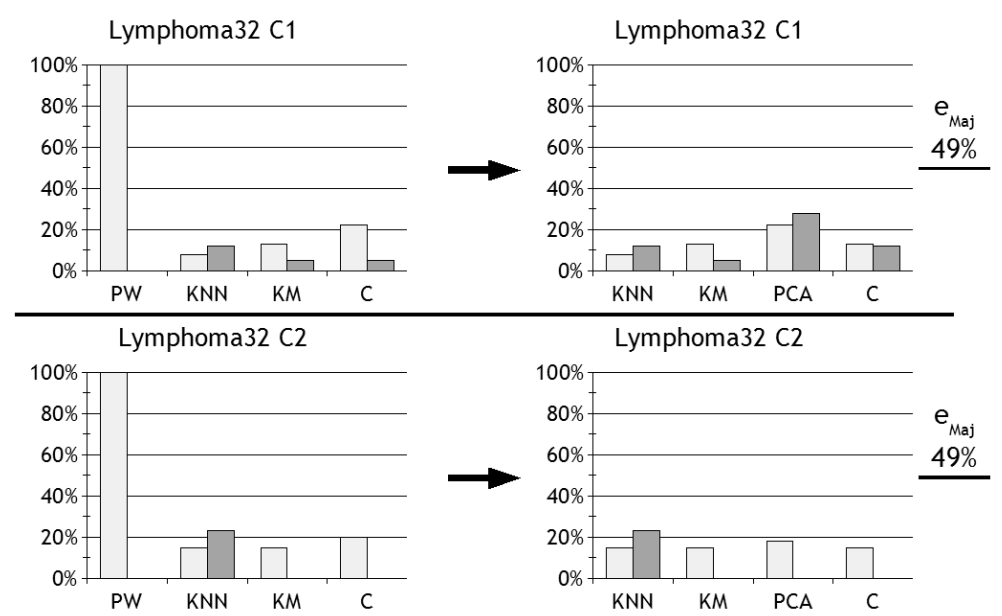

Figura 3.13: Mudanças com um conjunto diferente de 3 classificadores para lymphoma. 
Breast128 C1

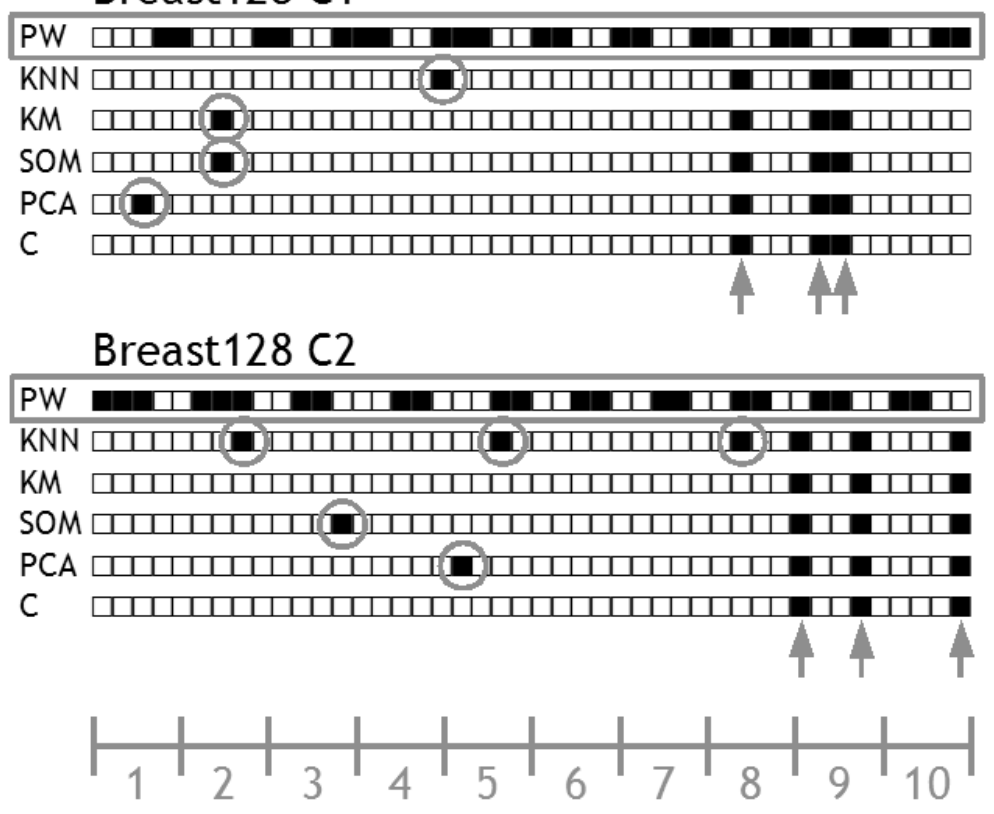

Figura 3.14: Erros cometidos por cada técnica para breast.

início da linha no exemplo em questão. Os erros são marcados com quadrados pretos, sejam eles do tipo falso-novidade ou falso-normal. A última linha representa os resultados da abordagem combinada. Com o uso da validação cruzada foi possível representar erros e acertos em todos os exemplos.

O primeiro aspecto a ser observado na Figura 3.14 é a ocorrência de sobre-ajuste ou sub-ajuste, fato marcado pelo número de retângulos pretos na linha referente ao classificador gerado pela técnica PW. Como já havia sido mostrado para o conjunto breast128, o classificador PW exibiu um comportamento de sub-ajuste.

Essa análise gráfica de erros também permite observar que erros esparsos cometidos por diferentes técnicas, marcados com círculos na Figura 3.14, são evitados pela abordagem combinada (última linha do gráfico). É exatamente esse comportamento que desejávamos obter, pois ele confirma a robustez conseguida pela combinação de um conjunto de classificadores.

Finalmente, na Figura 3.14 é possível identificar exemplos problemáticos, nos quais grande parte dos classificadores cometeu erros. Esses casos, marcados pelas setas, podem ser separados para uma futura análise.

As características visualizadas na Figura 3.14 para o conjunto breast128 se repetem para os outros conjuntos, representadas nas Figuras 3.15, 3.16 e 3.17.

\subsubsection{Conclusões}

A abordagem combinada utilizada para DN em dados de expressão gênica demonstrou ser mais robusta do que um único classificador, à medida que a decisão da maioria 
Colon 16 C1

\begin{abstract}
PW

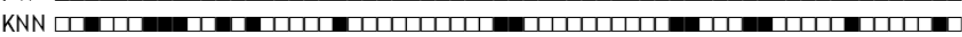
KM SOM ח

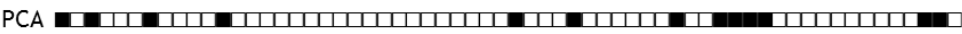
C
\end{abstract}

Colon16 C2

PW KNN

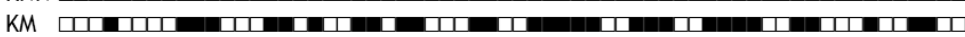
SOM

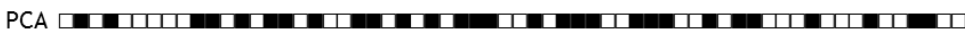

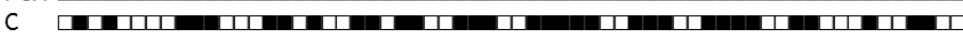

Figura 3.15: Erros cometidos por cada técnica para colon.

Leukemia64 C1

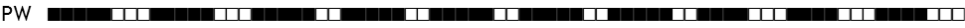

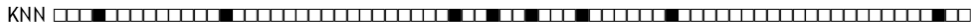

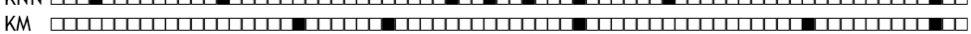
SOM

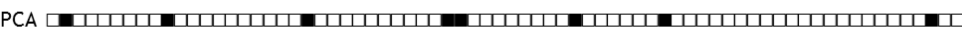
C C

Leukemia64 C2

PW

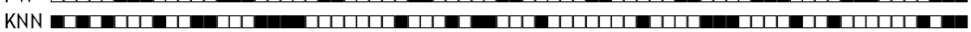
KM

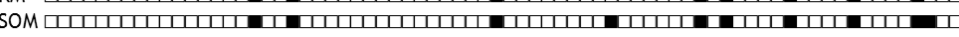
PCA

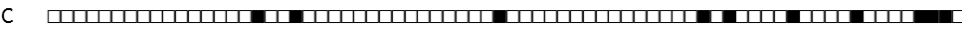

Figura 3.16: Erros cometidos por cada técnica para leukemia.

\title{
Lymphoma32 C1
}

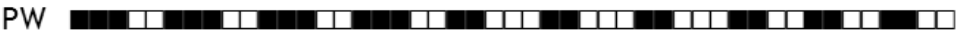

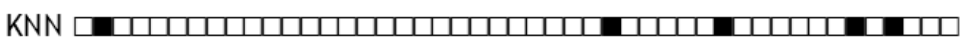

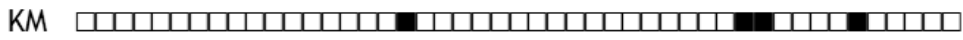

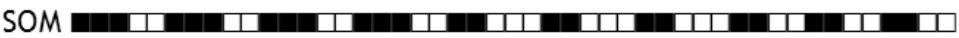

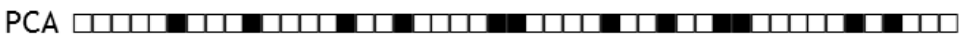

C

$$
\text { Lymphoma32 C2 }
$$

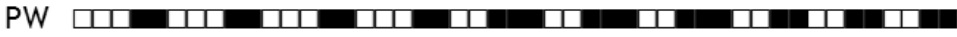

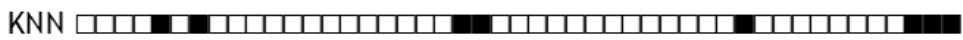

KM שחדים

SOM

PCA

e

Figura 3.17: Erros cometidos por cada técnica para lymphoma. 
evita tendências de alguns algoritmos de AM, dependendo do domínio de aplicação. Situações indesejáveis como sobre-ajuste e sub-ajuste, às vezes decorrentes de uma escolha inadequada dos parâmetros, também podem ser evitadas.

A quantidade de classificadores é parâmetro importante, já que, quanto maior o número de classificadores, menor será a influência de cada um e, portanto, mais robusta será a decisão final. Entretanto, os experimentos realizados mostram que mesmo um conjunto pequeno de classificadores é capaz de obter bons resultados.

A diversidade das técnicas de AM que formam o conjunto de classificadores é também um fator importante, pois com a abordagem combinada pretende-se que os erros cometidos por um classificador sejam supridos pelos acertos dos demais.

Finalmente, o uso de uma técnica de redução de atributos foi essencial para que fossem obtidos resultados satisfatórios, tendo em vista a alta dimensão dos dados de expressão gênica. A redução de atributos trouxe ainda como vantagem uma importante redução no custo computacional.

Mais informações sobre esta série de experimentos podem ser obtidas em Spinosa and de Carvalho (2005a).

\subsection{Considerações finais}

Os experimentos preliminares apresentados neste capítulo contribuíram para a exploração do problema da DN de uma maneira geral e para o estudo da aplicação de técnicas de DN ao problema da AEG de maneira específica.

A alta dimensão dos dados foi identificada como uma dos principais desafios, além da dificuldade natural do aprendizado feito a partir apenas de uma classe. Verificou-se que o uso de uma abordagem combinada de diversas técnicas de DN pode contribuir para obter melhores resultados, mesmo com um conjunto pequeno de classificadores.

O próximo capítulo apresenta a abordagem proposta neste trabalho. 


\section{Capítulo 4}

\section{Abordagem proposta}

Este capítulo descreve a abordagem para a identificação de novos conceitos proposta neste trabalho, denominada OLINDDA (OnLIne Novelty and Drift Detection Algorithm).

Seu desenvolvimento teve em conta dois pontos essenciais: a idéia de novidade como um conceito, e a relação intrínseca entre tempo e novidade, o que implica naturalmente a inserção da tarefa de DN no contexto de um processo de aprendizado contínuo.

\subsection{Detecção de novidade a partir da classificação com uma classe}

Como visto na Seção 2.2, na literatura, a DN é freqüentemente vista simplesmente como um problema de $\mathrm{C} 1 \mathrm{C}$. Em geral, as técnicas de $\mathrm{C} 1 \mathrm{C}$ concentram-se apenas na distinção entre os exemplos que pertencem a um determinado conceito-alvo e os que não pertencem, tendo como base para o aprendizado apenas exemplos do conceito-alvo. Apesar da importância do problema e do fato de que uma série de aplicações práticas podem beneficiar-se de técnicas de C1C, essa simples classificação não permite o aprendizado de novidade, como entendida neste trabalho.

Conforme definido na Seção 2.3, uma novidade é vista aqui como um novo conceito, representado por um grupo coeso de exemplos que compartilham características. Adotase, portanto, na abordagem proposta neste capítulo, uma perspectiva diferente: a de que DN seja realizada a partir da C1C. Partindo dos resultados da C1C, OLINDDA concentrase no problema da descoberta de novos conceitos emergentes em dados que podem assumir a forma de um fluxo contínuo. 


\subsection{Detecção de novidade como parte de um processo de aprendizado contínuo}

Considerando que a própria definição de novidade está diretamente ligada ao fator tempo, adota-se a visão do problema da DN como parte de um processo de aprendizado contínuo. Nesse contexto, à medida que dados são recebidos, novos conceitos podem surgir e conceitos aprendidos inicialmente podem modificar-se. O desenvolvimento de OLINDDA abordou o problema da DN desse ponto de vista.

Considerando a natureza não-supervisionada do aprendizado contínuo, algoritmos de agrupamento apresentam-se como uma alternativa natural. OLINDDA utiliza algoritmos de agrupamento tradicionais periodicamente, como apresentado nas próximas seções.

Um domínio de aplicação no qual esse tipo de cenário se observa claramente é o de FCD. Na Seção 2.4.2 foram discutidos os principais desafios impostos por essas aplicações: a possibilidade de descartar exemplos que já tenham sido analisados, a capacidade de aprender de maneira contínua, e o fato de que o tempo para o processamento de cada exemplo não deve ultrapassar o limite estabelecido pela velocidade a que os dados são gerados. Esses pontos influenciaram algumas escolhas em OLINDDA, que serão discutidas à medida que o algoritmo é apresentado.

\subsection{Grupos, conceitos, modelos e classes}

Diferentemente das técnicas que entendem a DN simplesmente como $\mathrm{C} 1 \mathrm{C}$, nas quais um único exemplo pode ser considerado novidade, a unidade fundamental com a qual OLINDDA trabalha são os grupos. Grupos (clusters) são sub-conjuntos de exemplos obtidos a partir do particionamento de um conjunto maior de exemplos por meio de um algoritmo de agrupamento. Pretende-se que os exemplos que fazem parte de um grupo sejam semelhantes em termos de suas características ou atributos. Contudo, atingir esse objetivo depende de uma série de fatores, entre os quais da capacidade do algoritmo de agrupamento de capturar a distribuição dos dados e de parâmetros, como o número de grupos a ser gerado $k$.

Do ponto de vista de AM simbólico, um conceito é uma regra de classificação que divide o espaço dos exemplos em duas regiões: a dos exemplos que satisfazem à regra e a dos que não a satisfazem (Michalski et al., 1986). Neste trabalho, considerando a ênfase em aprendizado não-supervisionado por técnicas de agrupamento, um conceito equivale a um ou mais grupos coesos de exemplos com características semelhantes. Como descrito mais detalhadamente nas próximas seções, a coesão implica restrições impostas a grupos denominados candidatos, e que conceitos são formados por grupos denominados válidos.

Neste trabalho, o conhecimento é representado por modelos baseados em fronteiras de decisão hiperesféricas. Cada hiperesfera é obtida a partir de um grupo, tendo como 
centro o centróide do grupo e como raio a distância ao exemplo mais afastado. Para cada hiperesfera, são armazenadas ainda algumas informações, entre as quais o valor da medida de coesão escolhida, o número de exemplos que pertencem ao grupo, o número de exemplos que foram explicados por ele, a composição do grupo em termos das classes reais do problema, e um rótulo. Um conceito, identificado unicamente por um rótulo, pode ser representado por uma ou mais hiperesferas, o que permite uma descrição mais flexível da distribuição real dos dados.

A estrutura dos modelos baseada em hiperesferas utilizada por OLINDDA ocupa pouco espaço em memória. Além disso, permite que os modelos sejam atualizados de maneira incremental, com baixo custo computacional. Esses fatores são especialmente importantes nas aplicações envolvendo FCD.

O termo classe é aqui usado exclusivamente para fazer referência às classes reais do problema. Embora os conceitos descobertos pela abordagem proposta possam ser muitas vezes equivalentes às classes reais, sendo esse, em última análise, o objetivo principal da técnica proposta, os termos conceito e classe são usados neste trabalho de maneira distinta para estabelecer claramente essa diferença.

A expressão perfis desconhecidos é utilizada para identificar o conjunto de exemplos que não foram identificados como membros de nenhum conceito conhecido.

\subsection{Visão geral do funcionamento de OLINDDA}

O fluxograma apresentado na Figura 4.1 sintetiza o funcionamento de OLINDDA. O símbolo * indica parâmetros do algoritmo, e ${ }^{* *}$ indica valores determinados automaticamente.

OLINDDA utiliza um algoritmo de agrupamento escolhido pelo usuário em dois momentos, identificados na Figura 4.1 por algoritmo de agrupamento. O algoritmo k-médias foi escolhido como padrão por apresentar como principais vantagens, além da simplicidade, a rápida convergência e o baixo custo computacional, fatores importantes nas aplicações envolvendo FCD.

Na versão atual de OLINDDA, também é possível utilizar o algoritmo Partitioning Around Medoids (PAM) ou o Clustering Large Applications (CLARA) (Kaufman and Rousseeuw, 1990). O algoritmo PAM seleciona inicialmente os $k$ exemplos mais representativos, denominados medóides, ao redor dos quais os grupos são formados. O algoritmo considera substituições dos medóides por outros exemplos, escolhendo o conjunto de medóides que oferecer o menor custo, que é calculado em função da soma das distâncias entre cada exemplo e o medóide mais próximo. O algoritmo CLARA foi desenvolvido a partir do algoritmo PAM para aplicação a uma grande quantidade de dados. Para reduzir o custo computacional, CLARA seleciona os medóides em amostras obtidas do conjunto de dados completo. Os conjuntos de medóides são avaliados no conjunto completo, e o 


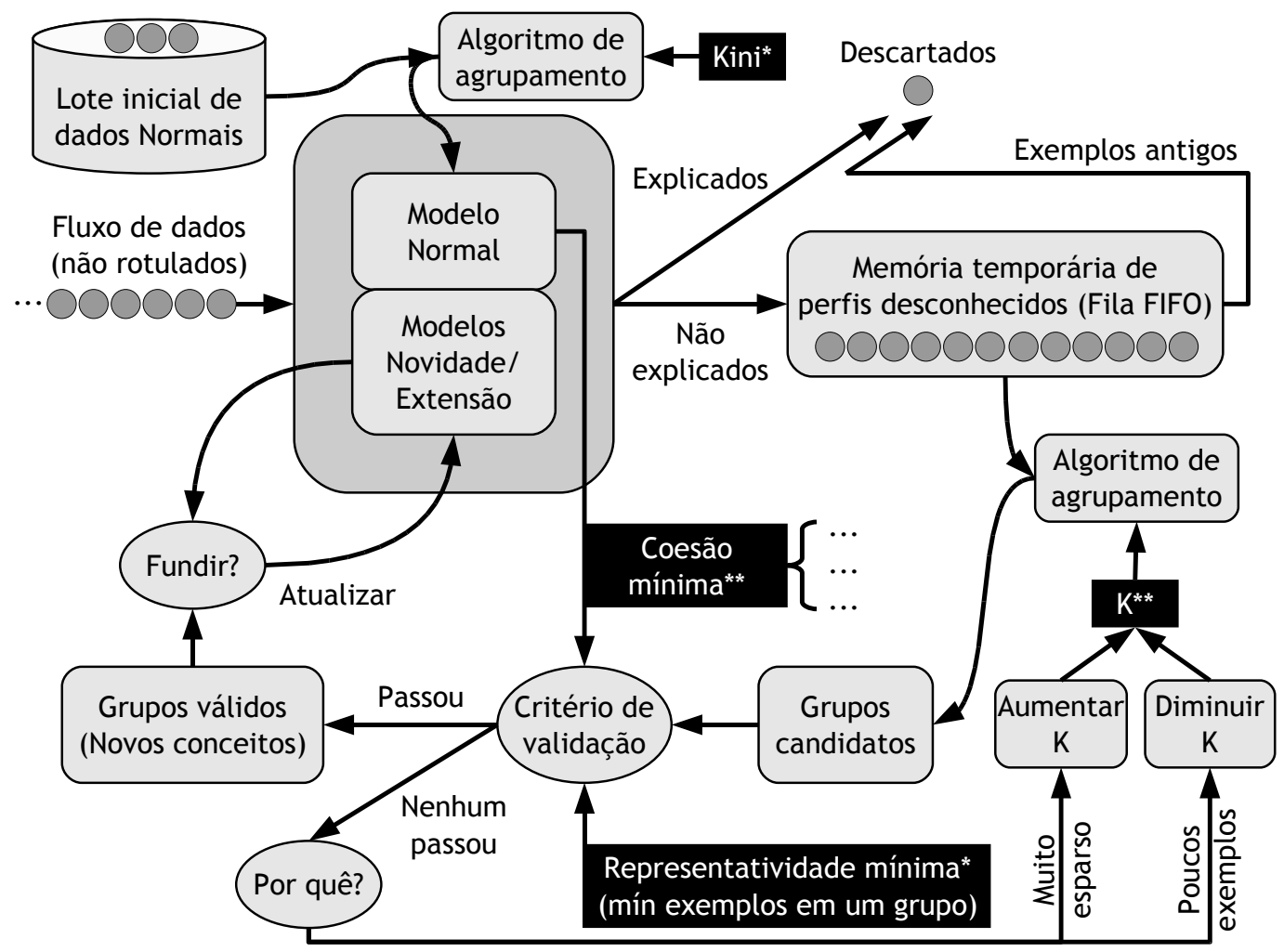

Figura 4.1: Fluxograma de OLINDDA.

que oferecer o menor custo é selecionado. Outros algoritmos de agrupamento podem ser facilmente incorporados a OLINDDA.

Quanto ao tipo de aprendizado empregado, a abordagem proposta pode ser dividida em duas fases, descritas a seguir.

\subsection{Fase inicial de aprendizado supervisionado do con- ceito normal}

A abordagem proposta considera inicialmente um conjunto de exemplos representando o conceito normal. Por meio de um algoritmo de agrupamento definido pelo usuário, gerase um modelo denominado normal para representar esse conceito.

O número de grupos para a geração do modelo normal $k_{i n i}$ é definido por um parâmetro. Sua influência será discutida na Seção 4.7 .

Uma vez gerado, o modelo normal permanece estático, servindo como referência ao conhecimento inicialmente disponível. Atualizações incrementais do conceito normal são possíveis por meio do modelo extensão, descrito a seguir. 


\subsection{Fase de aprendizado contínuo não-supervisionado de novos conceitos}

A partir deste ponto, o algoritmo passa a receber um fluxo de dados não-rotulados, que servirão de base para o aprendizado contínuo e não-supervisionado de novos conceitos. Nessa fase, os exemplos são analisados seqüencialmente e de maneira independente, de acordo com o modelo de FCD apresentado na Seção 2.4.2.

Em primeiro lugar, o algoritmo verifica se o exemplo pode ser explicado por um dos conceitos conhecidos naquele momento. Inicialmente, apenas o modelo normal estará presente. Mas com o passar do tempo, poderão existir também dois outros modelos que são gerados e atualizados dinamicamente pelo algoritmo, denominados novidade e extensão. O modelo novidade armazena conceitos novos cujas características diferem claramente daquelas do conceito normal. O modelo extensão contém os conceitos descobertos cujas características são semelhantes às do conceito normal.

Um exemplo é considerado explicado por um conceito se suas coordenadas estiverem no interior da região delimitada pela hiperesfera correspondente a esse conceito. Exemplos explicados por um dos conceitos conhecidos são descartados, uma vez que não apresentam novas características que possam eventualmente contribuir para a definição de um novo conceito.

Exemplos não explicados por nenhum conceito de nenhum dos modelos são temporariamente armazenados em uma memória temporária de perfis desconhecidos. O número máximo de exemplos nessa memória é estabelecido pelo usuário, considerando as limitações de tempo de processamento impostas pela aplicação. Uma vez atingido esse limite, a memória passa a funcionar como uma fila First In First Out (FIFO), eliminando o exemplo mais antigo para dar espaço a um novo exemplo. A versão atual de OLINDDA não elimina exemplos pelo tempo em que estão na memória temporária.

A função da memória temporária é armazenar exemplos cujas características diferem do que é conhecido, de onde, portanto, podem surgir novos conceitos.

\subsubsection{Busca por novos conceitos}

A cada novo exemplo adicionado à memória temporária, o algoritmo de agrupamento escolhido é aplicado sobre esses exemplos, dando origem a grupos candidatos. Dependendo da situação, pode-se determinar que essa busca seja feita menos freqüentemente, por exemplo, depois que um determinado número de exemplos tiver sido adicionado à memória temporária.

O número de grupos $k$, usado pelo algoritmo de agrupamento, é adaptado automaticamente por OLINDDA, segundo a estratégia a ser apresentada na Seção 4.6.5.

Em seguida, os grupos candidatos são avaliados com o objetivo de verificar se algum 
deles apresenta evidências que apontem para o aparecimento de um novo conceito.

\subsubsection{Critérios de validação}

Para que grupos candidatos sejam considerados novos conceitos, o critério de validação proposto considera duas características fundamentais: coesão e representatividade.

A coesão está relacionada ao grau de similaridade entre os exemplos que compõem um grupo candidato. Quanto mais coesos forem os exemplos de um grupo, mais fortes serão as evidências de que esse grupo pode representar um novo conceito.

Diversas medidas podem ser utilizadas para medir o grau de coesão dos exemplos de um grupo. Entre elas, OLINDDA considera as seguintes:

- Densidade. A densidade dens de um cluster $c_{i}$ é definida por:

$$
\operatorname{dens}\left(c_{i}\right)=\frac{n\left(c_{i}\right)}{\operatorname{vol}\left(c_{i}, m\right)}
$$

onde $n\left(c_{i}\right)$ é o número de exemplos que pertencem a $c_{i}$ e $\operatorname{vol}\left(c_{i}, m\right)$ é o volume da hiperesfera cujo raio $r$ é a distância do centróide ao exemplo mais afastado que pertence ao grupo $c_{i}$. O volume $\operatorname{vol}\left(c_{i}, m\right)$ num espaço de dimensão $m$ é dado por:

$$
\operatorname{vol}\left(c_{i}, m\right)=\frac{\pi^{\frac{m}{2}} r^{m}}{\Gamma\left(\frac{m}{2}+1\right)}
$$

onde $\Gamma$ representa a função gama, definida por:

$$
\Gamma\left(\frac{m}{2}+1\right)=\left\{\begin{array}{c}
\left(\frac{m}{2}\right) !, \text { para } n \text { par } ; \\
\sqrt{\pi} \frac{m ! !}{2^{(m+1) / 2}}, \text { para } n \text { impar }
\end{array}\right.
$$

Esse critério apresenta problemas em conjuntos de dados com um grande número de atributos, uma vez que, à medida que a dimensão $m$ aumenta, vol $\left(c_{i}, m\right)$ tende a zero (Stibor et al., 2006, Figura 2). Esse aspecto é avaliado experimentalmente na Seção 5.4 .9 .

- Soma dos quadrados das distâncias entre exemplos e centróide dividida pelo número de exemplos. A soma dos quadrados das distâncias entre exemplos que pertencem ao grupo $c_{i}$ e o centróide $\mu_{i}$ é definida por:

$$
d\left(x_{j}, \mu_{i}\right)=\sum_{x_{j} \in c_{i}}\left(x_{j}-\mu_{i}\right)^{2}
$$

Dividindo-se esse valor pelo número de exemplos que pertencem ao grupo $c_{i}$, obtémse uma medida comparável $d 1$ : 


$$
d 1\left(x_{j}, \mu_{i}\right)=\frac{d\left(x_{j}, \mu_{i}\right)}{n\left(c_{i}\right)}
$$

Caso o algoritmo de agrupamento selecionado seja o KM, o uso dessa medida de coesão é vantajoso do ponto de vista do custo computacional, uma vez que o valor de $\mathrm{d}\left(x_{j}, \mu_{i}\right)$ já é previamente calculado durante o processo de agrupamento.

- Distância média entre exemplos e centróide. É possível utilizar, ainda, simplesmente a distância média entre exemplos e centróide, $d 2$ :

$$
d 2\left(x_{j}, \mu_{i}\right)=\frac{\sum_{x_{j} \in c_{i}}\left|x_{j}-\mu_{i}\right|}{n\left(c_{i}\right)}
$$

Como limiar para aceitação, referente ao grau de coesão mínimo exigido, OLINDDA utiliza informações do modelo normal. Se a medida de coesão escolhida for a densidade, o grupo será considerado suficientemente coeso se sua densidade for igual ou superior à densidade mínima dos grupos do modelo normal. Se a medida de coesão for a soma dos quadrados das distâncias entre exemplos e centróide dividida pelo número de exemplos ou a distância média entre exemplos e centróide, o grupo será considerado suficientemente coeso se esse valor for igual ou inferior ao valor máximo da respectiva medida nos grupos do modelo normal.

A segunda característica considerada pelo critério de validação diz respeito à representatividade. Um grupo pequeno de exemplos pode ser muito coeso, mas, por não ser representativo, pode não indicar o aparecimento de um novo conceito. Em um caso extremo, um grupo de 1 elemento tem grau de coesão máximo, mas não é representativo. Pode ser um outlier, por exemplo.

Para considerar apenas grupos minimamente representativos, OLINDDA utiliza um parâmetro denominado número mínimo de exemplos em um novo grupo minexcl. Apenas grupos cujo número de exemplos for igual ou superior a minexcl são considerados representativos. A influência desse parâmetro será discutida na Seção 4.7.

Uma vez que um grupo candidato tenha passado nos testes de coesão e representatividade, ele é considerado um grupo válido, que corresponde a um novo conceito descoberto. Inicialmente, todo conceito consiste em um grupo válido. Mas com o tempo, à medida que grupos de diferentes conceitos sofram fusão, um conceito pode ser representado por um conjunto de grupos. A fusão de conceitos será tratada na Seção 4.6.4.

\subsubsection{Distinção entre conceitos de novidade e extensão}

Um aspecto importante em aprendizado contínuo é a capacidade de identificar uma pequena mudança em um conceito pré-existente. Como o modelo normal é estático, para 
que sirva de referência ao conhecimento inicial, OLINDDA permite que o conceito normal seja estendido por meio do modelo extensão.

Uma extensão do conceito normal estará naturalmente localizada na vizinhança do modelo normal, enquanto um conceito mais distante será identificado como novidade. Para estabelecer o limite entre extensão e novidade, OLINDDA constrói uma hiperesfera a partir dos centróides dos grupos do modelo normal. O centro dessa hiperesfera é o centróide dos centróides, isto é, o centróide de um conjunto de pontos que são os centróides dos grupos do modelo normal. Seu raio é a distância ao centróide mais afastado. Se o centróide do novo conceito estiver localizado no interior dessa hiperesfera, o novo conceito é considerado uma extensão. Caso contrário, uma novidade.

\subsubsection{Atualização dos modelos e fusão de conceitos}

Os modelos extensão e novidade são atualizados de maneira incremental, com baixo custo computacional.

É importante notar que, apesar de utilizar algoritmos de agrupamento e atualizar incrementalmente os modelos que descrevem os dados, OLINDDA não é um algoritmo de agrupamento incremental. Conforme discutido na Seção 2.7, algoritmos de agrupamento incremental em geral utilizam todos os exemplos na formação de grupos, analisando exemplos individualmente, podendo cada um ser adicionado a um grupo já existente ou ser usado para iniciar um novo grupo (Jain et al., 1999). OLINDDA, por outro lado, como uma técnica de DN, descarta exemplos que não apresentam características novas e analisa grupos que, dependendo dos critérios de validação, podem ou não ser aceitos.

No momento em que um novo conceito vai ser incorporado a um dos modelos, OLINDDA considera duas possibilidades: adicioná-lo como um novo conceito independente ou realizar a fusão entre o novo conceito e um ou mais conceitos já existentes.

O conceito que acaba de ser descoberto estará sempre relacionado a apenas um grupo, enquanto conceitos existentes podem ser formados por mais de um grupo, resultado de fusões anteriores.

A fusão de dois ou mais conceitos ocorre se houver interseção entre as hiperesferas associadas aos grupos que formam esses conceitos. Se ocorrer fusão, os conceitos envolvidos passam a ser representados pelo mesmo rótulo e as informações estatísticas são agregadas. Caso a fusão não ocorra, um novo rótulo é criado para o novo conceito.

Entre outros aspectos positivos, a fusão entre conceitos permite, em primeiro lugar, reduzir a quantidade de conceitos, o que facilita a análise e a comparação entre o resultado obtido e a distribuição real de classes.

Além disso, a fusão permite que os conceitos sejam compostos por várias hiperesferas, possibilitando o modelamento de distribuições mais complexas, que não seriam bem representadas por uma única hiperesfera. Esse aspecto, de uma certa maneira, reduz as 
possíveis limitações de um modelo baseado em hiperesferas na descrição de determinadas distribuições de dados.

À medida que os modelos são atualizados, os conceitos descobertos passam a contribuir para explicar, potencialmente, um número maior de exemplos. Como exemplos explicados são descartados, um número relativamente pequeno de exemplos que consiga formar grupos válidos pode permitir o descarte de uma quantidade muito maior de exemplos. Em FCD essa é uma característica positiva, uma vez que nessas aplicações somente é possível manter em memória uma pequena quantidade de exemplos.

\subsubsection{Adaptação automática do número de grupos}

O número de grupos $k$ é um parâmetro utilizado no momento da geração de grupos candidatos pelo algoritmo de agrupamento escolhido. OLINDDA introduz uma estratégia de adaptação automática do valor de $k$ direcionada para otimizar as chances de gerar grupos que atendam aos critérios de validação.

A adaptação ocorre nas iterações em que tenham sido gerados grupos candidatos sem que nenhum deles tenha sido considerado válido. Nesses casos, o algoritmo verifica a causa responsável pela rejeição de cada grupo candidato: o grupo não atendeu ao critério de coesão mínima (muito esparso) ou o grupo não atendeu ao critério de representatividade mínima (poucos exemplos). Em seguida, a causa de rejeição mais freqüente nessa iteração é considerada para decidir como o valor de $k$ deve ser alterado. Se na maior parte das vezes os grupos estão sendo rejeitados por serem muito esparsos, o valor de $k$ é incrementado. Com um número maior de grupos, o grau de coesão deverá aproximar-se do grau adequado para validação. Se a causa mais freqüente para rejeição é a pouca quantidade de exemplos no grupos candidatos, o valor de $k$ é decrementado. Com um número menor de grupos, haverá mais exemplos por grupo, o que procura solucionar o problema da falta de representatividade.

Verificou-se, ao longo do desenvolvimento de OLINDDA, que essa estratégia contribui de maneira importante na geração de um número maior de grupos válidos (Spinosa et al., 2007a), e, conseqüentemente, na descoberta de um maior número de conceitos novos.

\subsection{Influência dos parâmetros}

Os dois principais parâmetros de OLINDDA são o número de grupos para a geração do modelo normal $k_{i n i}$ e o número mínimo de exemplos em um novo grupo minexcl, indicados na Figura 4.1 por *.

Conforme descrito na Seção 4.6.2, para que grupos candidatos sejam considerados válidos (novos conceitos), uma das condições é que eles devem ter um grau mínimo de coesão, que é determinado pelo modelo normal. Como o parâmetro $k_{i n i}$ define o número 
de grupos do modelo normal, ele pode influenciar indiretamente a coesão dos grupos desse modelo, e, portanto, o limiar do grau de coesão que será usado pelo critério de validação. Esse impacto será avaliado experimentalmente na Seção 5.4 .3 .

Já o parâmetro minexcl, que define o número mínimo de exemplos em um novo grupo, tem influência direta sobre o aspecto do critério de validação que avalia o grau de representatividade de um grupo candidato. Esse parâmetro tem a importante função de evitar que sejam aceitos grupos pouco representativos.

A influência desses parâmetros nos resultados obtidos por OLINDDA será analisada ao longo da Seção 5.4 .

\subsection{Complexidade}

O custo computacional de OLINDDA é influenciado por diferentes fatores em cada uma das três fases descritas a seguir.

- Na fase em que se verifica se o exemplo é explicado por um dos conceitos existentes, o custo é função do número total de conceitos nos três modelos. A complexidade nesta fase é, portanto, $O\left(n c_{n o r}+n c_{e x t}+n c_{n o v}\right)$.

- Na fase de geração de grupos candidatos, o custo depende do número de exemplos identificados como perfis desconhecidos $n_{\text {des }}$, considerando que a geração de grupos candidatos só ocorre nas iterações em que um exemplo é identificado como um perfil desconhecido, do número de exemplos na memória temporária $n_{m e m}$ e do custo do próprio algoritmo de agrupamento.

O custo do algoritmo de agrupamento representa, portanto, um fator importante. Por esse motivo, optou-se pelo algoritmo k-médias que oferece rápida convergência, embora OLINDDA possa utilizar outros algoritmos. A complexidade de k-médias é $O(n . d . k . T)$, onde $n$ é o número de exemplos, $d$ é o número de dimensões, $k$ é o numero de grupos e $T$ é o número de iterações, que é, em geral, muito menor do que o número de exemplos Duda and Hart (2001). Arthur and Vassilvitskii (2006) defendem que, no pior caso, k-médias tenha uma complexidade super-polinomial. Entretanto, mesmo considerando que em algumas situações a complexidade de kmédias possa ultrapassar o valor tradicionalmente aceito, o que se observa na prática é que k-médias converge rapidamente, especialmente quando comparado com outros algoritmos de agrupamento.

Portanto, a complexidade nesta fase é $O\left(n_{\text {des }} . n_{m e m} . n . d . k . T\right)$.

No caso típico, entretanto, considerando que na maior parte das aplicações a novidade está associada a uma situação excepcional, a maior parte dos exemplos deve ser 
explicada pelo conceito normal ou por outros conceitos já aprendidos. Assim, esperase que o fator $n_{\text {des }}$ seja pouco relevante. É possível, ainda, reduzir a freqüência com que OLINDDA gera grupos candidatos, o que diminuiria ainda mais a participação de $n_{\text {des }}$ no custo.

Como o número máximo de exemplos na memória temporária de perfis desconhecidos é definido pelo usuário, a contribuição do fator $n_{m e m}$ ao custo também pode ser limitada, considerando os recursos computacionais disponíveis.

- Na fase de atualização dos modelos, para verificar se a hiperesfera associada ao novo conceito intercepta a de algum conceito existente, o custo depende do número total de conceitos nos modelos extensão e novidade, portanto, $O\left(n c_{e x t}+n c_{n o v}\right)$.

O próximo capítulo inclui uma avaliação experimental do tempo de execução de OLINDDA em diversos conjuntos de dados.

\subsection{Considerações finais}

Este capítulo apresentou a abordagem proposta neste trabalho, que pretende realizar a detecção de novos conceitos representados por grupos coesos e representativos de exemplos que não tenham sido previamente explicados por nenhum dos conceitos conhecidos.

O aprendizado é feito de maneira contínua e não-supervisionada, procurando atender às restrições impostas por aplicações envolvendo FCD. Novos conceitos podem sofrer fusão, ampliando a capacidade de representação dos dados e, potencialmente, reduzindo a quantidade de conceitos descobertos, procurando aproximar a resposta de OLINDDA à distribuição de classes real do problema.

Os objetivos e funcionamento desejado do algoritmo proposto foram inicialmente descritos na monografia do exame de qualificação relativo a este trabalho (Spinosa, 2005). A publicação dos primeiros resultados (Spinosa et al., 2006) foi seguida de uma série de melhorias que consideraram, entre outros aspectos, os comentários dos avaliadores dos artigos que foram sendo publicados ao longo do desenvolvimento (Spinosa et al., 2007d b c a).

O desempenho de OLINDDA é avaliado experimentalmente em vários conjuntos de dados no próximo capítulo. 


\section{Capítulo 5}

\section{Avaliação experimental de OLINDDA}

Neste capítulo são inicialmente descritos os conjuntos de dados, a metodologia e as métricas para avaliação de desempenho utilizadas. Em seguida, os resultados são analisados, enfatizando em cada seção um determinado aspecto considerado relevante no contexto da abordagem proposta neste trabalho e das aplicações pretendidas.

\subsection{Conjuntos de dados}

A Tabela 5.1 descreve os conjuntos de dados usados nos experimentos deste capítulo. Para que os experimentos abrangessem uma maior variedade de situações, foram utilizados conjuntos de dados artificiais, direcionados à avaliação de aspectos específicos, e reais, que contribuem com uma maior diversidade de distribuições encontradas na prática, avaliando o algoritmo de um ponto de vista geral.

Os conjuntos de dados $k d d c u p_{-} p c 10$ e kddcup_pc10_c5 correspondem ao desafio da KDD Cup 1999 (Elkan, 2000), envolvendo o problema de análise de FCD para detecção de intrusão em redes de computadores. Os exemplos representam informações de conexões de rede, classificadas como normais ou de ataque. Optou-se pelo conjunto de dados com 10\% dos exemplos (494020 exemplos), disponível na página da competição, por já ser capaz de representar bem o problema. No conjunto $k d d c u p \_p c 10$ há 22 tipos de ataque. O conjunto $k d d c u p \_p c 10 \_c 5$ é composto pelos mesmos exemplos, divididos em 5 classes (4 categorias de ataque).

\subsection{Metodologia}

Os experimentos apresentados neste capítulo seguiram a seguinte metodologia:

- Para simular novos conceitos adotou-se o procedimento normalmente utilizado na 


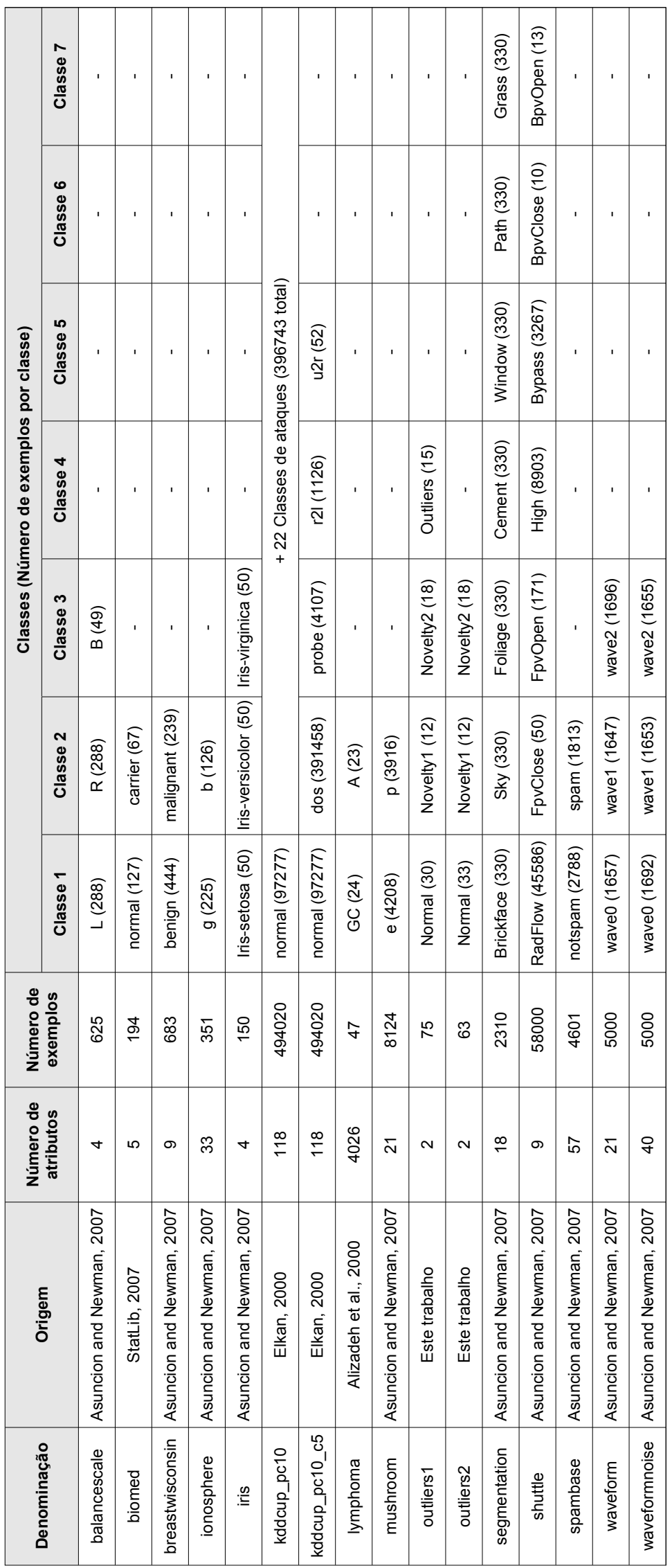

Tabela 5.1: Conjuntos de dados utilizados na avaliação experimental de OLINDDA. 
literatura para avaliação de técnicas de DN. Em cada experimento, uma das classes é considerada o conceito normal, enquanto as demais devem ser identificadas pelo algoritmo. É usual selecionar como normal a classe que corresponde a esse tipo de situação, como, por exemplo, para os conjuntos de dados da Tabela 5.1, as classes normal, benign, good, edible, notspam, etc.

- O conjunto de dados completo (união dos conjuntos de treino e de teste nos casos em que são disponibilizados separadamente) é dividido em: um conjunto contendo apenas exemplos da classe normal, usado para geração do modelo normal inicial; e um conjunto contendo exemplos de todas as classes, inclusive da classe normal, que será apresentado, exemplo a exemplo, na fase de aprendizado contínuo.

- Utilizou-se validação cruzada com 10 partições. Todos os resultados apresentados correspondem ao resultado médio obtido nas 10 partições, representando, portanto, o comportamento típico do algoritmo.

- Os exemplos foram embaralhados no momento da geração das partições para evitar seqüências de exemplos de uma mesma classe, o que poderia facilitar a descoberta dessa classe. Depois disso, as partições e a ordem dos exemplos foram mantidas em todos os experimentos, para permitir comparações entre os resultados.

- Atributos nominais foram transformados em numéricos usando-se codificação binária, garantindo a equidistância entre diferentes valores do mesmo atributo.

- Exemplos idênticos, presentes nos conjuntos $k d d c u p \_p c 10$ e $k d d c u p \_p c 10 \_c 5$, foram mantidos, uma vez que OLINDDA é capaz de lidar com esse tipo de situação, não adicionando à memória temporária exemplos que já lá existam.

\subsection{Métricas}

A cada $5 \%$ do processo de aprendizado, são coletadas uma série de métricas, descritas a seguir, o que permite a avaliação, ao longo do tempo, de diversos aspectos do desempenho do algoritmo.

\subsubsection{Taxas de erro, sensibilidade e especificidade}

O par de taxas de erro falso-positivo e falso-negativo são freqüentemente utilizadas na literatura para avaliar as técnicas de DN. A matriz de confusão com a nomenclatura adotada neste trabalho é apresentada na Tabela 5.2. O termo negativo foi atribuído aos exemplos do conceito normal, como Hoffmann (2007), e positivo aos perfis desconhecidos, dentre os quais poderão surgir novos conceitos. 


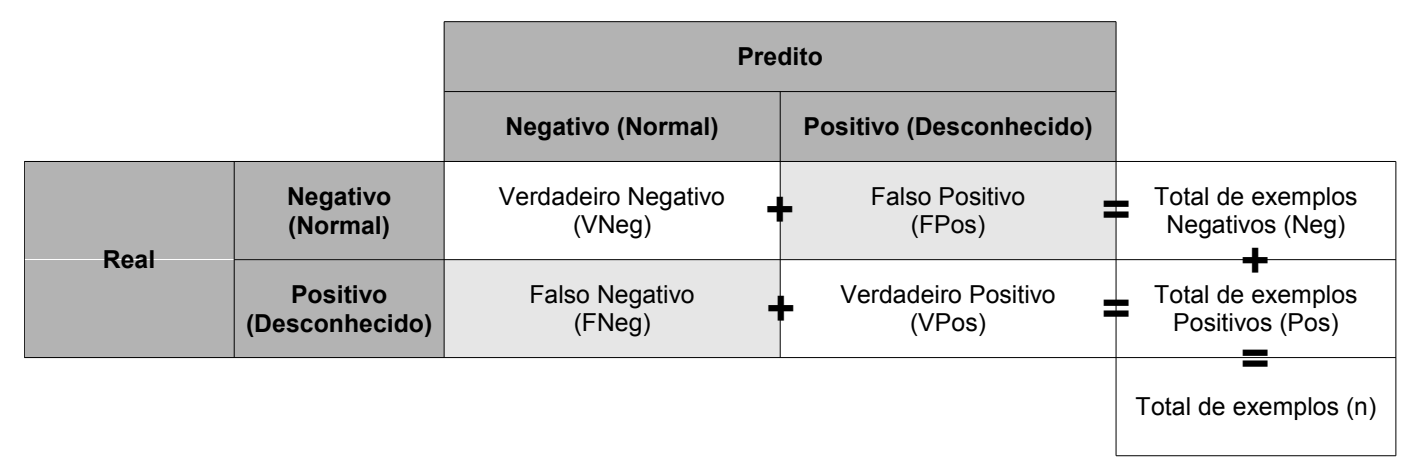

Tabela 5.2: Matriz de confusão com a nomenclatura adotada neste trabalho.

A taxa de erro falso-positivo $e_{F P o s}$ mede o erro cometido quando exemplos do conceito normal são identificados como perfis desconhecidos. Um valor elevado de $e_{F P o s}$ indica sobre-ajuste (overfitting). Analogamente, a taxa de erro falso-negativo $e_{F N e g}$ mede o erro cometido quando exemplos que não pertencem ao conceito normal são identificados como tal. O sub-ajuste (underfitting) é o comportamento extremo nesse sentido.

$$
\begin{aligned}
& e_{F P o s}=\frac{F P o s}{N e g} \\
& e_{F N e g}=\frac{F N e g}{P o s}
\end{aligned}
$$

É natural que as taxas de erro obtidas em $\mathrm{C} 1 \mathrm{C}$ sejam superiores às obtidas por classificadores binários tradicionais, dada a dificuldade adicional decorrente da ausência de exemplos de outros conceitos. Assim, não faz sentido comparar o desempenho de classificadores $\mathrm{C} 1 \mathrm{C}$ com o de classificadores tradicionais.

A precisão, a revocação e a medida F1 não serão utilizadas por serem influenciadas pela quantidade de exemplos por classe. Como em problemas de $\mathrm{C} 1 \mathrm{C}$ apenas exemplos de uma classe estão presentes no conjunto de treino, os conjuntos de teste tendem a possuir uma distribuição de classes desequilibrada, especialmente nos conjuntos de dados menores, e considerando, ainda, a divisão necessária para validação cruzada.

O compromisso entre $e_{F P o s}$ e $e_{F N e g}$ é ilustrado na Figura 5.1, que apresenta o gráfico das funções densidades de probabilidade $p$. As taxas de acerto verdadeiro-positivo e verdadeiro-negativo também podem ser referidas pelos termos sensibilidade e especificidade, respectivamente. As curvas $p\left(x \mid w_{i}\right)$ representam, para cada valor de $x$, o valor das densidades de probabilidade condicionais relativas ao estado $w$, que pode assumir os valores $w_{N e g}$ e $w_{P o s}$. O limiar $x^{*}$ varia ao longo do eixo horizontal, estabelecendo a partir de que valor de $x$ os exemplos deixam de ser considerados negativos. 


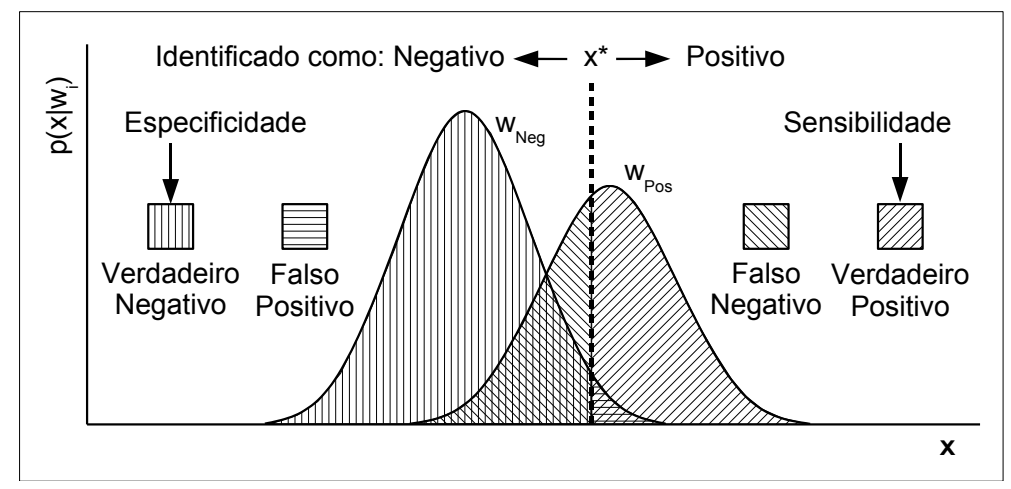

Figura 5.1: Interpretação gráfica de sensibilidade e especificidade.

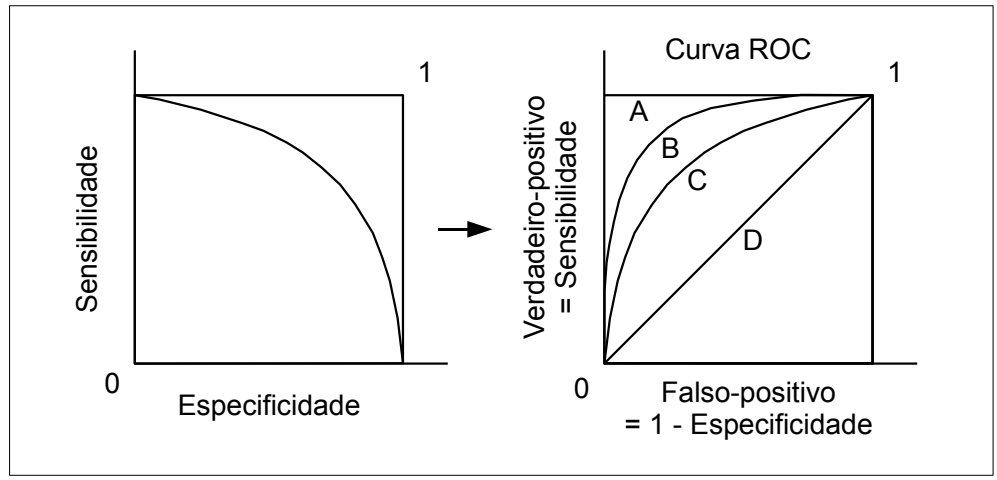

Figura 5.2: Exemplos de curvas ROC.

\subsubsection{Curva ROC}

Um retrato mais completo do desempenho de um classificador pode ser obtido pela curva denominada Receiver Operating Characteristic (ROC) (Fawcett, 2006). Na Figura 5.2, à esquerda, ilustra-se a curva da sensibilidade em função da especificidade. Rebatido, esse gráfico corresponde à curva ROC. A situação ideal é representada pela linha reta horizontal $A$. A diagonal $D$, por outro lado, indica a situação equivalente à escolha aleatória. As curvas $B$ e $C$ representam situações típicas, em que $B$ representa um melhor resultado do que $C$.

Além dessas métricas, geralmente usadas para a avaliação de classificadores, foram propostas outras, descritas a seguir, voltadas à avaliação de aspectos importantes no contexto da abordagem proposta e das aplicações pretendidas.

\subsubsection{Pureza média dos conceitos}

A abordagem proposta visa identificar conceitos puros em termos das classes reais do problema. Para avaliar esse aspecto, definimos como medida de pureza de um grupo a proporção de elementos da classe dominante nesse grupo. Por exemplo, a pureza de um grupo em que $80 \%$ dos exemplos pertencem à Classe $C 1,15 \%$ à Classe $C 2$ e $5 \%$ à Classe C3, vale $80 \%$. 
Duas medidas de pureza são armazenadas ao longo do tempo. A pureza média dos conceitos no momento da descoberta PurConcDescob é a média da pureza de todos os conceitos identificados, obtida no momento em que eles foram descobertos. Ela avalia a capacidade do algoritmo de identificar conceitos cuja composição se aproxima da de uma classe real.

A segunda medida, denominada simplesmente pureza média dos conceitos PurConc é a média da pureza de todos os conceitos já encontrados, atualizada (1) com a informação de classe dos exemplos identificados como membros de cada conceito e (2) pelo efeito da fusão de conceitos. Ela indica se os conceitos estão sendo capazes de identificar exemplos e de combinar-se a outros conceitos de composição semelhante à sua.

\subsubsection{Número de grupos válidos e número de conceitos}

O número de grupos válidos NumGrVal indica se OLINDDA está conseguindo encontrar grupos que atendam aos critérios de validação. Permite analisar também a complexidade dos modelos extensão e novidade.

O número de conceitos NumConc mostra se os grupos válidos estão sofrendo fusão com o passar do tempo. O valor de NumConc será igual a NumGrVal se não houve nenhuma fusão, e menor caso elas tenham ocorrido.

\subsubsection{Uso da memória temporária de perfis desconhecidos}

O número de exemplos na memória temporária de perfis desconhecidos NumExDes permite verificar, por exemplo, se o algoritmo está descartando exemplos antigos por falta de espaço, além de informar a quantidade de exemplos envolvida na geração periódica de grupos candidatos, um dos fatores que afeta o custo computacional.

\subsubsection{Número de grupos}

O número de grupos $k$ é usado pelo algoritmo de agrupamento e adaptado automaticamente por OLINDDA conforme descrito na Seção 4.6.5. A análise da evolução desse valor ao longo do aprendizado permite avaliar a estratégia de adaptação automática de $k$.

\subsubsection{Tempo médio de processamento}

Para avaliar a eficiência de OLINDDA, o que é especialmente importante em problemas envolvendo FCD, são medidos: o tempo médio, em milisegundos, para processar um exemplo desde o início do aprendizado MsPorEx e o tempo médio, também em milisegundos, para processar um exemplo em cada etapa correspondente a $5 \%$ do aprendizado de maneira isolada MsPorEx5pc. O valor de MsPorEx5pc mostra mais claramente 


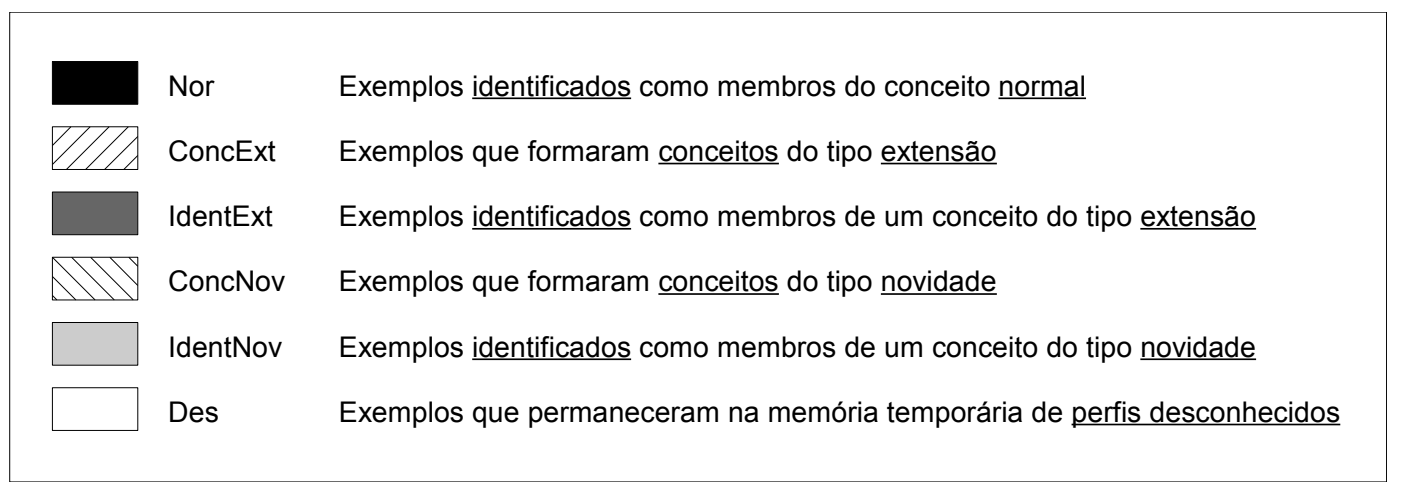

Tabela 5.3: Legenda da distribuição de classes padrão.

pequenas variações locais, enquanto MsPorEx proporciona uma visão mais global da evolução dessa medida.

\subsubsection{Distribuições de classes}

A abordagem proposta pretende descobrir conceitos que correspondam, tanto quanto possível, às classes reais do problema. Para avaliar esse aspecto, é preciso conhecer a composição dos conceitos em termos das classes, ou seja, como os exemplos de cada classe real estão distribuídos. Para permitir diferentes níveis de detalhamento, a evolução da distribuição de classes pode ser analisada em 3 níveis, denominados padrão, resumido e em cada conceito.

\section{Distribuição de classes padrão}

A distribuição de classes padrão indica como as classes reais estão distribuídas nas 6 possíveis situações: exemplos identificados como membros do conceito normal, exemplos que formaram conceitos do tipo extensão, exemplos identificados como membros de um conceito do tipo extensão, exemplos que formaram conceitos do tipo novidade, exemplos identificados como membros de um conceito do tipo novidade, e exemplos que permaneceram na memória temporária de perfis desconhecidos. A legenda apresentada na Tabela 5.3 estabelece a equivalência entre cada uma dessas situações e os respectivos padrões (usados nos gráficos) e siglas (usadas nas tabelas).

\section{Distribuição de classes resumida}

Uma análise mais simples pode ser feita a partir da distribuição resumida, que agrupa as 6 situações da distribuição de classes padrão em apenas 3: exemplos identificados como membros do conceito normal (denominada Nor), exemplos que formaram ou foram explicados por conceitos dos tipos extensão ou novidade (denominada ExtNov), e exemplos que permaneceram na memória temporária de perfis desconhecidos (denominada Des). 


\section{Distribuição de classes em conceitos}

É possível, em um experimento com uma partição dos dados específica (fold), observar a composição de cada conceito individualmente. Neste caso, cores são usadas para representar conceitos.

\subsection{Análise dos resultados}

Nesta seção são apresentados e discutidos os resultados obtidos nos experimentos que avaliam a abordagem proposta, de diversos pontos de vista. Para cada aspecto analisado são apresentados resultados em diversos conjuntos de dados e em um problema de FCD envolvendo a detecção de intrusão em redes de computadores, para o qual foram utilizados os conjuntos de dados da competição KDD Cup 1999 (Elkan, 2000). Mais detalhes sobre os conjuntos de dados podem ser vistos na Seção 5.1 .

\subsubsection{Distinção entre o conceito normal e perfis desconhecidos}

A busca por novos conceitos ocorre entre os exemplos que não foram identificados como membros de nenhum dos conceitos conhecidos. Como no início apenas o conceito normal é conhecido, se a distinção entre normal e desconhecido não for feita adequadamente, o algoritmo não terá os exemplos corretos para trabalhar na busca por novos conceitos.

Curvas ROC foram utilizadas para avaliar detalhadamente esse aspecto. As Figuras 5.3 e 5.4 representam o desempenho da estratégia padrão usada por OLINDDA na distinção entre normal e desconhecido, baseada em hiperesferas obtidas de grupos gerados pelo algoritmo de agrupamento k-médias. Como estabelecido na Seção 5.3.1, o termo positivo foi atribuído aos exemplos de perfis desconhecidos, que poderão, potencialmente, formar conceitos de novidade.

As curvas indicam um comportamento bom, especialmente considerando a dificuldade adicional imposta por um problema de C1C. Para os conjuntos ionosphere e mushroom, em que os pontos não se ajustam muito bem à curva de regressão logarítmica, vale observar que o desempenho real é aquele indicado pelos pontos, não pela curva, que foi adicionada ao gráfico apenas como uma referência adicional.

\subsubsection{Comparação com outras técnicas de C1C}

A distinção entre o conceito normal e perfis desconhecidos, que corresponde a uma tarefa de $\mathrm{C} 1 \mathrm{C}$, equivale ao que alguns trabalhos na literatura denominam DN. Como discutido na Seção 4.1, a abordagem proposta trata o problema da DN a partir da C1C. Entretanto, é possível comparar isoladamente a fase de $\mathrm{C} 1 \mathrm{C}$, em que faz-se a distinção 


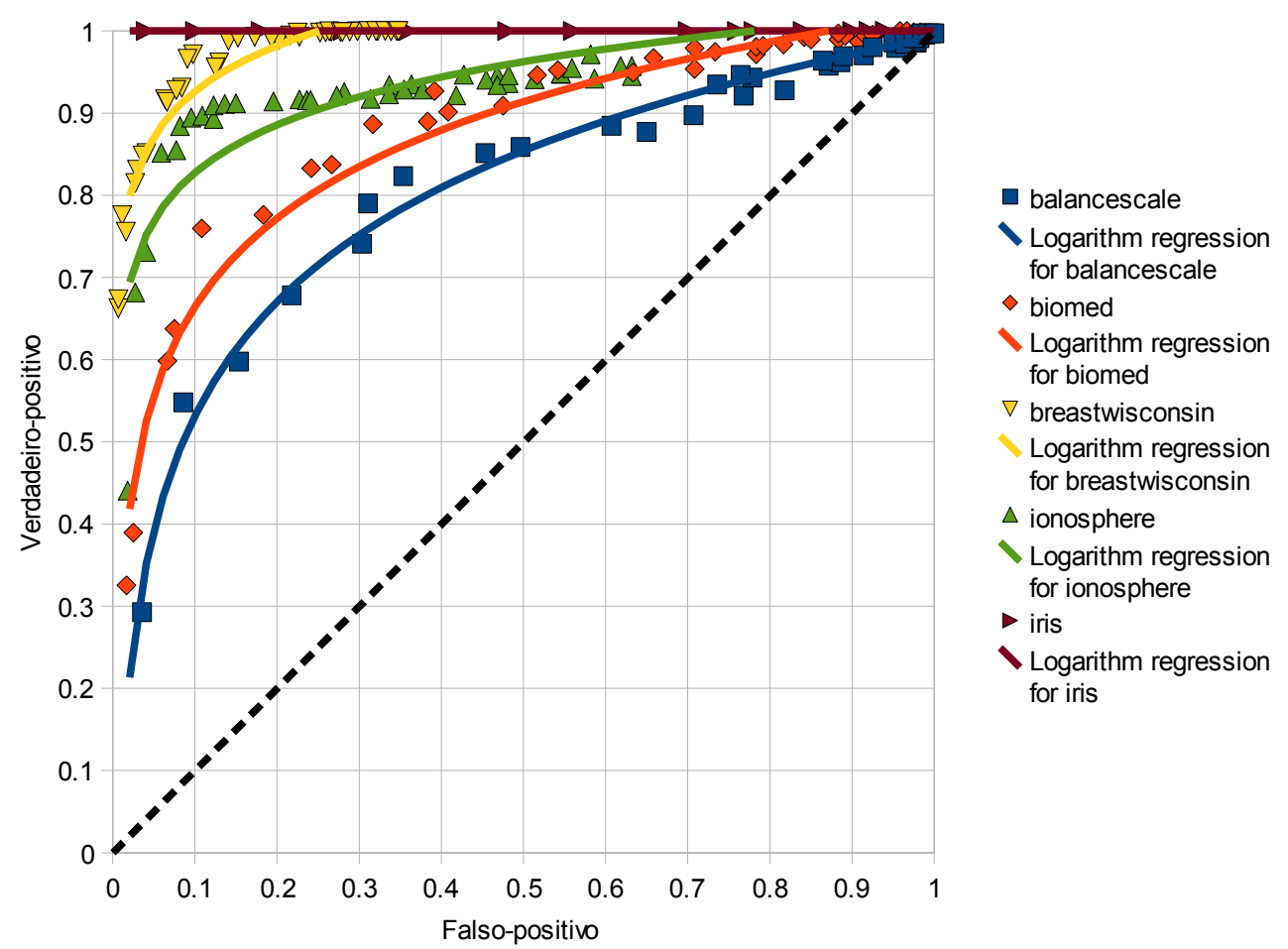

Figura 5.3: Curvas ROC para diversos conjuntos de dados.

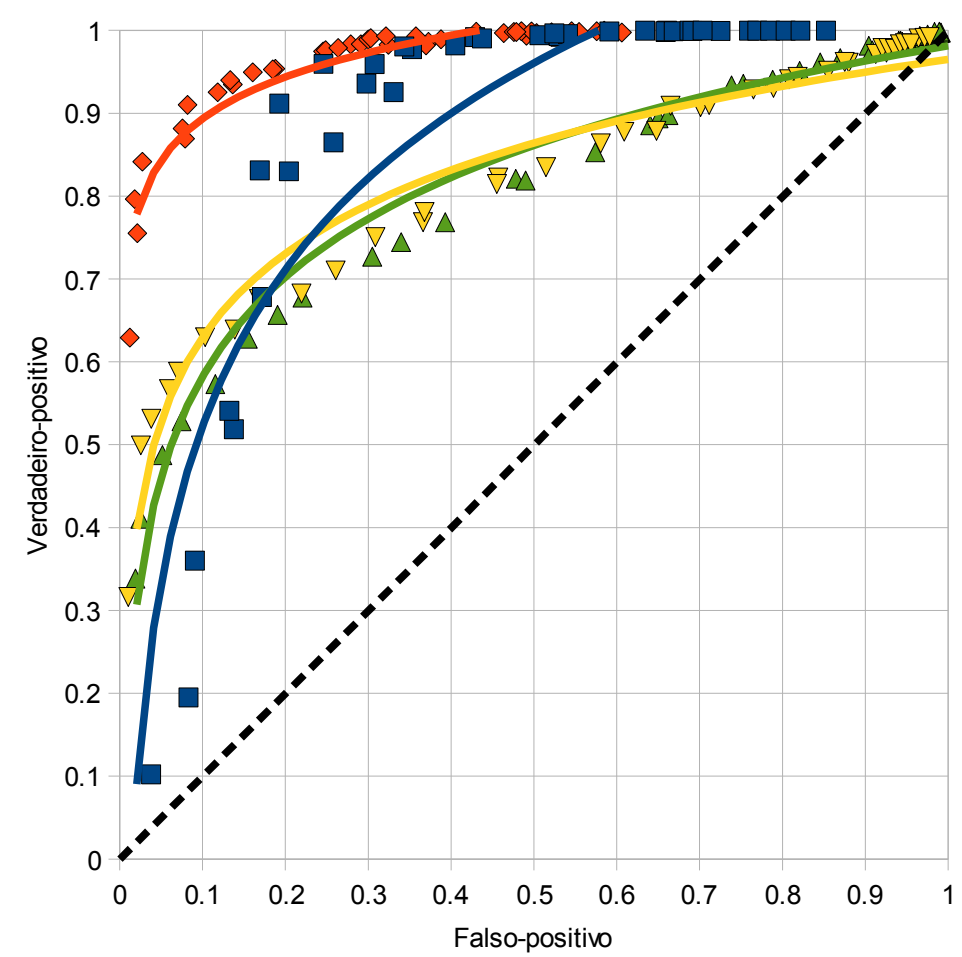

mushroom

Logarithm regression for mushroom

$\diamond$ segmentation

- Logarithm regression for segmentation

$\nabla$ waveform

Logarithm regression for waveform

$\triangle$ waveformnoise

- Logarithm regression for waveformnoise

Figura 5.4: Curvas ROC para diversos conjuntos de dados. 
entre exemplos do conceito normal e perfis desconhecidos, com outras técnicas. É importante notar que o que está sendo avaliado e comparado nesse caso não é a abordagem OLINDDA em si, mas, essencialmente, o modelo baseado em hiperesferas obtidas a partir dos grupos gerados pelo algoritmo de agrupamento utilizado; nesse caso, o algoritmo k-médias.

OLINDDA permite a integração com um pacote de diversas técnicas de DN denominado Data Description toolbox (DDtools) (Tax, 2005), possibilitando o uso de uma outra técnica na etapa referente à distinção entre o conceito normal e perfis desconhecidos. Para esses experimentos comparativos, foram selecionadas as seguintes técnicas de $\mathrm{C} 1 \mathrm{C}$ do pacote DDtools: gausdd (Gaussian target distribution), kmeansdd (k-means data description), knndd (k-nearest neighbor data description), lpdd (linear programming data description), parzendd (Parzen density estimator), pcadd (principal component analysis data description), somdd (self-organizing map data description), e svdd (support vector data description). O algoritmo k-médias original, opção padrão usada por OLINDDA, é indicado nos resultados por kmeans, diferenciando-o do kmeansdd (Tax, 2001), descrito na Seção 2.5.4.

Como algumas técnicas podem ser sensíveis à normalização dos dados, essa série de experimentos foi realizada com conjuntos de dados normalizados. Em todas as técnicas, foram usados os valores padrão (default) dos parâmetros. Para kmeansdd e kmeans, duas opções foram consideradas para o valor de $k$.

A Figura 5.5 apresenta graficamente os valores do par de taxas de erro $e_{F P o s}$ e $e_{F N e g}$ obtidos por cada técnica em cada conjunto de dados, que também podem ser consultados na Tabela 5.4 .

As técnicas lpdd e parzendd apresentaram problemas de sub-ajuste em diversas situações. A técnica pcadd, o modelo base kmeans e, em um caso, a técnica svdd apresentaram taxas de eFNeg um pouco mais altas do que as das demais técnicas.

No conjunto balancescale, as taxas de erro um pouco mais elevadas em todas as técnicas devem-se à dificuldade de diferenciar o conceito normal $L$ da classe $B$. Dificuldade semelhante, em maior grau, foi observada no conjunto spambase. Esse tipo de situação naturalmente impossibilita a descoberta dessas classes como novos conceitos, uma vez que elas foram confundidas com o conceito normal. Isso reforça a importância da etapa de $\mathrm{C} 1 \mathrm{C}$ no contexto da abordagem proposta.

Comparando o resultado da distinção feita por hiperesferas obtidas de grupos gerados pelo algoritmo k-médias padrão (kmeans), opção padrão usada por OLINDDA, com o da técnica mais semelhante (kmeansdd), percebe-se que kmeans obtém um resultado um pouco pior na maior parte das vezes, para o mesmo valor de $k$. A técnica kmeansdd mostrou-se também um pouco menos sensível à variação de $k$ do que kmeans. A principal diferença entre essas duas técnicas está no fato de que kmeansdd inclui como parâmetro um fator de rejeição que obriga que um certo percentual dos exemplos normais sejam 

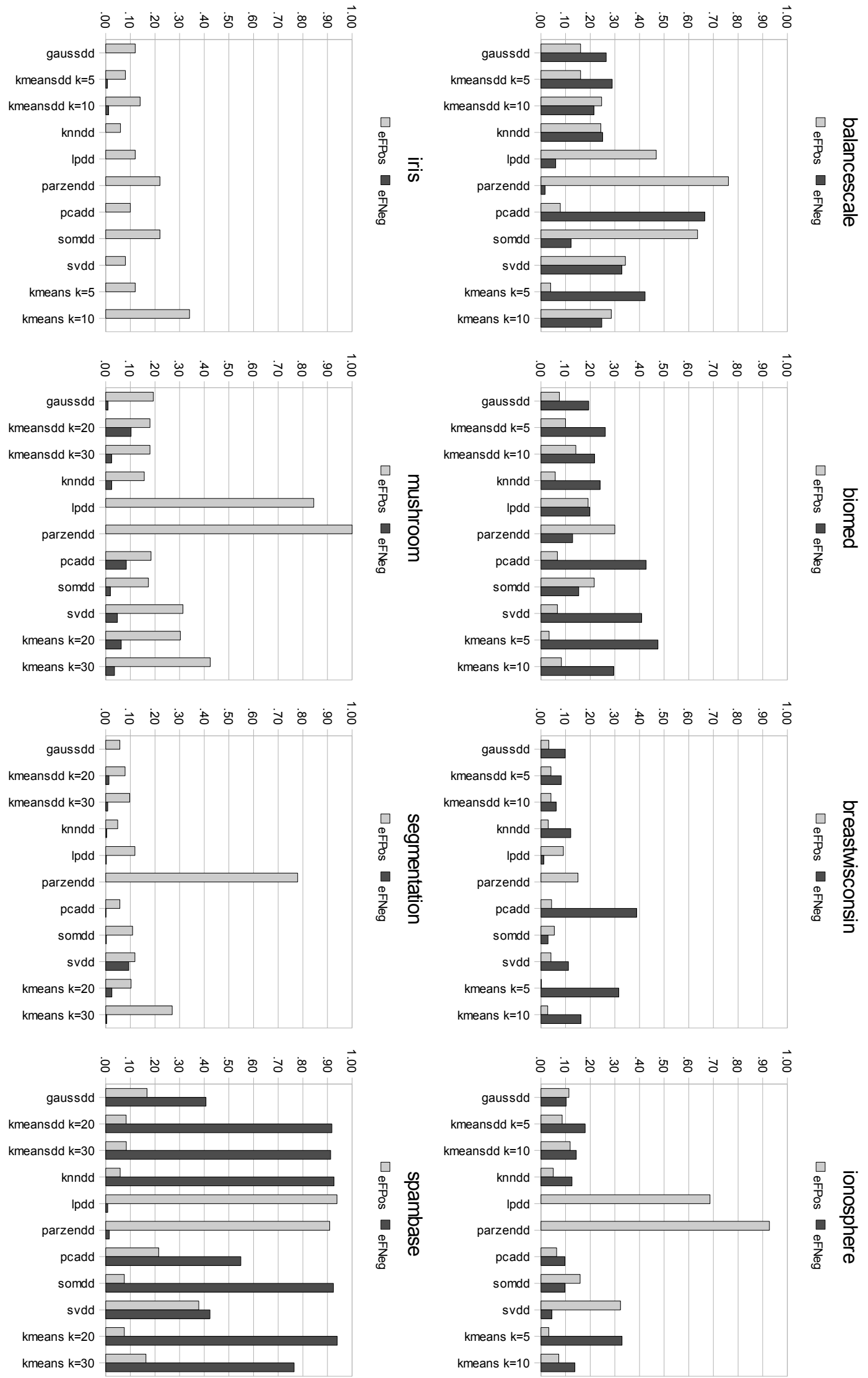

Figura 5.5: Comparação com outras técnicas de C1C. 


\begin{tabular}{|c|c|c|c|c|c|c|c|c|c|c|c|c|}
\hline $\begin{array}{l}\text { Conjunto de } \\
\text { dados }\end{array}$ & $\begin{array}{c}\text { Técnica } \\
\text { Métrica } \\
\nabla\end{array}$ & 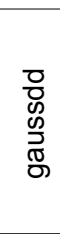 & 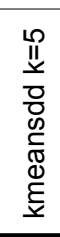 & 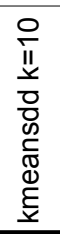 & $\begin{array}{l}\text { 음 } \\
\frac{C}{\tilde{x}} \\
\text {. }\end{array}$ & 흥 & $\begin{array}{l}\text { 음 } \\
\frac{C}{0} \\
\stackrel{D}{N} \\
\frac{1}{0} \\
0\end{array}$ & $\begin{array}{l}\text { 믐 } \\
\text { ரூ } \\
0\end{array}$ & $\begin{array}{l}\text { 뮴 } \\
\text { हั } \\
\text { On }\end{array}$ & क & 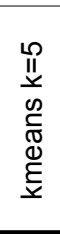 & 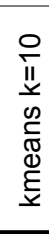 \\
\hline \multirow{2}{*}{ balancescale } & eFPos & .16 & .16 & .25 & .24 & .47 & .76 & .08 & .64 & .34 & .04 & .29 \\
\hline & eFNeg & .26 & .29 & .22 & .25 & .06 & .02 & .66 & .12 & .33 & .42 & .25 \\
\hline \multirow{2}{*}{ biomed } & eFPos & .08 & .10 & .14 & .06 & .19 & .30 & .07 & .22 & .07 & .03 & .08 \\
\hline & eFNeg & .19 & .26 & .22 & .24 & .20 & .13 & .43 & .15 & .41 & .47 & .30 \\
\hline \multirow{2}{*}{ breastwisconsin } & eFPos & .03 & .04 & .04 & .03 & .09 & .15 & .04 & .05 & .04 & .00 & .03 \\
\hline & eFNeg & .10 & .08 & .06 & .12 & .01 & .00 & .39 & .03 & .11 & .32 & .16 \\
\hline \multirow{2}{*}{ ionosphere } & eFPos & .11 & .09 & .12 & .05 & .69 & .93 & .06 & .16 & .32 & .03 & .07 \\
\hline & eFNeg & .10 & .18 & .14 & .13 & .00 & .00 & .10 & .10 & .04 & .33 & .14 \\
\hline \multirow{2}{*}{ iris } & eFPos & .12 & .08 & .14 & .06 & .12 & .22 & .10 & .22 & .08 & .12 & .34 \\
\hline & eFNeg & .00 & .01 & .01 & .00 & .00 & .00 & .00 & .00 & .00 & .00 & .00 \\
\hline $\begin{array}{l}\text { Conjunto de } \\
\text { dados }\end{array}$ & $\begin{array}{c}\text { Técnica } \\
\text { Métrica } \\
\nabla\end{array}$ & 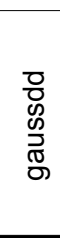 & 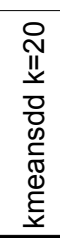 & 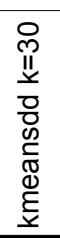 & $\begin{array}{l}\text { 음 } \\
\frac{C}{\frac{1}{L}}\end{array}$ & 흥 & $\begin{array}{l}\frac{0}{0} \\
\frac{\bar{d}}{\Phi} \\
\frac{N}{\pi} \\
\stackrel{0}{\alpha}\end{array}$ & $\begin{array}{l}\text { 믐 } \\
\text { ర্ } \\
0\end{array}$ & $\begin{array}{l}\frac{0}{0} \\
\frac{0}{0} \\
\text { O) }\end{array}$ & $\frac{7}{0}$ & 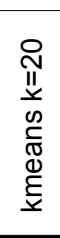 & 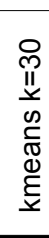 \\
\hline \multirow{2}{*}{ mushroom } & eFPos & .19 & .18 & .18 & .16 & .84 & 1.00 & .18 & .17 & .31 & .30 & .42 \\
\hline & eFNeg & .01 & .10 & .02 & .02 & .00 & .00 & .08 & .02 & .05 & .06 & .04 \\
\hline \multirow{2}{*}{ segmentation } & eFPos & .06 & .08 & .10 & .05 & .12 & .78 & .06 & .11 & .12 & .10 & .27 \\
\hline & eFNeg & .00 & .01 & .01 & .00 & .00 & .00 & .00 & .00 & .09 & .03 & .00 \\
\hline \multirow{2}{*}{ spambase } & eFPos & .17 & .08 & .08 & .06 & .94 & .91 & .22 & .08 & .38 & .08 & .16 \\
\hline & eFNeg & .41 & .92 & .91 & .93 & .01 & .01 & .55 & .92 & .42 & .94 & .76 \\
\hline
\end{tabular}

Tabela 5.4: Comparação com outras técnicas de C1C. 
mantidos fora das fronteiras de decisão do conceito normal. O valor padrão (default) desse parâmetro, utilizado nesses experimentos, é 5\%. Essa estratégia produz uma descrição mais específica, o que pode ser uma vantagem em certas situações, pois evita que exemplos de perfis desconhecidos, que estejam em regiões periféricas nas quais pode haver confusão com o conceito normal, sejam erradamente considerados como tal. Por outro lado, introduz mais um parâmetro.

Nos demais experimentos apresentados a partir deste ponto, utilizou-se a opção padrão de OLINDDA: modelo baseado em hiperesferas obtidas a partir de grupos gerados pelo algoritmo k-médias padrão. Na Seção 5.4 .8 avalia-se a influência do algoritmo de agrupamento.

\subsubsection{Descoberta de novos conceitos}

A distribuição de classes padrão será usada para avaliar a descoberta de novos conceitos. Um exemplo da evolução dessa métrica ao longo do processo de aprendizado para o conjunto iris, tendo a classe Iris-versicolor como normal, é mostrado na Figura 5.6. A legenda para essa figura pode ser vista na Tabela 5.3 .

Percebe-se que OLINDDA foi capaz de, ao longo do tempo, identificar corretamente exemplos do conceito normal (preto) e formar grupos válidos (conceitos) do tipo novidade com grande parte dos exemplos das classes Iris-setosa e Iris-virginica $(\backslash \backslash \backslash)$. O fato de que tais conceitos tenham servido para explicar boa parte dos exemplos (cinza claro) confirma que eles representam um conceito que realmente existia nos dados, mas que até então não era conhecido. É interessante perceber, ainda, que alguns elementos da classe Irisvirginica tenham formado conceitos do tipo extensão $(/ / /)$ e sido identificados como tal (cinza escuro). Isso acontece pela proximidade dessa classe ao conceito normal. A pequena interseção existente entre essas duas classes é também responsável pela identificação de alguns poucos exemplos da classe Iris-virginica como normais (preto).

Para incluir resultados de uma quantidade maior de experimentos, foram agrupados na Tabela 5.5 a distribuição de classes padrão obtida no final do aprendizado para diversos conjuntos de dados. Nesses experimentos, o parâmetro minexcl foi mantido em 3 e $k_{i n i}$ assumiu os valores $5,10,15$ e 20 . Nessa tabela, tons de cinza mais escuros indicam maior concentração de exemplos.

O primeiro ponto a observar a respeito do impacto de $k_{i n i}$ é que seu aumento reduz o número de exemplos identificados como normal, o que é uma conseqüência natural à medida que um maior $k_{\text {ini }}$ produz um modelo mais ajustado aos dados iniciais.

Com relação à descoberta de novos conceitos, para os conjuntos balancescale, breastwisconsin e iris, boa parte dos exemplos de novos conceitos são descobertos como novidade. Em balancescale, a classe $B$ não é identificada porque é confundida com o conceito normal L. Como mencionado anteriormente, esse problema ocorreu em todas as técnicas de C1C 

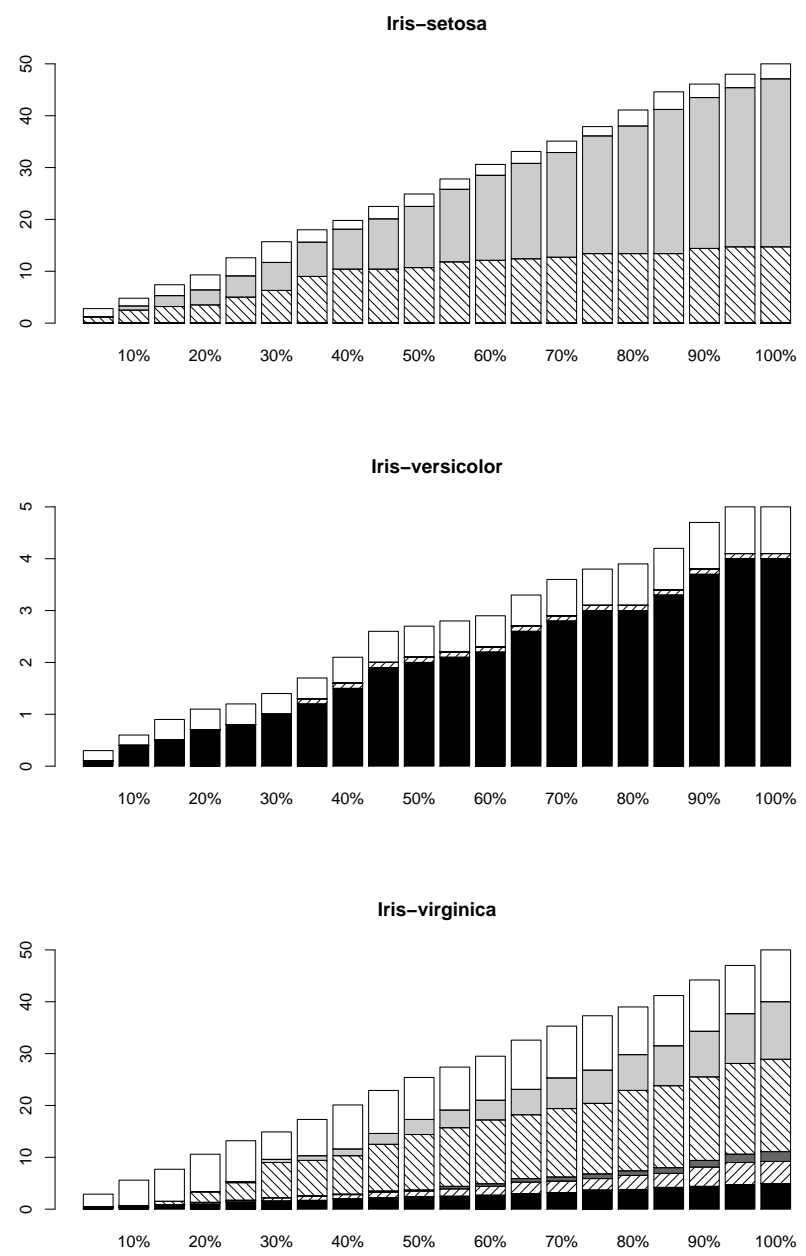

Figura 5.6: Distribuição de classes padrão para o conjunto de dados iris. 


\begin{tabular}{|c|c|c|c|c|c|c|c|c|}
\hline \multirow[b]{2}{*}{$\begin{array}{l}\text { Conjunto de } \\
\text { dados }\end{array}$} & \multirow[b]{2}{*}{ kini } & \multirow[b]{2}{*}{$\begin{array}{c}\text { Classe } \\
\text { (Normal em } \\
\text { negrito) }\end{array}$} & \multicolumn{6}{|c|}{ Distribuição de classes } \\
\hline & & & ̀̀ & $\begin{array}{l}\vec{x} \\
\text { ü } \\
\text { ठ }\end{array}$ & 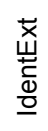 & $\begin{array}{l}\text { o } \\
\text { o } \\
\text { Oे } \\
0\end{array}$ & $\begin{array}{l}\text { Do } \\
\text { 立 } \\
\text { 에 } \\
\text { 으 }\end{array}$ & \& \\
\hline \multirow{12}{*}{ balancescale } & \multirow{3}{*}{5} & $\mathbf{L}$ & .94 & .00 & .00 & .03 & .03 & .00 \\
\hline & & $\mathrm{R}$ & .36 & .00 & .00 & .15 & .48 & .01 \\
\hline & & $B$ & .81 & .00 & .00 & .08 & .07 & .04 \\
\hline & \multirow{3}{*}{10} & $\mathbf{L}$ & .75 & .03 & .01 & .10 & .07 & .04 \\
\hline & & $\mathrm{R}$ & .18 & .00 & .02 & .23 & .55 & .02 \\
\hline & & B & .66 & .00 & .00 & .13 & .16 & .05 \\
\hline & \multirow{3}{*}{15} & $\mathbf{L}$ & .60 & .10 & .04 & .11 & .10 & .05 \\
\hline & & $\mathrm{R}$ & .12 & .04 & .11 & .27 & .44 & .03 \\
\hline & & B & .50 & .08 & .06 & .16 & .14 & .06 \\
\hline & \multirow{3}{*}{20} & $\mathbf{L}$ & .48 & .13 & .10 & .13 & .10 & .06 \\
\hline & & $R$ & .07 & .06 & .13 & .28 & .44 & .03 \\
\hline & & B & .43 & .09 & .07 & .20 & .14 & .07 \\
\hline \multirow{8}{*}{ biomed } & \multirow{2}{*}{5} & normal & .96 & .01 & .01 & .00 & .00 & .03 \\
\hline & & carrier & .55 & .04 & .01 & .07 & .00 & .32 \\
\hline & \multirow{2}{*}{10} & normal & .85 & .04 & .01 & .00 & .00 & .10 \\
\hline & & carrier & .27 & .24 & .07 & .03 & .00 & .40 \\
\hline & \multirow{2}{*}{15} & normal & .75 & .14 & .02 & .00 & .00 & .09 \\
\hline & & carrier & .14 & .34 & .10 & .02 & .00 & .40 \\
\hline & 20 & normal & .67 & .21 & .05 & .00 & .00 & .08 \\
\hline & 20 & carrier & .11 & .35 & .10 & .01 & .00 & .43 \\
\hline \multirow{8}{*}{ breastwisconsin } & \multirow{2}{*}{5} & benign & .99 & .00 & .00 & .00 & .00 & .01 \\
\hline & & malignant & .25 & .00 & .00 & .33 & .35 & .06 \\
\hline & \multirow{2}{*}{10} & benign & .98 & .00 & .00 & .00 & .00 & .01 \\
\hline & & malignant & .18 & .03 & .01 & .39 & .33 & .07 \\
\hline & \multirow{2}{*}{15} & benign & .96 & .02 & .00 & .00 & .00 & .01 \\
\hline & & malignant & .13 & .04 & .01 & .43 & .30 & .08 \\
\hline & 20 & benign & .94 & .03 & .01 & .01 & .00 & .02 \\
\hline & 20 & malignant & .10 & .06 & .04 & .43 & .25 & .13 \\
\hline \multirow{8}{*}{ ionosphere } & \multirow{2}{*}{5} & g & .97 & .00 & .00 & .00 & .00 & .03 \\
\hline & & $\mathrm{b}$ & .38 & .00 & .00 & .00 & .00 & .62 \\
\hline & \multirow{2}{*}{10} & g & .92 & .00 & .00 & .00 & .00 & .08 \\
\hline & & $b$ & .14 & .01 & .00 & .00 & .00 & .85 \\
\hline & 15 & g & .90 & .00 & .00 & .00 & .00 & .10 \\
\hline & & $b$ & .10 & .00 & .00 & .00 & .00 & .89 \\
\hline & 20 & g & .85 & .01 & .00 & .01 & .00 & .12 \\
\hline & & $b$ & .09 & .01 & .00 & .00 & .00 & .90 \\
\hline & & Iris-setosa & .78 & .00 & .00 & .00 & .00 & .22 \\
\hline & 5 & Iris-versicolor & .00 & .00 & .00 & .51 & .30 & .18 \\
\hline & & Iris-virginica & .00 & .00 & .00 & .51 & .22 & .27 \\
\hline & & Iris-setosa & .54 & .00 & .00 & .00 & .00 & .46 \\
\hline & 10 & Iris-versicolor & .00 & .00 & .00 & .55 & .20 & .25 \\
\hline iris & & Iris-virginica & .00 & .00 & .00 & .54 & .14 & .33 \\
\hline 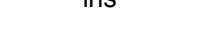 & & Iris-setosa & .44 & .00 & .00 & .00 & .00 & .56 \\
\hline & 15 & Iris-versicolor & .00 & .00 & .00 & .60 & .11 & .30 \\
\hline & & Iris-virginica & .00 & .00 & .00 & .45 & .06 & .49 \\
\hline & & Iris-setosa & .14 & .12 & .00 & .00 & .00 & .74 \\
\hline & 20 & Iris-versicolor & .00 & .00 & .00 & .49 & .06 & .46 \\
\hline & & Iris-virginica & .00 & .00 & .00 & .35 & .02 & .63 \\
\hline
\end{tabular}

Tabela 5.5: Distribuição de classes padrão para diversos conjuntos de dados. 
testadas.

Para biomed, uma parte pequena é descoberta como extensão, indicando que esses dois conceitos estão muito próximos. Para o conjunto ionosphere, não foi possível descobrir a classe $b$. Esse tipo de situação indesejável pode ser conseqüência da impossibilidade de capturar com hiperesferas a distribuição dessa classe, o que motiva o estudo por modelos mais flexíveis.

Tendo em vista os objetivos deste trabalho, o mais importante não é a quantidade de exemplos que formou ou foi identificada por novos conceitos, mas o fato de que esses conceitos tenham sido descobertos. Em alguns casos, bastam poucos exemplos para gerar grupos válidos que identifiquem o aparecimento de um novo conceito. As restrições impostas na validação de grupos podem reduzir a quantidade de exemplos que forme ou seja identificada por novos conceitos, mas se isso não interferir no fato de que esses novos conceitos sejam descobertos, o objetivo continua sendo atingido. As restrições impostas pelo critério de validação são importantes para evitar a detecção de conceitos pouco representativos e outliers, aspecto que será analisado na Seção 5.4.4. O número de grupos válidos e de conceitos descobertos será analisado na Seção 5.4.6.

$\mathrm{Na}$ Seção 4.7, mencionou-se a possível influência de $k_{i n i}$ sobre a descoberta de novos conceitos, à medida que o limiar do critério de coesão mínima é definido com base no modelo normal, que tem o número de grupos definido por $k_{i n i}$. O fluxograma de OLINDDA pode ser visto na Figura 4.1. Os resultados apresentados na Tabela 5.5 mostram que isso se verifica somente para valores extremamente altos de $k_{i n i}$. No conjunto iris, por exemplo, apenas para valores de $k_{i n i}$ acima de 15 verifica-se queda no número de exemplos que formam conceitos de novidade e aumento equivalente na quantidade de exemplos que permaneceu na memória temporária de perfis desconhecidos, indicando que o critério de coesão tornou-se rígido demais.

O fator mais importante capaz de influenciar negativamente a descoberta de novos conceitos parece ser, por outro lado, valores muito baixos de $k_{i n i}$, que fazem com que exemplos das classes a serem descobertas sejam erroneamente identificados como membros do conceito normal (sub-ajuste). Uma vez que isso aconteça, esses exemplos serão descartados e, portanto, não estarão disponíveis para formarem novos grupos.

Para avaliar a descoberta de novos conceitos em FCD, considerou-se o problema da detecção de intrusão em redes de computadores com dados da competição KDD Cup 1999 (Elkan, 2000). As Tabelas 5.6 e 5.7 apresentam a distribuição de classes resumida final para os conjuntos $k d d c u p \_p c 10 \_c 5$ e $k d d c u p \_p c 10$ respectivamente.

Os primeiros resultados obtidos neste trabalho para esses conjuntos de dados deram origem a um artigo aceito para publicação (Spinosa et al., 2008). Agora apresenta-se novos resultados com validação cruzada com 10 partições, e inclui-se uma análise mais completa e detalhada.

A Tabela 5.6 mostra que, para valores de $k_{i n i}$ em torno de 30, que permitem descrever 


\begin{tabular}{|c|c|c|c|c|c|c|c|c|c|c|}
\hline \multirow{4}{*}{$\begin{array}{l}\text { Número de } \\
\text { exemplos } \\
\text { por classe }\end{array}$} & kini $>$ & \multicolumn{3}{|c|}{20} & \multicolumn{3}{|c|}{30} & \multicolumn{3}{|c|}{40} \\
\hline & eFPos $>$ & \multicolumn{3}{|c|}{0.12} & \multicolumn{3}{|c|}{0.21} & \multicolumn{3}{|c|}{0.29} \\
\hline & eFNeg $>$ & \multicolumn{3}{|c|}{0.44} & \multicolumn{3}{|c|}{0.12} & \multicolumn{3}{|c|}{0.09} \\
\hline & Classe & Nor & ExtNov & Des & Nor & ExtNov & Des & Nor & ExtNov & Des \\
\hline 9727 & normal & 0.88 & 0.10 & 0.02 & 0.79 & 0.19 & 0.02 & 0.71 & 0.26 & 0.03 \\
\hline 391458 & dos & 0.44 & 0.56 & 0.00 & 0.12 & 0.88 & 0.00 & 0.08 & 0.92 & 0.00 \\
\hline 4107 & probe & 0.73 & 0.26 & 0.01 & 0.59 & 0.40 & 0.01 & 0.52 & 0.47 & 0.01 \\
\hline 1126 & r2l & 0.56 & 0.41 & 0.03 & 0.24 & 0.74 & 0.03 & 0.21 & 0.75 & 0.04 \\
\hline 52 & $u 2 r$ & 0.47 & 0.43 & 0.10 & 0.27 & 0.65 & 0.08 & 0.21 & 0.69 & 0.10 \\
\hline
\end{tabular}

Tabela 5.6: Taxas de erro e distribuição de classes resumida para $k d d c u p \_p c 10 \_c 5$.

\begin{tabular}{|c|c|c|c|c|c|c|c|c|c|c|}
\hline \multirow{4}{*}{$\begin{array}{l}\text { Número de } \\
\text { exemplos } \\
\text { por classe }\end{array}$} & kini $>$ & \multicolumn{3}{|c|}{20} & \multicolumn{3}{|c|}{30} & \multicolumn{3}{|c|}{40} \\
\hline & eFPos $>$ & \multicolumn{3}{|c|}{0.13} & \multicolumn{3}{|c|}{0.20} & \multicolumn{3}{|c|}{0.30} \\
\hline & eFNeg $>$ & \multicolumn{3}{|c|}{0.44} & \multicolumn{3}{|c|}{0.17} & \multicolumn{3}{|c|}{0.12} \\
\hline & Classe & Nor & ExtNov & Des & Nor & ExtNov & Des & Nor & ExtNov & Des \\
\hline 97277 & normal & 0.87 & 0.10 & 0.02 & 0.80 & 0.18 & 0.02 & 0.70 & 0.27 & 0.03 \\
\hline 2203 & back & 0.00 & 0.97 & 0.03 & 0.00 & 0.95 & 0.05 & 0.00 & 0.97 & 0.03 \\
\hline 30 & buffer_overflow & 0.29 & 0.64 & 0.07 & 0.20 & 0.69 & 0.10 & 0.12 & 0.70 & 0.19 \\
\hline 8 & ftp_write & 0.70 & 0.23 & 0.08 & 0.44 & 0.50 & 0.06 & 0.31 & 0.58 & 0.11 \\
\hline 53 & guess_passwd & 1.00 & 0.00 & 0.00 & 0.55 & 0.45 & 0.00 & 0.37 & 0.63 & 0.00 \\
\hline 12 & imap & 0.83 & 0.08 & 0.10 & 0.48 & 0.43 & 0.08 & 0.38 & 0.51 & 0.11 \\
\hline 1247 & ipsweep & 1.00 & 0.00 & 0.00 & 0.99 & 0.01 & 0.00 & 0.83 & 0.17 & 0.00 \\
\hline 21 & land & 1.00 & 0.00 & 0.00 & 0.99 & 0.01 & 0.00 & 0.88 & 0.12 & 0.00 \\
\hline 9 & loadmodule & 0.64 & 0.33 & 0.02 & 0.28 & 0.69 & 0.03 & 0.18 & 0.72 & 0.10 \\
\hline 7 & multihop & 0.53 & 0.17 & 0.30 & 0.26 & 0.43 & 0.31 & 0.20 & 0.46 & 0.34 \\
\hline 107201 & neptune & 0.82 & 0.18 & 0.00 & 0.58 & 0.42 & 0.00 & 0.41 & 0.59 & 0.00 \\
\hline 231 & nmap & 1.00 & 0.00 & 0.00 & 0.91 & 0.08 & 0.01 & 0.75 & 0.25 & 0.00 \\
\hline 3 & perl & 0.87 & 0.13 & 0.00 & 0.60 & 0.40 & 0.00 & 0.17 & 0.77 & 0.07 \\
\hline 4 & phf & 0.90 & 0.10 & 0.00 & 0.80 & 0.20 & 0.00 & 0.80 & 0.20 & 0.00 \\
\hline 264 & pod & 0.46 & 0.54 & 0.00 & 0.21 & 0.76 & 0.02 & 0.27 & 0.72 & 0.01 \\
\hline 1040 & portsweep & 0.91 & 0.05 & 0.04 & 0.72 & 0.22 & 0.06 & 0.63 & 0.33 & 0.04 \\
\hline 10 & rootkit & 0.93 & 0.04 & 0.03 & 0.77 & 0.21 & 0.02 & 0.62 & 0.31 & 0.07 \\
\hline 1589 & satan & 0.33 & 0.67 & 0.00 & 0.21 & 0.79 & 0.00 & 0.11 & 0.86 & 0.03 \\
\hline 280790 & smurf & 0.28 & 0.72 & 0.00 & 0.00 & 1.00 & 0.00 & 0.00 & 1.00 & 0.00 \\
\hline 2 & spy & 0.20 & 0.80 & 0.00 & 0.00 & 0.90 & 0.10 & 0.00 & 0.85 & 0.15 \\
\hline 979 & teardrop & 0.99 & 0.01 & 0.00 & 0.87 & 0.13 & 0.00 & 0.74 & 0.26 & 0.00 \\
\hline 1020 & warezclient & 0.59 & 0.39 & 0.02 & 0.33 & 0.64 & 0.03 & 0.21 & 0.76 & 0.04 \\
\hline 20 & warezmaster & 0.11 & 0.55 & 0.35 & 0.06 & 0.66 & 0.29 & 0.06 & 0.70 & 0.25 \\
\hline
\end{tabular}

Tabela 5.7: Taxas de erro e distribuição de classes resumida para kddcup_pc10. 


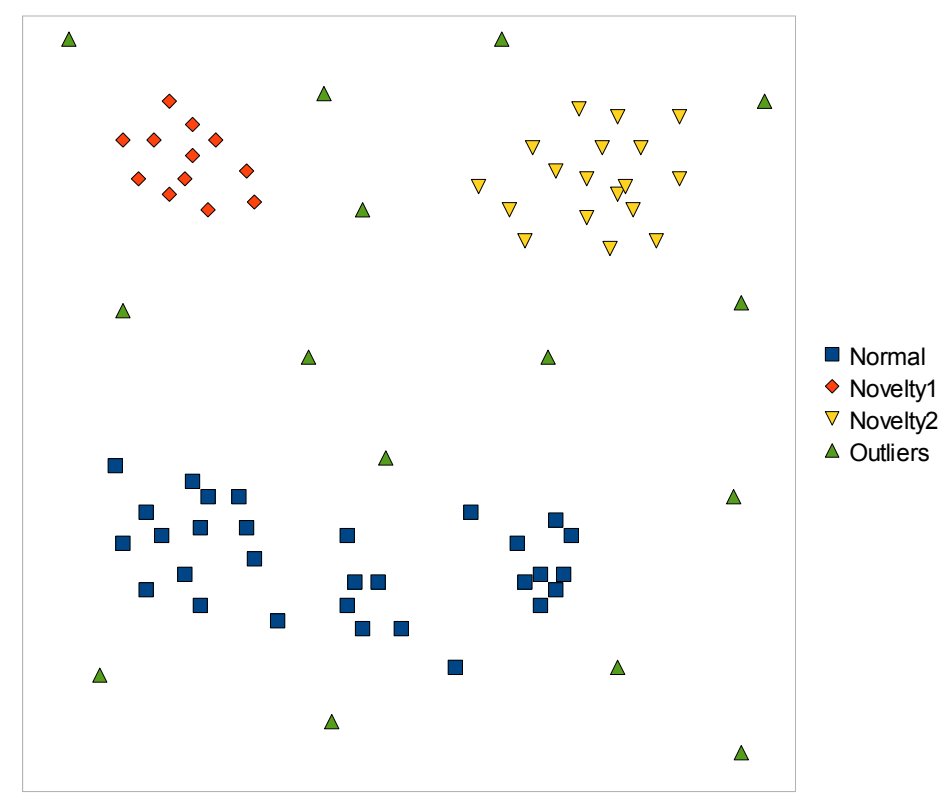

Figura 5.7: Conjunto de dados outliers1.

adequadamente o conceito normal, boa parte dos exemplos das 4 classes de ataques forma novos conceitos ou é explicada por eles.

Nos experimentos com o conjunto de dados em que os 4 principais tipos de ataque são divididos em 22 (Tabela 5.7), percebe-se que alguns ataques pouco representativos são confundidos com o conceito normal. Nesse caso, é necessário considerar o grande desequilíbrio na quantidade de exemplos de cada classe (primeira coluna): algumas com centenas de milhares de exemplos e outras com menos de 10.

\subsubsection{Robustez à presença de outliers}

\section{Outliers entre os conceitos a descobrir}

O conjunto de dados outliers1 foi artificialmente gerado para simular uma expressiva presença de outliers distribuídos entre três conceitos. A distribuição dos exemplos de outliers1 é mostrada na Figura 5.7.

Considerando a classe Normal como o conceito normal, obtém-se a distribuição de classes padrão mostrada na Figura 5.8. Observa-se claramente que os exemplos da classe Normal são corretamente identificados, os das classes Novelty1 e Novelty2 formam novos conceitos, e os da classe Outliers são praticamente todos ignorados. De maneira equivalente, quando uma das outras classes (Novelty1 e Novelty2) é considerada como o conceito normal, OLINDDA é capaz de descobrir as outras duas, sempre ignorando a grande maioria dos exemplos da classe Outliers.

Uma das descrições produzidas por OLINDDA é apresentada na Figura 5.9. No quadro à esquerda, na parte inferior, estão representados os três grupos que definem o conceito 

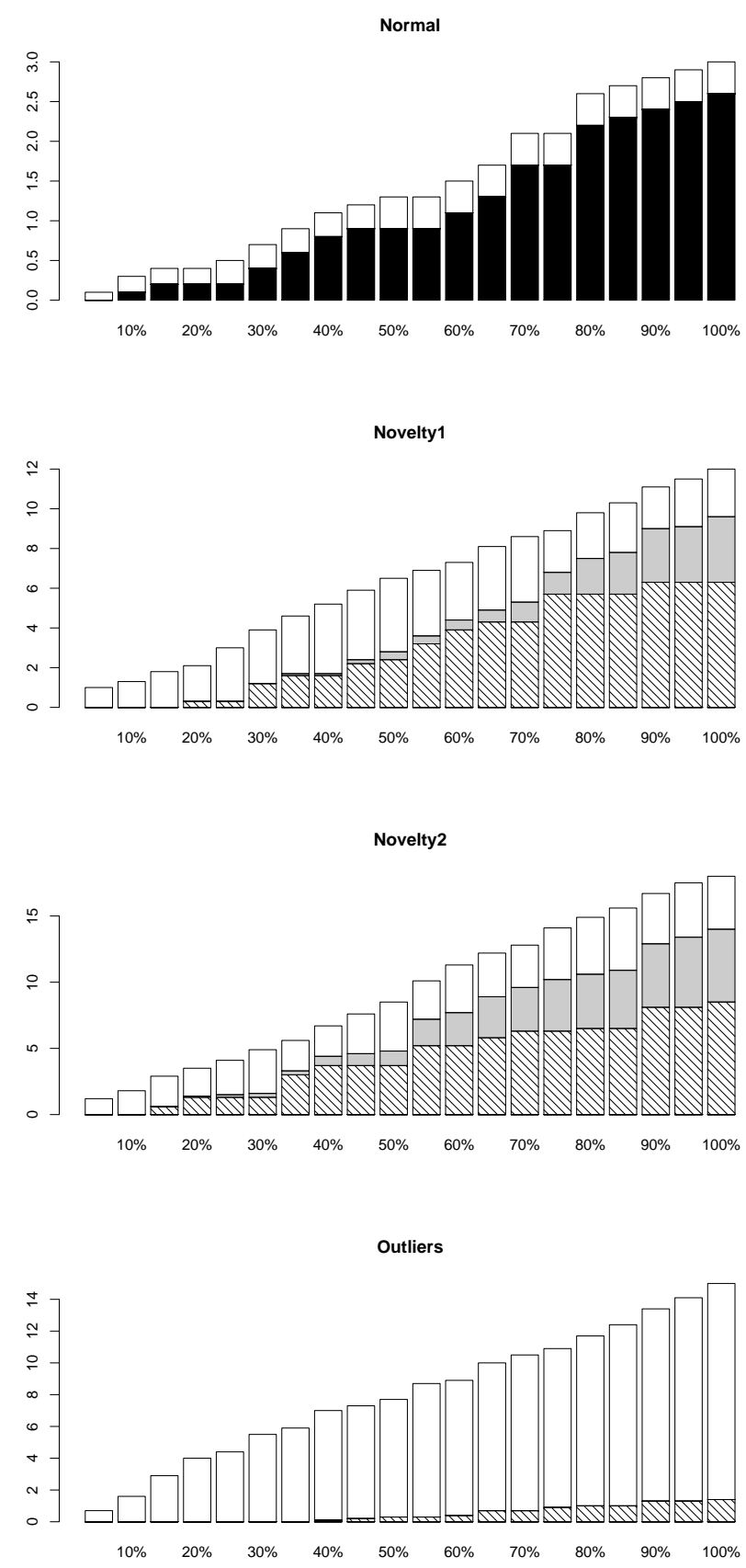

Figura 5.8: Distribuição de classes padrão para o conjunto de dados outliers1. 

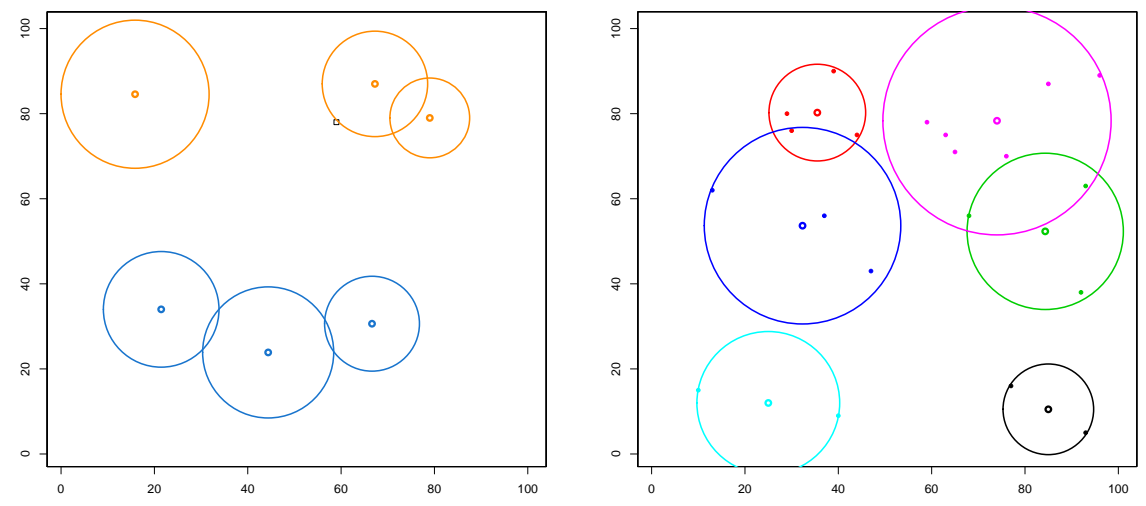

Figura 5.9: Exemplo de descrição produzida por OLINDDA para o conjunto outliers1.

normal, e na parte superior, os 3 grupos que representam os 2 novos conceitos descobertos. No quadro à direita aparecem grupos candidatos gerados nessa iteração, mas não aceitos.

A robustez a outliers é uma importante característica em sistemas de AM voltados para aplicações reais. O critério de validação proposto em OLINDDA é o elemento que proporciona essa robustez. Os outliers permanecem na memória temporária de perfis desconhecidos, mas, pela sua natureza esparsa, não são capazes de formar grupos que atendam às restrições de coesão e representatividade.

\section{Outliers no conceito normal}

O conjunto de dados outliers2, representado na Figura 5.10, foi criado para simular a presença de uma quantidade relativamente pequena de outliers entre os exemplos do conceito normal (classe Normal).

A distribuição de classes padrão, apresentada na Figura 5.11, mostra que a maior parte dos exemplos da classe Novelty1 foi corretamente detectada como novidade, mas que a classe Novelty2 foi confundida com o conceito normal.

A razão fica clara quando se observa, na Figura 5.12, um exemplo de descrição produzida por OLINDDA. Os 2 exemplos isolados da classe Normal localizados em torno da classe Novelty2 fizeram com que a região ocupada por Novelty2 fosse incluída na definição do conceito normal, delimitada, neste exemplo, pelas três circunferências de maior raio. As duas circunferências menores correspondem ao conceito Novelty1, corretamente identificado.

Poder-se-ia dizer, portanto, que da maneira como está proposta, OLINDDA não é robusta à presença de outliers no conceito normal. Entretanto, esta, além de ser um característica comum a diversas técnicas de AM, representa um aspecto menos importante do que a robustez a outliers na fase de aprendizado não-supervisionado, demonstrada anteriormente, principalmente porque é possível inspecionar e pré-processar facilmente os 


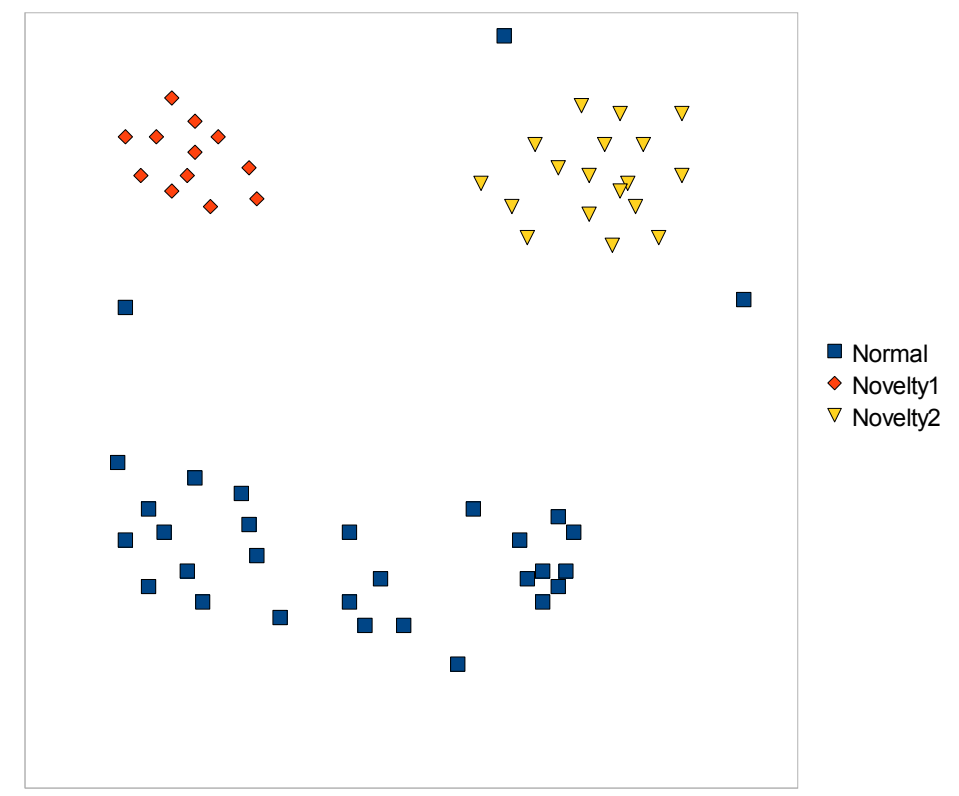

Figura 5.10: Conjunto de dados outliers2.
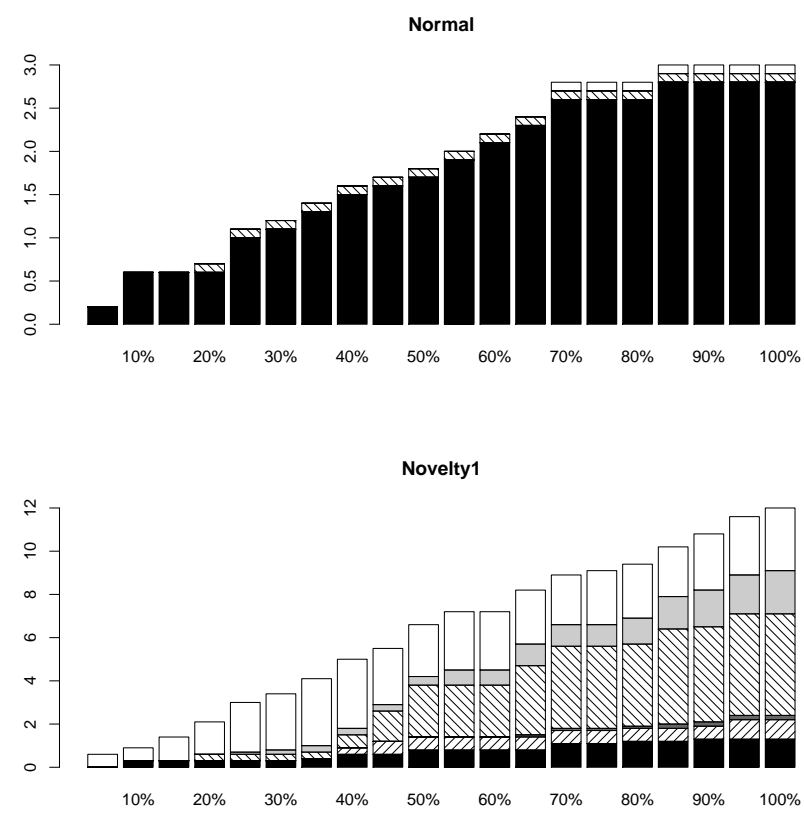

Novelty2

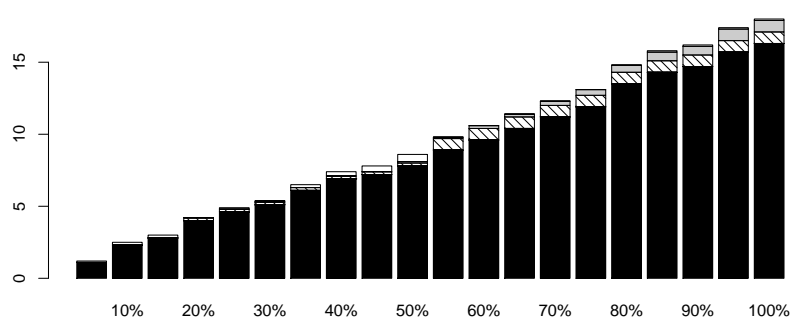

Figura 5.11: Distribuição de classes padrão para o conjunto de dados outliers2. 

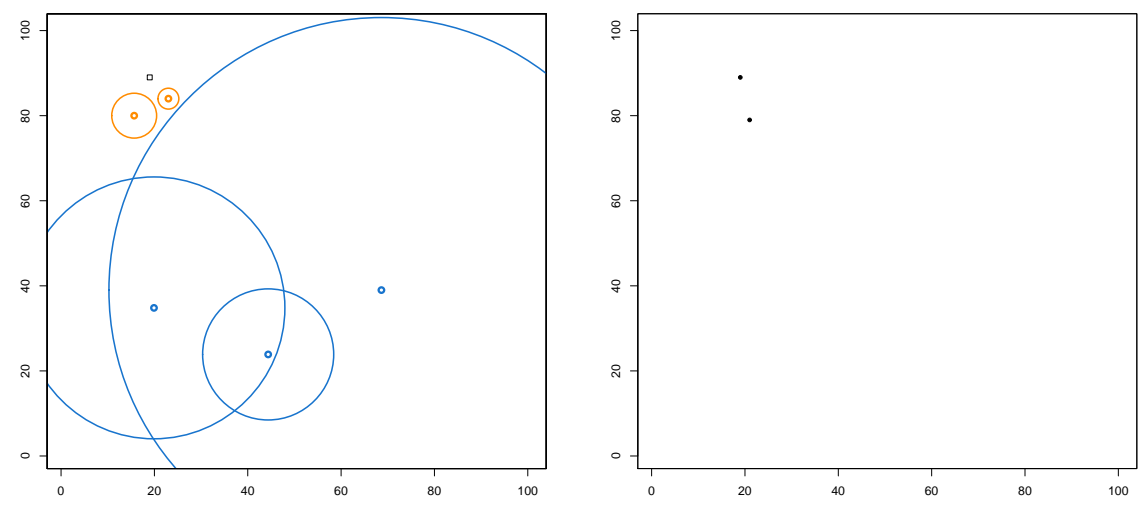

Figura 5.12: Exemplo de descrição produzida por OLINDDA para o conjunto outliers2.

dados iniciais para evitar que outliers sejam incluídos no modelo normal. Uma maneira de fazê-lo é por meio de um fator de rejeição, como Tax (2001).

\subsubsection{Pureza dos conceitos}

As Tabelas 5.8, 5.9 e 5.10 apresentam resultados de diversas métricas que serão analisadas a partir desta seção, entre as quais a pureza média dos conceitos no momento da descoberta PurConcDescob e a pureza média dos conceitos PurConc, que é atualizada com a informação de classe dos exemplos identificados como membros de cada conceito e pelo efeito da fusão de conceitos.

Os resultados, tanto para PurConcDescob quanto para PurConc, mostraram-se muito bons, atingindo valores médios de $93 \%$ e $86 \%$, respectivamente, para todos os conjuntos e variações de parâmetros. Eliminando da análise os conjuntos waveform e waveformnoise, esses valores seriam 94\% e 93\%. Nesses dois conjuntos, a fusão de conceitos prejudicou um pouco o valor de PurConc, aspecto que será analisado na próxima seção.

Altos valores de PurConcDescob indicam que os conceitos encontrados por OLINDDA são, individualmente, bem semelhantes a uma das classes reais. É um fator muito importante, pois mostra que a técnica está sendo capaz de construir, de maneira nãosupervisionada e contínua, conceitos que foram formados por exemplos que possuem características semelhantes, e que essas características correspondem às de uma classe que realmente existe.

Bons resultados para PurConcDescob, exceto nos conjuntos waveform e waveformnoise, confirmam que os conceitos criados por OLINDDA estão sendo capazes de identificar exemplos e de combinar-se a outros conceitos de composição semelhante à sua, o que é outro fator muito importante. 


\begin{tabular}{|c|c|c|c|c|c|c|c|c|c|c|}
\hline \multirow[b]{2}{*}{$\begin{array}{l}\text { Conjunto de } \\
\text { dados }\end{array}$} & \multicolumn{2}{|c|}{ Parâmetros } & \multicolumn{8}{|c|}{ Métricas obtidas ao final da aprendizagem } \\
\hline & 产 & 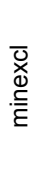 & 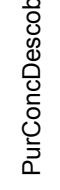 & 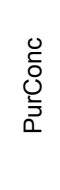 & 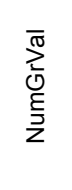 & 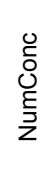 & 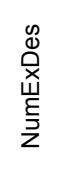 & $x$ & 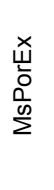 & 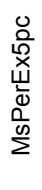 \\
\hline \multirow{12}{*}{ balancescale } & \multirow{3}{*}{5} & 3 & .82 & .94 & 12.7 & 2.3 & 6 & 2 & 7 & 6 \\
\hline & & 5 & .87 & .96 & 6.3 & 1.0 & 12 & 2 & 6 & 6 \\
\hline & & 7 & .89 & .96 & 5.9 & 1.0 & 13 & 2 & 7 & 6 \\
\hline & \multirow{3}{*}{10} & 3 & .80 & .92 & 21.5 & 3.5 & 10 & 4 & 10 & 8 \\
\hline & & 5 & .85 & .90 & 13.5 & 1.8 & 15 & 3 & 9 & 8 \\
\hline & & 7 & .85 & .93 & 10.2 & 1.2 & 23 & 3 & 9 & 8 \\
\hline & \multirow{3}{*}{15} & 3 & .81 & .88 & 29.4 & 6.5 & 13 & 5 & 13 & 11 \\
\hline & & 5 & .81 & .87 & 18.0 & 3.0 & 22 & 4 & 12 & 10 \\
\hline & & 7 & .85 & .87 & 13.7 & 2.5 & 33 & 5 & 13 & 10 \\
\hline & \multirow{3}{*}{20} & 3 & .81 & .86 & 33.8 & 3.7 & 13 & 5 & 15 & 11 \\
\hline & & 5 & .83 & .86 & 22.0 & 2.4 & 29 & 5 & 15 & 12 \\
\hline & & 7 & .84 & .86 & 18.3 & 2.8 & 36 & 5 & 16 & 13 \\
\hline \multirow{12}{*}{ biomed } & \multirow{3}{*}{5} & 3 & .99 & .99 & 2.0 & 1.7 & 22 & 7 & 11 & 12 \\
\hline & & 5 & - & - & 0.0 & 0.0 & 30 & 6 & 9 & 12 \\
\hline & & 7 & - & - & 0.0 & 0.0 & 33 & 3 & 8 & 10 \\
\hline & \multirow{3}{*}{10} & 3 & .96 & .98 & 4.7 & 2.5 & 28 & 9 & 17 & 15 \\
\hline & & 5 & .99 & .99 & 0.9 & 0.9 & 43 & 9 & 14 & 19 \\
\hline & & 7 & 1.00 & 1.00 & 0.1 & 0.1 & 51 & 6 & 13 & 14 \\
\hline & \multirow{3}{*}{15} & 3 & .93 & .93 & 6.6 & 3.4 & 28 & 10 & 20 & 20 \\
\hline & & 5 & .96 & .94 & 1.9 & 1.4 & 44 & 9 & 17 & 21 \\
\hline & & 7 & .71 & .71 & 0.1 & 0.1 & 59 & 8 & 15 & 24 \\
\hline & \multirow{3}{*}{20} & 3 & .95 & .90 & 6.9 & 3.3 & 30 & 10 & 20 & 23 \\
\hline & & 5 & .92 & .92 & 1.7 & 1.5 & 49 & 10 & 19 & 27 \\
\hline & & 7 & .88 & .89 & 0.1 & 0.1 & 61 & 7 & 16 & 26 \\
\hline \multirow{12}{*}{ breastwisconsin } & \multirow{3}{*}{5} & 3 & 1.00 & 1.00 & 23.7 & 1.2 & 15 & 5 & 14 & 14 \\
\hline & & 5 & 1.00 & 1.00 & 9.6 & 1.1 & 30 & 6 & 12 & 13 \\
\hline & & 7 & 1.00 & 1.00 & 5.9 & 1.0 & 36 & 5 & 11 & 11 \\
\hline & \multirow{3}{*}{10} & 3 & .98 & .99 & 29.5 & 2.2 & 18 & 6 & 19 & 17 \\
\hline & & 5 & .98 & .99 & 14.6 & 1.9 & 41 & 8 & 18 & 19 \\
\hline & & 7 & 1.00 & 1.00 & 9.0 & 1.7 & 51 & 7 & 16 & 16 \\
\hline & \multirow{3}{*}{15} & 3 & .97 & .96 & 33.9 & 2.0 & 21 & 7 & 22 & 22 \\
\hline & & 5 & .98 & .98 & 14.4 & 2.0 & 49 & 10 & 20 & 24 \\
\hline & & 7 & .98 & .98 & 9.0 & 1.9 & 64 & 9 & 19 & 20 \\
\hline & \multirow{3}{*}{20} & 3 & .97 & .97 & 36.0 & 9.2 & 30 & 10 & 25 & 27 \\
\hline & & 5 & .98 & .98 & 14.4 & 2.0 & 65 & 13 & 25 & 31 \\
\hline & & 7 & .97 & .98 & 9.7 & 2.0 & 101 & 14 & 29 & 41 \\
\hline \multirow{12}{*}{ ionosphere } & & 3 & 1.00 & 1.00 & 0.1 & 0.1 & 78 & 25 & 68 & 106 \\
\hline & 5 & 5 & .60 & .60 & 0.1 & 0.1 & 80 & 16 & 49 & 85 \\
\hline & & 7 & - & - & 0.0 & 0.0 & 85 & 11 & 44 & 74 \\
\hline & & 3 & 1.00 & 1.00 & 0.3 & 0.3 & 108 & 31 & 117 & 194 \\
\hline & 10 & 5 & - & - & 0.0 & 0.0 & 110 & 18 & 79 & 132 \\
\hline & & 7 & - & - & 0.0 & 0.0 & 108 & 14 & 63 & 100 \\
\hline & & 3 & 1.00 & 1.00 & 0.1 & 0.1 & 114 & 31 & 124 & 204 \\
\hline & 15 & 5 & - & - & 0.0 & 0.0 & 114 & 19 & 84 & 136 \\
\hline & & 7 & - & - & 0.0 & 0.0 & 115 & 14 & 68 & 110 \\
\hline & & 3 & .86 & .86 & 0.4 & 0.3 & 115 & 30 & 128 & 206 \\
\hline & 20 & 5 & - & - & 0.0 & 0.0 & 118 & 19 & 89 & 140 \\
\hline & & 7 & - & - & 0.0 & 0.0 & 117 & 13 & 71 & 114 \\
\hline
\end{tabular}

Tabela 5.8: Valores finais de diversas métricas para diversos conjuntos de dados e parâmetros, parte 1 de 3 . 


\begin{tabular}{|c|c|c|c|c|c|c|c|c|c|c|}
\hline \multirow[b]{2}{*}{$\begin{array}{l}\text { Conjunto de } \\
\text { dados }\end{array}$} & \multicolumn{2}{|c|}{ Parâmetros } & \multicolumn{8}{|c|}{ Métricas obtidas ao final da aprendizagem } \\
\hline & 言 & 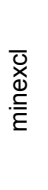 & 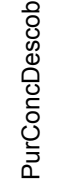 & 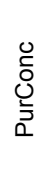 & 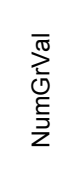 & 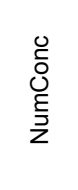 & 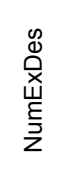 & $x$ & $\begin{array}{l}\text { 幽 } \\
\frac{0}{0} \\
\sum\end{array}$ & 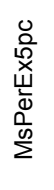 \\
\hline \multirow{12}{*}{ iris } & \multirow{3}{*}{5} & 3 & .98 & .86 & 14.8 & 12.7 & 24 & 8 & 20 & 15 \\
\hline & & 5 & .99 & .83 & 6.8 & 4.1 & 39 & 7 & 18 & 17 \\
\hline & & 7 & .96 & .84 & 4.9 & 2.5 & 50 & 7 & 18 & 19 \\
\hline & \multirow{3}{*}{10} & 3 & .98 & .92 & 15.8 & 12.6 & 31 & 10 & 26 & 20 \\
\hline & & 5 & .98 & .88 & 6.5 & 5.3 & 54 & 10 & 23 & 27 \\
\hline & & 7 & .99 & .90 & 2.9 & 1.9 & 72 & 10 & 21 & 29 \\
\hline & \multirow{3}{*}{15} & 3 & .97 & .96 & 15.7 & 13.0 & 42 & 14 & 32 & 31 \\
\hline & & 5 & .96 & .87 & 5.4 & 3.0 & 68 & 13 & 28 & 41 \\
\hline & & 7 & .96 & .97 & 1.1 & 1.0 & 93 & 13 & 24 & 37 \\
\hline & \multirow{3}{*}{20} & 3 & .98 & .97 & 13.0 & 11.2 & 57 & 19 & 38 & 45 \\
\hline & & 5 & .97 & .93 & 3.5 & 2.8 & 82 & 16 & 30 & 47 \\
\hline & & 7 & 1.00 & .93 & 0.8 & 0.6 & 96 & 14 & 24 & 37 \\
\hline \multirow{15}{*}{ mushroom } & \multirow{3}{*}{20} & 3 & .98 & .98 & 25.9 & 12.1 & 6 & 2 & 15 & 15 \\
\hline & & 5 & .98 & .98 & 15.5 & 5.5 & 9 & 2 & 15 & 14 \\
\hline & & 7 & .97 & .98 & 8.7 & 3.1 & 13 & 2 & 14 & 14 \\
\hline & \multirow{3}{*}{25} & 3 & .95 & .98 & 29.0 & 9.5 & 6 & 3 & 16 & 16 \\
\hline & & 5 & .96 & .98 & 18.0 & 5.0 & 11 & 2 & 15 & 15 \\
\hline & & 7 & .98 & .97 & 15.1 & 4.1 & 15 & 2 & 15 & 15 \\
\hline & \multirow{3}{*}{30} & 3 & .95 & .98 & 33.6 & 13.2 & 8 & 3 & 17 & 17 \\
\hline & & 5 & .96 & .98 & 22.2 & 10.7 & 14 & 3 & 16 & 16 \\
\hline & & 7 & .97 & .98 & 14.6 & 3.7 & 18 & 2 & 16 & 15 \\
\hline & \multirow{3}{*}{35} & 3 & .98 & .98 & 49.4 & 29.4 & 11 & 4 & 20 & 21 \\
\hline & & 5 & .98 & .98 & 23.3 & 13.6 & 15 & 3 & 17 & 16 \\
\hline & & 7 & .96 & .98 & 16.8 & 3.4 & 20 & 3 & 17 & 16 \\
\hline & \multirow{3}{*}{40} & 3 & .97 & .98 & 42.4 & 25.7 & 11 & 4 & 19 & 18 \\
\hline & & 5 & .98 & .98 & 20.6 & 6.7 & 14 & 3 & 17 & 17 \\
\hline & & 7 & .98 & .97 & 24.0 & 13.8 & 34 & 5 & 19 & 18 \\
\hline \multirow{15}{*}{ segmentation } & \multirow{3}{*}{20} & 3 & .96 & .97 & 242.1 & 227.7 & 190 & 63 & 134 & 124 \\
\hline & & 5 & .96 & .90 & 68.6 & 60.8 & 198 & 39 & 146 & 129 \\
\hline & & 7 & .92 & .91 & 18.4 & 16.7 & 199 & 28 & 110 & 101 \\
\hline & \multirow{3}{*}{25} & 3 & .97 & .97 & 242.9 & 232.4 & 193 & 64 & 149 & 131 \\
\hline & & 5 & .94 & .94 & 56.2 & 51.6 & 199 & 40 & 172 & 159 \\
\hline & & 7 & .92 & .92 & 14.5 & 13.0 & 200 & 29 & 117 & 113 \\
\hline & \multirow{3}{*}{30} & 3 & .96 & .97 & 245.4 & 233.5 & 192 & 64 & 161 & 139 \\
\hline & & 5 & .97 & .94 & 58.0 & 54.4 & 199 & 40 & 170 & 156 \\
\hline & & 7 & .88 & .87 & 9.5 & 8.7 & 200 & 28 & 122 & 121 \\
\hline & \multirow{3}{*}{35} & 3 & .95 & .97 & 228.8 & 217.9 & 196 & 65 & 169 & 152 \\
\hline & & 5 & .93 & .92 & 44.5 & 43.1 & 198 & 39 & 191 & 181 \\
\hline & & 7 & .91 & .91 & 7.8 & 7.4 & 200 & 28 & 125 & 127 \\
\hline & \multirow{3}{*}{40} & 3 & .98 & .97 & 227.6 & 221.4 & 196 & 66 & 184 & 168 \\
\hline & & 5 & .92 & .92 & 38.4 & 34.4 & 199 & 39 & 202 & 200 \\
\hline & & 7 & .89 & .88 & 7.7 & 7.1 & 200 & 28 & 127 & 126 \\
\hline
\end{tabular}

Tabela 5.9: Valores finais de diversas métricas para diversos conjuntos de dados e parâmetros, parte 2 de 3. 


\begin{tabular}{|c|c|c|c|c|c|c|c|c|c|c|}
\hline \multirow[b]{2}{*}{$\begin{array}{l}\text { Conjunto de } \\
\text { dados }\end{array}$} & \multicolumn{2}{|c|}{ Parâmetros } & \multicolumn{8}{|c|}{ Métricas obtidas ao final da aprendizagem } \\
\hline & $\overline{\underline{\underline{z}}}$ & 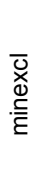 & 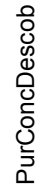 & 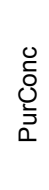 & 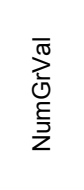 & $\begin{array}{l}0 \\
\text { ¿ } \\
\text { U } \\
\text { E } \\
z\end{array}$ & $\begin{array}{l}\stackrel{0}{凶} \\
\stackrel{Q}{x} \\
\stackrel{\text { है }}{\Sigma}\end{array}$ & $x$ & $\begin{array}{l}\stackrel{x}{W} \\
\vdots \\
0 \\
\frac{0}{2}\end{array}$ & 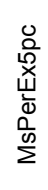 \\
\hline \multirow{15}{*}{ shuttle } & \multirow{3}{*}{20} & 3 & .97 & .94 & 70.7 & 66.4 & 156 & 48 & 12 & 13 \\
\hline & & 5 & .92 & .87 & 18.5 & 8.2 & 200 & 3 & 12 & 12 \\
\hline & & 7 & .96 & .87 & 18.5 & 9.7 & 200 & 2 & 12 & 12 \\
\hline & \multirow{3}{*}{25} & 3 & .96 & .94 & 94.7 & 84.4 & 158 & 50 & 15 & 16 \\
\hline & & 5 & .97 & .86 & 29.4 & 6.6 & 191 & 4 & 13 & 12 \\
\hline & & 7 & .94 & .85 & 16.8 & 5.5 & 200 & 2 & 13 & 12 \\
\hline & \multirow{3}{*}{30} & 3 & .95 & .93 & 100.7 & 88.4 & 162 & 50 & 16 & 17 \\
\hline & & 5 & .93 & .87 & 27.8 & 10.8 & 200 & 2 & 14 & 13 \\
\hline & & 7 & .97 & .86 & 20.6 & 8.7 & 196 & 3 & 14 & 13 \\
\hline & \multirow{3}{*}{35} & 3 & .96 & .95 & 131.6 & 123.2 & 175 & 50 & 19 & 22 \\
\hline & & 5 & .98 & .90 & 42.5 & 19.9 & 200 & 2 & 15 & 14 \\
\hline & & 7 & .93 & .85 & 24.4 & 10.9 & 200 & 2 & 14 & 13 \\
\hline & \multirow{3}{*}{40} & 3 & .95 & .93 & 128.8 & 114.6 & 167 & 48 & 19 & 21 \\
\hline & & 5 & .98 & .90 & 41.6 & 26.2 & 200 & 3 & 15 & 15 \\
\hline & & 7 & .99 & .84 & 28.0 & 11.0 & 196 & 4 & 15 & 13 \\
\hline \multirow{15}{*}{ waveform } & \multirow{3}{*}{20} & 3 & .93 & .66 & 283.4 & 10.1 & 17 & 6 & 47 & 80 \\
\hline & & 5 & .90 & .64 & 114.2 & 4.6 & 79 & 16 & 29 & 33 \\
\hline & & 7 & .88 & .64 & 59.4 & 3.3 & 174 & 25 & 32 & 35 \\
\hline & \multirow{3}{*}{25} & 3 & .91 & .67 & 301.0 & 6.7 & 16 & 5 & 57 & 103 \\
\hline & & 5 & .90 & .68 & 165.1 & 5.1 & 121 & 24 & 46 & 60 \\
\hline & & 7 & .91 & .67 & 71.1 & 2.7 & 192 & 27 & 43 & 46 \\
\hline & \multirow{3}{*}{30} & 3 & .91 & .68 & 364.8 & 9.6 & 22 & 7 & 80 & 156 \\
\hline & & 5 & .87 & .65 & 194.6 & 6.5 & 143 & 29 & 61 & 85 \\
\hline & & 7 & .89 & .62 & 74.3 & 2.4 & 197 & 28 & 49 & 50 \\
\hline & \multirow{3}{*}{35} & 3 & .95 & .66 & 376.0 & 2.7 & 21 & 7 & 90 & 176 \\
\hline & & 5 & .90 & .64 & 211.8 & 3.5 & 149 & 30 & 68 & 97 \\
\hline & & 7 & .89 & .60 & 84.2 & 2.0 & 196 & 28 & 62 & 62 \\
\hline & \multirow{3}{*}{40} & 3 & .89 & .64 & 458.4 & 4.5 & 27 & 9 & 137 & 285 \\
\hline & & 5 & .91 & .57 & 231.4 & 2.2 & 170 & 34 & 83 & 124 \\
\hline & & 7 & .90 & .62 & 85.8 & 1.9 & 193 & 27 & 58 & 60 \\
\hline \multirow{15}{*}{ waveformnoise } & \multirow{3}{*}{20} & 3 & .90 & .62 & 366.8 & 2.7 & 11 & 3 & 88 & 162 \\
\hline & & 5 & .93 & .65 & 201.5 & 2.4 & 76 & 15 & 69 & 92 \\
\hline & & 7 & .94 & .63 & 114.0 & 1.9 & 192 & 27 & 83 & 88 \\
\hline & \multirow{3}{*}{25} & 3 & .88 & .66 & 440.0 & 3.0 & 14 & 5 & 129 & 260 \\
\hline & & 5 & .92 & .62 & 245.8 & 2.0 & 87 & 18 & 93 & 131 \\
\hline & & 7 & .94 & .65 & 127.3 & 2.1 & 193 & 28 & 105 & 111 \\
\hline & \multirow{3}{*}{30} & 3 & .89 & .66 & 558.8 & 2.7 & 13 & 5 & 227 & 492 \\
\hline & & 5 & .92 & .65 & 264.7 & 2.3 & 94 & 19 & 106 & 160 \\
\hline & & 7 & .93 & .69 & 128.2 & 2.3 & 191 & 27 & 109 & 119 \\
\hline & \multirow{3}{*}{35} & 3 & .90 & .65 & 580.5 & 18.8 & 12 & 4 & 258 & 579 \\
\hline & & 5 & .92 & .65 & 331.4 & 2.2 & 126 & 25 & 169 & 285 \\
\hline & & 7 & .94 & .65 & 127.4 & 2.4 & 196 & 28 & 130 & 137 \\
\hline & & 3 & .94 & .66 & 678.7 & 4.9 & 14 & 5 & 383 & 901 \\
\hline & 40 & 5 & .93 & .64 & 357.8 & 1.9 & 142 & 29 & 203 & 347 \\
\hline & & 7 & .92 & .61 & 126.9 & 1.6 & 200 & 28 & 150 & 152 \\
\hline
\end{tabular}

Tabela 5.10: Valores finais de diversas métricas para diversos conjuntos de dados e parâmetros, parte 3 de 3 . 


\subsubsection{Complexidade dos modelos e fusão de conceitos}

A análise do número de grupos válidos NumGrVal e do número de conceitos NumConc descobertos também contribui para avaliar a relação entre os conceitos descobertos e as classes reais. Como descrito na Seção 4.6.4 conceitos são inicialmente descobertos como grupos válidos, mas seu número pode reduzir-se à medida que sofram fusão.

Com relação ao número de grupos válidos NumGrVal que compõem os modelos extensão e novidade, percebe-se que, para os mesmos valores de minexcl, eles podem aumentar com o aumento no valor de $k_{i n i}$ (Tabelas 5.8, 5.9 e 5.10). Isso deve-se ao fato de que, à medida que $k_{i n i}$ aumenta, o modelo normal torna-se mais restritivo, diminuindo o número de exemplos identificados como membros do conceito normal e aumentando o número de exemplos que vai para a memória temporária de perfis desconhecidos, a partir de onde os grupos são gerados. No conjunto balancescale, por exemplo, onde a classe $B$ é confundida com o conceito normal $L$, à medida que $k_{i n i}$ aumenta, mais exemplos da classe $B$ deixam de ser incorretamente identificados como membros do conceito normal, como visto na Tabela 5.5. Esses exemplos passam a gerar grupos válidos, como atesta NumGrVal na Tabela 5.8.

Em alguns conjuntos, entretanto, NumGrVal não aumenta com o aumento de $k_{\text {ini }}$. No conjunto iris, por exemplo, como não há confusão do conceito normal com as demais classes, os exemplos normais direcionados para a memória temporária de perfis desconhecidos pelo sobre-ajuste que ocorre com o aumento excessivo de $k_{\text {ini }}$ não se misturam com outras classes na formação de novos grupos (Tabela 5.5).

Com relação ao número de conceitos NumConc, observa-se que seu valor é quase sempre inferior ao de NumGrVal (Tabelas 5.8, 5.9 e 5.10), o que confirma que a fusão de conceitos está contribuindo para ajudar a encontrar um número menor de conceitos. A possibilidade de representar conceitos formados por vários grupos permite uma descrição mais detalhada e, geralmente, mais adequada, além de facilitar a análise. Para os conjuntos balancescale, breastwisconsin, mushroom, shuttle e, especialmente para waveform e waveformnoise, NumConc é bastante inferior a NumGrVal.

A evolução das métricas cujos valores finais constam das Tabelas 5.8, 5.9 e 5.10 ao longo do processo de aprendizado também pode ser analisada. As Figuras 5.13, 5.14 e 5.15 apresentam essa evolução para os conjuntos breastwisconsin, kddcup_pc10_c5 e $k d d c u p \_p c 10$, respectivamente, para diferentes valores de $k_{i n i}$. Os valores de minexcl utilizados são indicados nas legendas de cada figura.

Um ponto interessante a observar é que NumConc é menos sensível à variação de $k_{i n i}$ do que NumGrVal, exceto para valores muito elevados de $k_{i n i}$, o que também é um aspecto positivo. Na Figura 5.13 pode-se observar ao longo do tempo que, para o conjunto breastwisconsin, apenas para $k_{i n i}=20$ NumConc continua aumentando, seguindo a tendência de NumGrVal. Para os demais valores de $k_{i n i}$, a fusão de conceitos mantém 

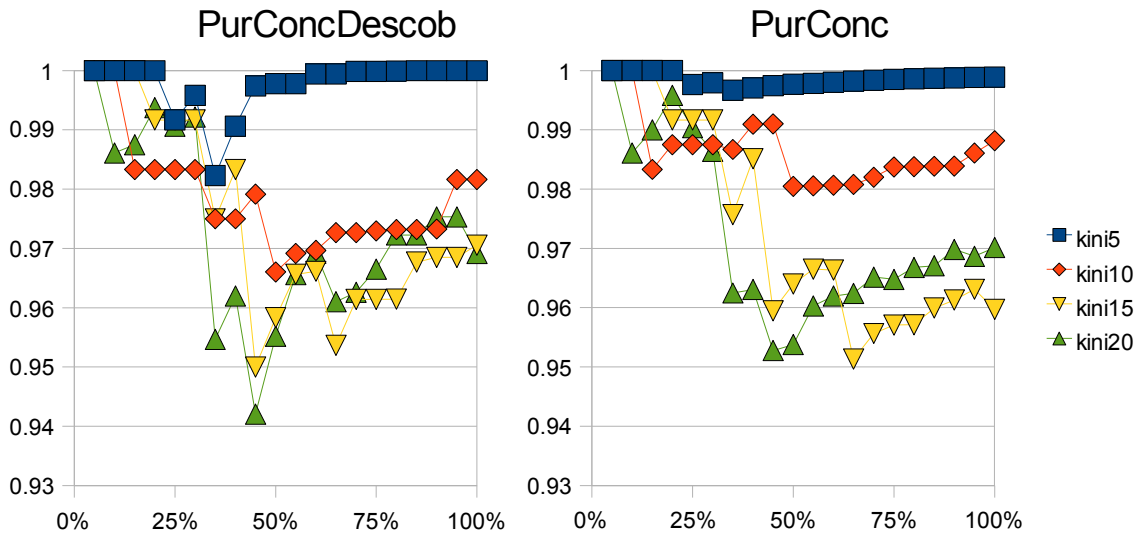

NumGrVal

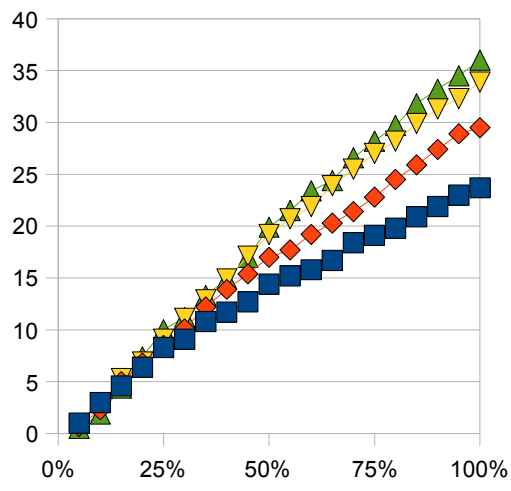

NumConc
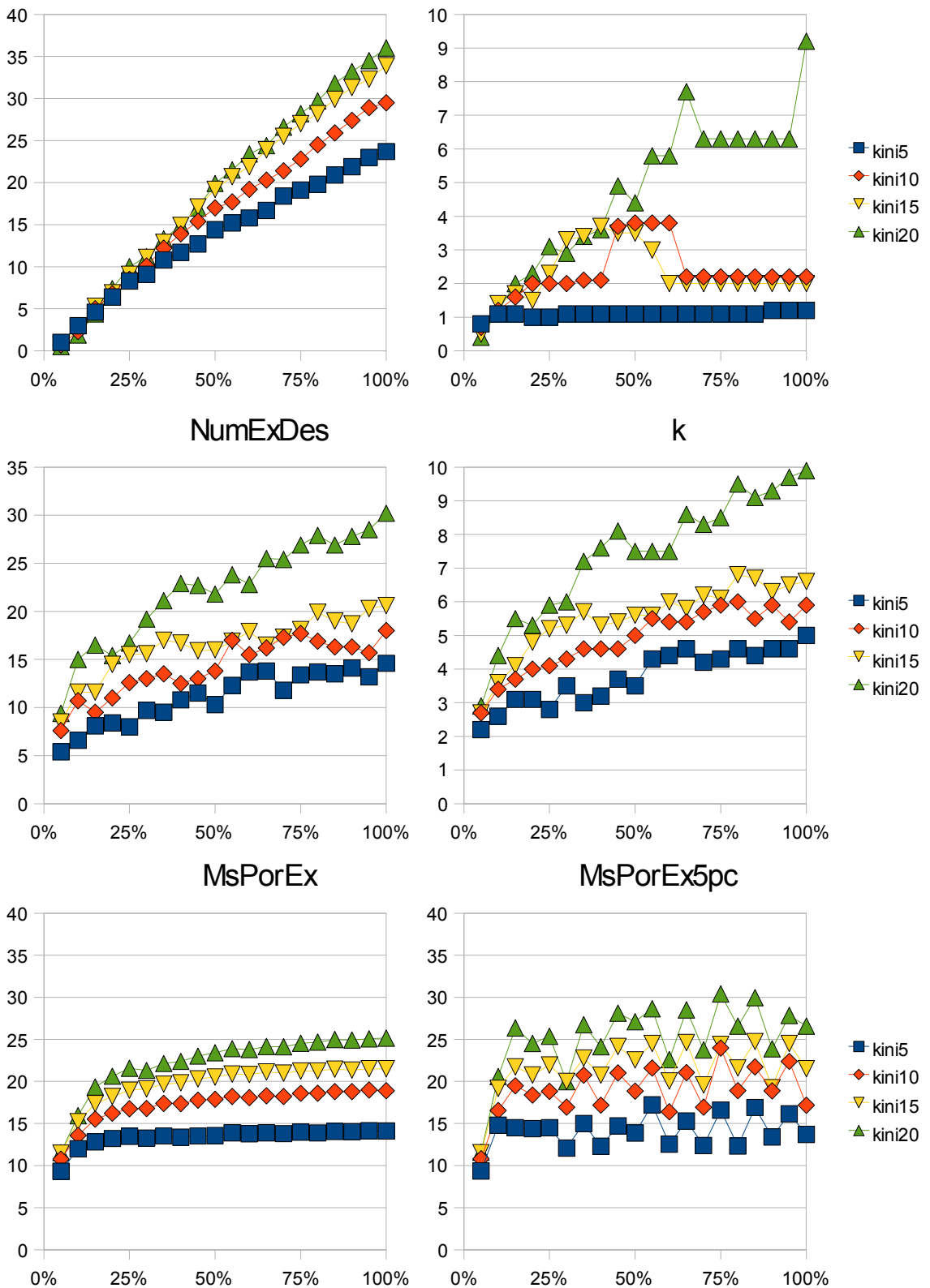

Figura 5.13: Evolução de diversas métricas ao longo do tempo para breastwisconsin, com minexcl=3. 

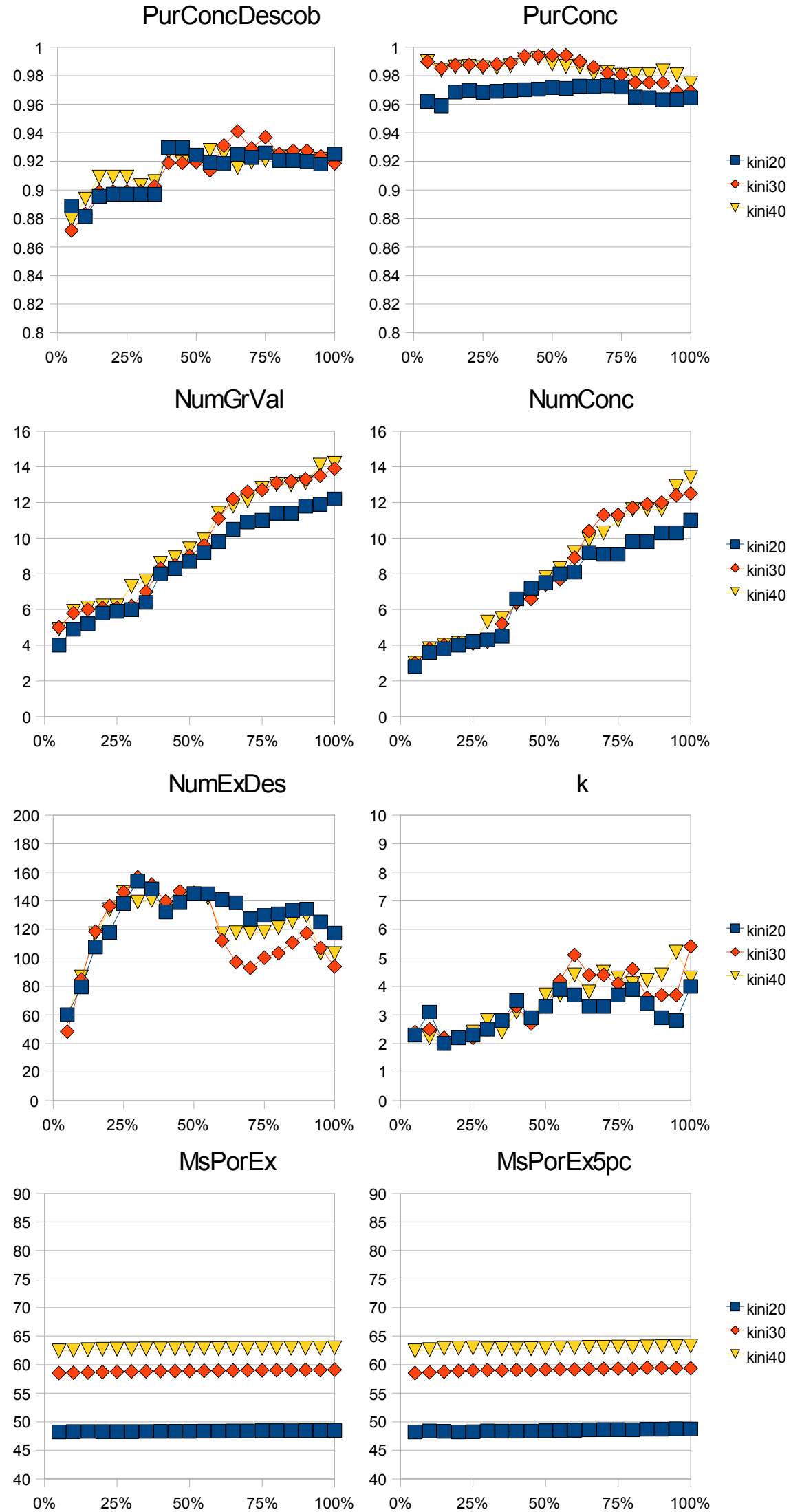

Figura 5.14: Evolução de diversas métricas ao longo do tempo para kddcup_pc10_c5 com minexcl $=5$. 
PurConcDescob

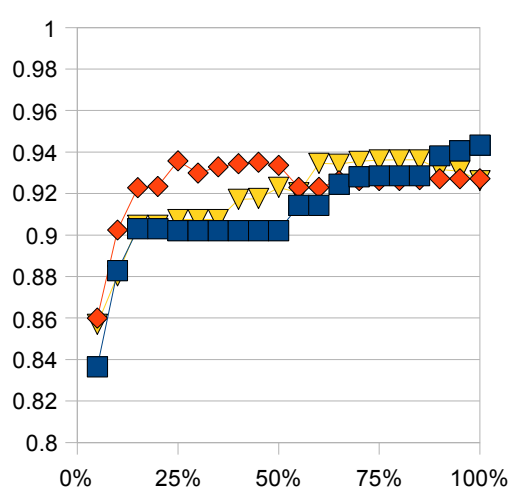

NumGrVal
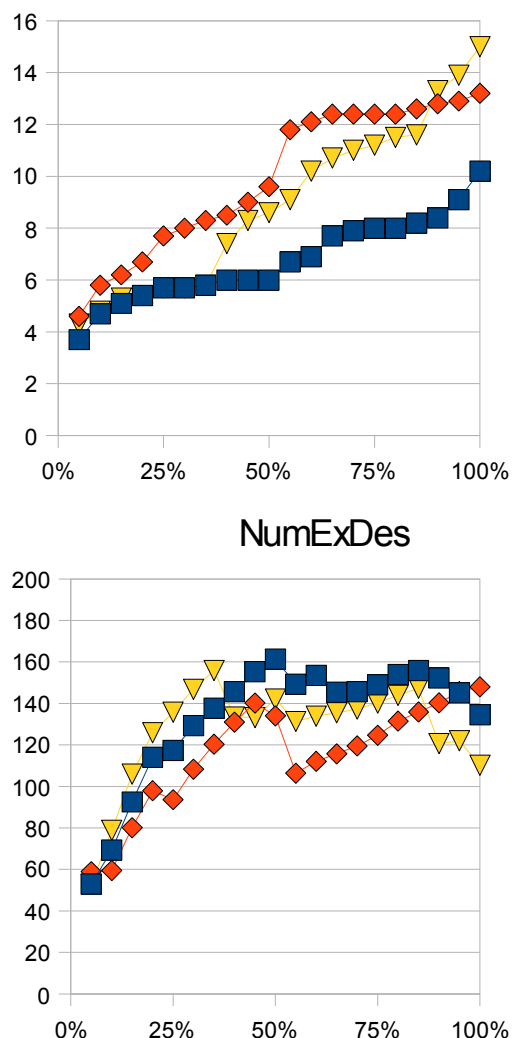

MsPorEx

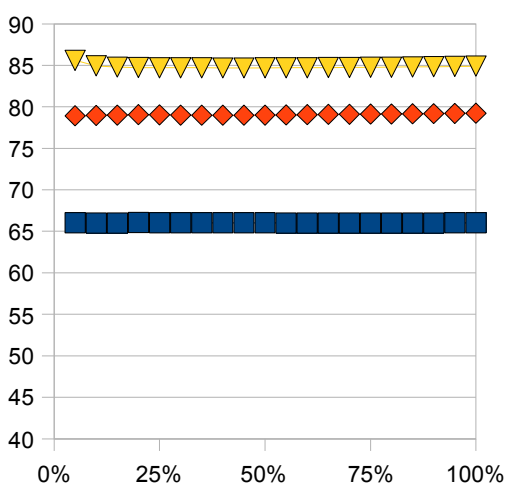

PurConc

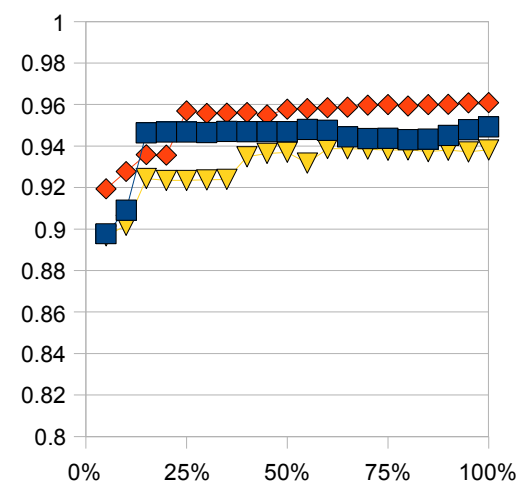

NumConc
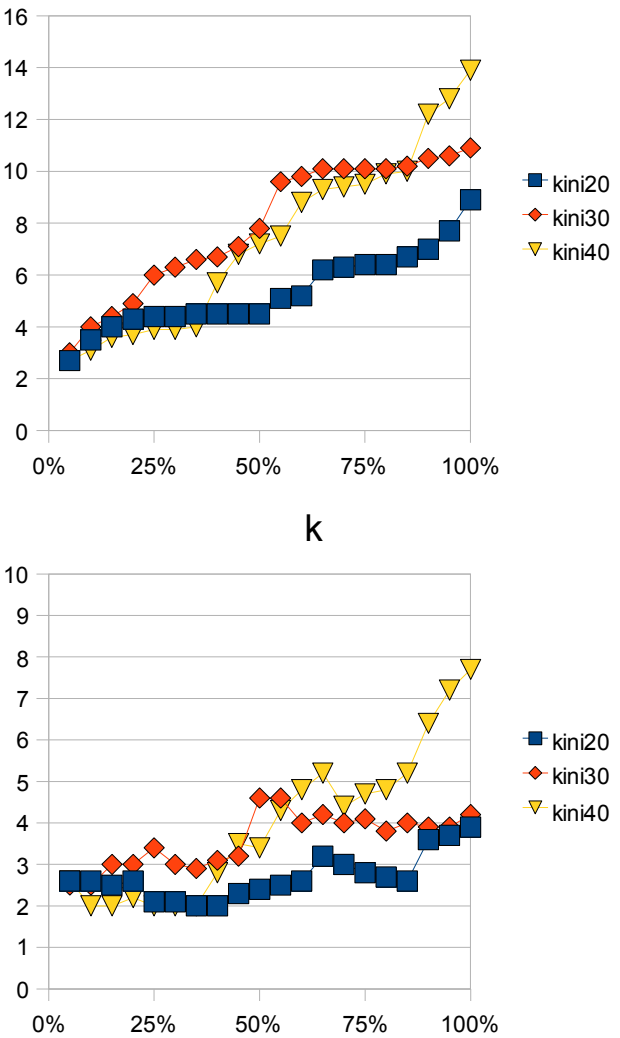

MsPorEx5pc

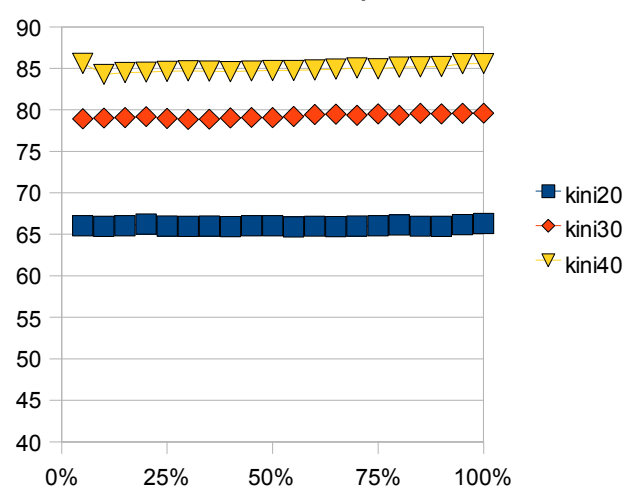

Figura 5.15: Evolução de diversas métricas ao longo do tempo para $k d d c u p \_p c 10$ com minexcl $=5$. 
NumConc em patamares bastante mais baixos do que os de NumGrVal.

Já para os conjuntos $k d d c u p \_p c 10$ e $k d d c u p \_p c 10 \_c 5$, a natureza muito específica dos conceitos descobertos dificultou a fusão entre eles, o que pode ser verificado pela semelhança entre as curvas de NumGrVal e NumConc nas Figuras 5.14 e 5.15.

A Figura 5.16 apresenta os resultados para o conjunto $k d d c u p \_p c 10 \_c 5$ quando minexcl foi aumentado de seu valor padrão 5 (Figura 5.14) para 10. A principal mudança foi a redução tanto de NumGrVal quanto de NumConc, aproximando o valor final de NumConc, em torno de 3 para qualquer opção de $k_{i n i}$, do número real de categorias de ataque a serem descobertas: 4 .

Um exemplo da fusão de conceitos para o conjunto iris tendo a classe Iris-versicolor como normal é ilustrado pela Figura 5.17. A seqüência de gráficos do lado esquerdo representa a evolução da distribuição de classes em conceitos para o modelo novidade. A seqüência à direita refere-se ao modelo extensão. Cada cor indica um conceito. Cores iguais em modelos diferentes indicam conceitos diferentes. É possível observar que os conceitos descobertos neste experimentos são puros em termos das classes reais, e que a fusão entre eles produz, no fim do aprendizado, 2 conceitos de novidade, que correspondem às classes Iris-setosa e Iris-virginica, e 1 conceito de extensão menos representativo, formado por alguns exemplos de Iris-virginica.

\subsubsection{Custo computacional}

Em FCD, o tempo necessário para tratar cada exemplo é um aspecto fundamental. Para avaliar esse aspecto, foram medidos o tempo médio, em milisegundos, para processar um exemplo desde o início do aprendizado MsPorEx, e o tempo médio, também em milisegundos, para processar um exemplo em cada etapa correspondente a $5 \%$ do aprendizado de maneira isolada MsPorEx5pc.

Parte do custo computacional deve-se à classificação de um novo exemplo como membro de um conceito conhecido ou como um perfil desconhecido. Quanto maior o número de grupos existentes nos modelos, maior o número de verificações a serem feita nessa etapa. Esperar-se-ia, portanto, que MsPorEx aumentasse com o aumento de NumGrVal. Os resultados das Tabelas 5.8, 5.9 e 5.10 mostram que isso realmente se verifica.

Outro aspecto que influencia o custo computacional é a geração de grupos candidatos, que ocorre, na configuração padrão (default), sempre que um novo exemplo é adicionado à memória temporária de perfis desconhecidos. Como discutido na Seção 5.4.6, no conjunto balancescale, à medida que $k_{i n i}$ aumenta, mais exemplos da classe $B$ deixam de ser incorretamente identificados como membros do conceito normal, aumentando o número de iterações em que agrupamentos candidatos são gerados. Isso pode ser verificado comparando as colunas $k_{i n i}$ e MsPorEx da Tabela 5.8 para o conjunto balancescale.

Na Figura 5.13 , percebe-se $M s$ PorEx $5 p c$ realmente captura as variações do tempo de 
PurConcDescob

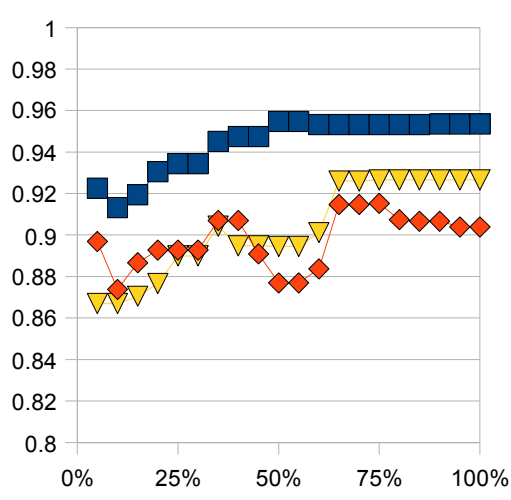

NumGrVal

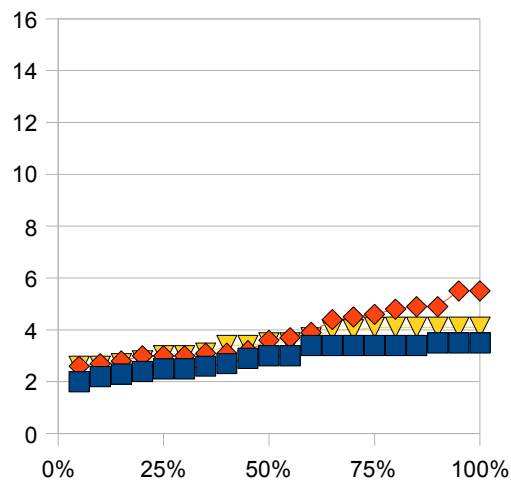

NumExDes

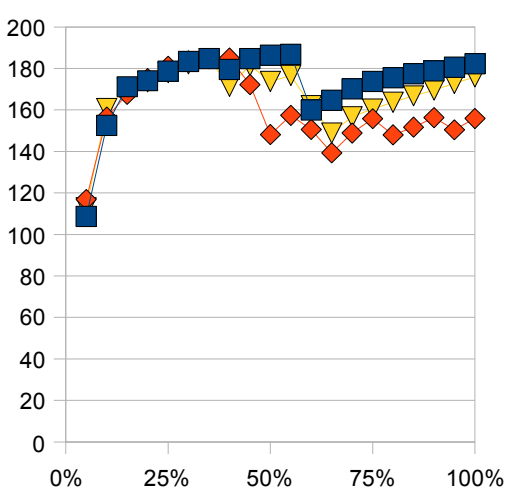

MsPorEx

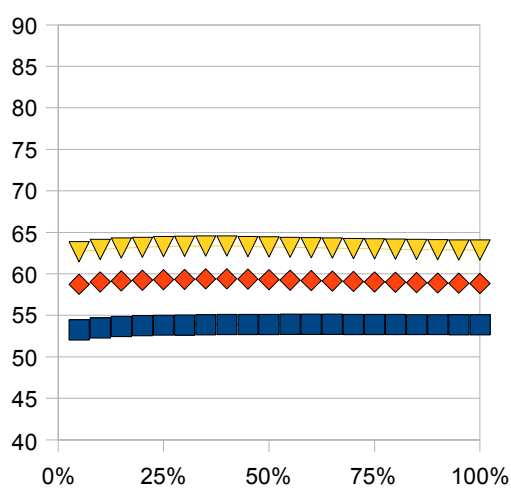

PurConc

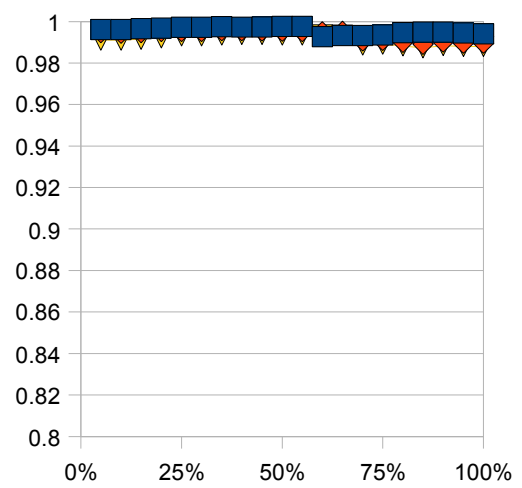

NumConc
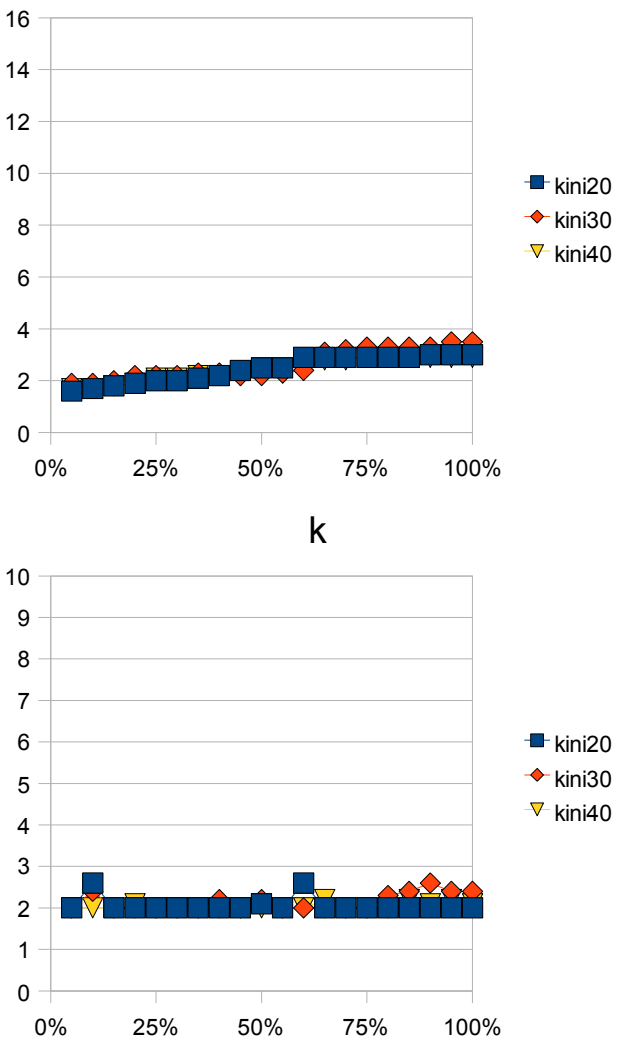

MsPorEx5pc

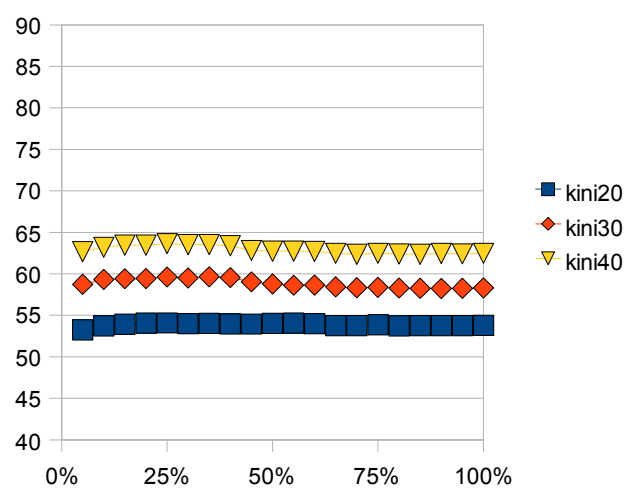

Figura 5.16: Evolução de diversas métricas ao longo do tempo para kddcup_pc10_c5 com minexcl $=10$. 

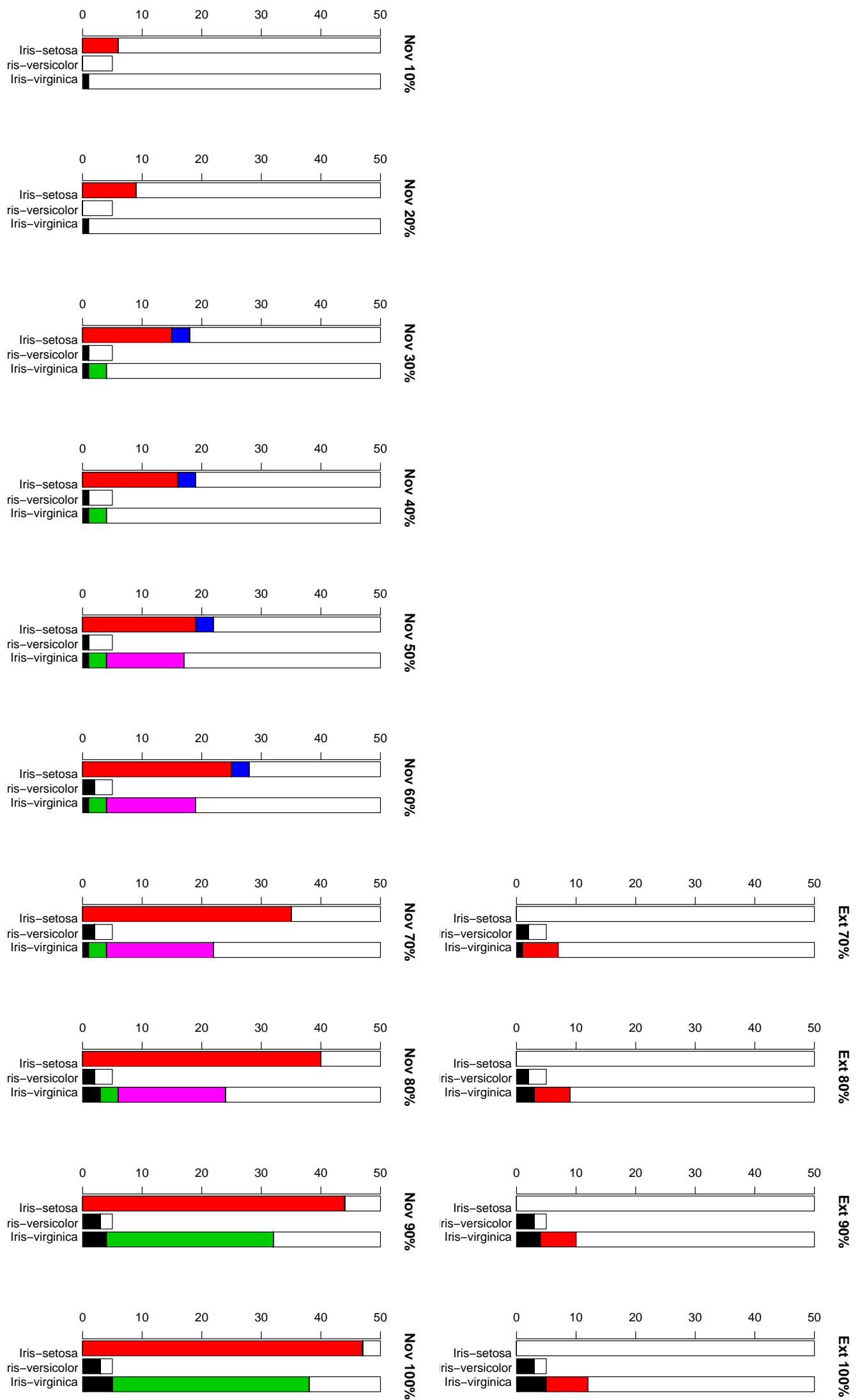

Figura 5.17: Exemplo de fusão de conceitos para o conjunto de dados iris. 
processamento, mas observa-se que essa variação é pequena, oscilando em torno de um valor que permanece praticamente constante, ou com uma pequena taxa de crescimento, como mostra o gráfico de MsPorEx.

Esse aspecto fica mais evidente com um número maior de exemplos, como pode ser verificado nas Figuras 5.14 e 5.15, referentes aos conjuntos $k d d c u p p_{-} p c 10_{-} c 5$ e $k d d-$ cup_pc10. Nesses casos, o valor de MsPorEx permaneceu praticamente constante, uma característica importante em aplicações como essa, envolvendo FCD.

\subsubsection{Influência do algoritmo de agrupamento}

Como visto na Seção 4.4, além do algoritmo k-médias, OLINDDA pode utilizar outros algoritmos de agrupamento. A opção escolhida pode afetar tanto a qualidade do modelo normal quanto a dos grupos candidatos gerados periodicamente. As Tabelas 5.11 e 5.12 apresentam os resultados obtidos por OLINDDA utilizando os algoritmos de agrupamento k-médias, PAM e CLARA. Nesses experimentos, usou-se a medida de coesão baseada na distância média entre exemplos e centróide ( $d 2$, descrita na Seção 4.6.2). Para a medida baseada em densidade, os resultados foram semelhantes.

Com relação à descoberta de novos conceitos (Tabela 5.11), os resultados conseguidos por OLINDDA usando o algoritmo k-médias foram melhores do que com PAM e CLARA, que obtiveram resultados semelhantes. Com k-médias, uma maior quantidade de exemplos das classes a serem descobertas formou grupos válidos. Para o conjunto biomed, em que observou-se maior dificuldade, PAM e CLARA praticamente não conseguiram gerar grupos válidos. Utilizando outro critério de validação, baseado na densidade, isso foi possível, mas ainda assim o desempenho de k-médias foi superior.

Ainda na Tabela 5.11, para o conjunto balancescale, vê-se que k-médias gerou um modelo mais ajustado aos dados iniciais do que PAM e CLARA, o que poderia explicar o fato de que nesse caso uma maior quantidade de exemplos tenha estado disponível para formar novos grupos. Entretanto, os resultados para o conjunto iris, em que não houve ocorrência de falso-negativo para os três algoritmos, mostram que o melhor desempenho com k-médias não está relacionado ao nível de ajuste ao modelo normal, mas à sua capacidade de gerar grupos candidatos que melhor atendam aos critérios de validação.

Na Tabela 5.12 verifica-se o maior número de grupos válidos NumGrVal encontrados por OLINDDA com k-médias, sem, entretanto, um aumento equivalente no número de conceitos NumConc. Isso indica que, com k-médias, foi possível descrever mais detalhadamente os conceitos, uma vez que eles são formados por um número maior de grupos, ou hiperesferas. Em geral, a fusão entre grupos não deteriorou o valor da pureza PurConc, exceto para o conjunto iris.

Com relação ao custo computacional, avaliado pelo tempo médio para processar um exemplo MsPorEx, não foi possível observar diferenças substanciais entre os algoritmos, 


\begin{tabular}{|c|c|c|c|c|c|c|c|c|}
\hline \multirow[b]{2}{*}{$\begin{array}{l}\text { Conjunto de } \\
\text { dados }\end{array}$} & \multirow[b]{2}{*}{$\begin{array}{l}\text { Algoritmo de } \\
\text { agrupamento }\end{array}$} & \multirow[b]{2}{*}{$\begin{array}{c}\text { Classe } \\
\text { (Normal em } \\
\text { negrito) }\end{array}$} & \multicolumn{6}{|c|}{ Distribuição de classes } \\
\hline & & & ̀̀ & $\begin{array}{l}\text { 爻 } \\
\text { ठ } \\
\text { ठ }\end{array}$ & 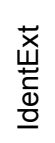 & $\begin{array}{l}\text { o } \\
\text { Zे } \\
\text { ర } \\
0\end{array}$ & $\begin{array}{l}\text { O) } \\
\sum_{1} \\
\frac{1}{0} \\
\underline{0}\end{array}$ & \& \\
\hline \multirow{9}{*}{ balancescale } & \multirow{3}{*}{ k-médias } & $\mathbf{L}$ & .76 & .00 & .00 & .11 & .09 & .05 \\
\hline & & $\mathrm{R}$ & .17 & .00 & .01 & .22 & .57 & .03 \\
\hline & & $B$ & .63 & .01 & .00 & .12 & .17 & .07 \\
\hline & \multirow{3}{*}{ PAM } & $\mathbf{L}$ & .90 & .01 & .02 & .02 & .02 & .03 \\
\hline & & $\mathrm{R}$ & .31 & .00 & .02 & .14 & .50 & .03 \\
\hline & & $B$ & .81 & .00 & .01 & .03 & .09 & .05 \\
\hline & \multirow{3}{*}{ CLARA } & $\mathbf{L}$ & .91 & .00 & .00 & .03 & .05 & .00 \\
\hline & & $\mathrm{R}$ & .40 & .01 & .05 & .11 & .41 & .02 \\
\hline & & $\mathrm{B}$ & .84 & .00 & .00 & .04 & .09 & .02 \\
\hline \multirow{6}{*}{ biomed } & \multirow{2}{*}{ k-médias } & normal & .80 & .09 & .02 & .00 & .00 & .09 \\
\hline & & carrier & .16 & .18 & .03 & .00 & .00 & .63 \\
\hline & \multirow{2}{*}{ PAM } & normal & .87 & .00 & .00 & .00 & .00 & .13 \\
\hline & & carrier & .24 & .00 & .00 & .00 & .00 & .76 \\
\hline & \multirow{2}{*}{ CLARA } & normal & .84 & .00 & .01 & .00 & .00 & .15 \\
\hline & & carrier & .23 & .01 & .00 & .00 & .00 & .75 \\
\hline \multirow{6}{*}{ breastwisconsin } & \multirow{2}{*}{ k-médias } & benign & .98 & .01 & .00 & .01 & .00 & .01 \\
\hline & & malignant & .18 & .02 & .01 & .30 & .32 & .17 \\
\hline & \multirow{2}{*}{ PAM } & benign & .98 & .00 & .00 & .00 & .00 & .01 \\
\hline & & malignant & .20 & .01 & .00 & .20 & .37 & .22 \\
\hline & \multirow{2}{*}{ CLARA } & benign & .99 & .00 & .00 & .00 & .00 & .01 \\
\hline & & malignant & .32 & .02 & .02 & .17 & .32 & .15 \\
\hline \multirow{9}{*}{ iris } & \multirow{3}{*}{ k-médias } & Iris-setosa & .84 & .00 & .00 & .00 & .00 & .16 \\
\hline & & Iris-versicolor & .00 & .00 & .00 & .44 & .29 & .27 \\
\hline & & Iris-virginica & .00 & .00 & .00 & .41 & .17 & .42 \\
\hline & \multirow{3}{*}{ PAM } & Iris-setosa & .94 & .00 & .00 & .00 & .00 & .06 \\
\hline & & Iris-versicolor & .00 & .00 & .00 & .39 & .28 & .33 \\
\hline & & Iris-virginica & .00 & .00 & .00 & .23 & .12 & .65 \\
\hline & \multirow{3}{*}{ CLARA } & Iris-setosa & .92 & .00 & .00 & .00 & .00 & .08 \\
\hline & & Iris-versicolor & .00 & .00 & .00 & .40 & .22 & .37 \\
\hline & & Iris-virginica & .00 & .00 & .00 & .27 & .08 & .64 \\
\hline
\end{tabular}

Tabela 5.11: Influência do algoritmo de agrupamento sobre a distribuição de classes. 


\begin{tabular}{|c|c|c|c|c|c|c|c|c|c|}
\hline \multirow[b]{2}{*}{$\begin{array}{l}\text { Conjunto de } \\
\text { dados }\end{array}$} & \multirow[b]{2}{*}{$\begin{array}{l}\text { Algoritmo de } \\
\text { agrupamento }\end{array}$} & \multicolumn{8}{|c|}{ Métricas obtidas ao final da aprendizagem } \\
\hline & & 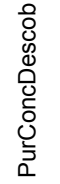 & 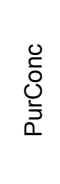 & $\begin{array}{l}\bar{N} \\
\sum_{0}^{0} \\
\sum \\
\sum \\
\Sigma\end{array}$ & 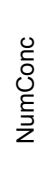 & 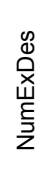 & 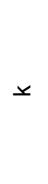 & 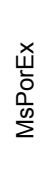 & 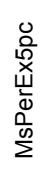 \\
\hline \multirow{3}{*}{ balancescale } & k-médias & .83 & .92 & 12.4 & 1.2 & 13 & 3 & 13 & 11 \\
\hline & PAM & .90 & .94 & 7.4 & 1.5 & 12 & 2 & 11 & 9 \\
\hline & CLARA & .92 & .95 & 5.9 & 1.6 & 8 & 2 & 9 & 9 \\
\hline \multirow{3}{*}{ biomed } & k-médias & .93 & .93 & 1.9 & 0.9 & 43 & 9 & 25 & 32 \\
\hline & PAM & - & - & 0.0 & 0.0 & 53 & 9 & 26 & 45 \\
\hline & CLARA & 1.00 & .90 & 0.1 & 0.1 & 52 & 9 & 26 & 38 \\
\hline \multirow{3}{*}{ breastwisconsin } & k-médias & .95 & .98 & 14.0 & 1.8 & 40 & 8 & 26 & 27 \\
\hline & PAM & .99 & .99 & 8.6 & 1.2 & 53 & 10 & 25 & 24 \\
\hline & CLARA & 1.00 & 1.00 & 7.6 & 1.5 & 37 & 7 & 20 & 18 \\
\hline \multirow{3}{*}{ iris } & k-médias & .99 & .67 & 7.2 & 3.2 & 35 & 7 & 26 & 22 \\
\hline & PAM & .95 & .73 & 5.2 & 2.0 & 49 & 9 & 31 & 30 \\
\hline & CLARA & .94 & .80 & 5.6 & 2.0 & 50 & 10 & 33 & 32 \\
\hline
\end{tabular}

Tabela 5.12: Influência do algoritmo de agrupamento sobre diversas métricas.

provavelmente pela pequena quantidade de exemplos na memória temporária.

\subsubsection{Influência do critério de validação}

O critério de validação tem a importante função de permitir que apenas grupos coesos e representativos sejam incorporados aos modelos. Na Seção 4.6 .2 foram apresentados 3 critérios possíveis para avaliar a coesão de um grupo candidato: com base na densidade (dens), na soma dos quadrados das distâncias entre exemplos e centróide dividida pelo número de exemplos $(d 1)$ ou na distância média entre exemplos e centróide $(d 2)$. Como mencionado na Seção 4.6.2, o cálculo de dens apresenta problemas em conjuntos de dados com um grande número de atributos, uma vez que, à medida que a dimensão $n$ aumenta, $\operatorname{vol}\left(c_{i}, n\right)$ tende a zero (Stibor et al., 2006, Figura 2).

As Tabelas 5.13 e 5.14 apresentam os resultados com o uso de cada critério de validação para conjuntos de dados cujo número de dimensões varia de 4 a 4026 .

O critério de validação influenciou a quantidade de exemplos que formaram conceitos (grupos válidos) dos tipos extensão e novidade. Na distribuição de classes, apresentada na Tabela 5.13, isso pode ser observado nas colunas ConcExt e ConcNov. Para os conjuntos iris e breastwisconsin, respectivamente com 4 e 9 atributos, os 3 critérios aceitam aproximadamente a mesma quantidade de exemplos como formadores de novos grupos. Na Tabela 5.14, os valores de NumGrVal confirmam esse ponto. Para waveform e waveformnoise, respectivamente com 21 e 40 atributos, já nota-se uma redução do número de exemplos que formou grupos do tipo extensão e de NumGrVal para o critério de validação dens, indicando que, para esse número de dimensões, esse critério já começa a tornar-se inadequado. Para o conjunto lymphoma, uma situação extrema com 4026 atributos, não é possível obter o valor da função gama, o que impossibilita o cálculo de 


\begin{tabular}{|c|c|c|c|c|c|c|c|c|c|}
\hline \multirow[b]{2}{*}{$\begin{array}{l}\text { Conjunto de } \\
\text { dados }\end{array}$} & \multirow[b]{2}{*}{$\begin{array}{l}\text { Número de } \\
\text { atributos } \\
\text { (dimensões) }\end{array}$} & \multirow[b]{2}{*}{$\begin{array}{l}\text { Critério de } \\
\text { validação } \\
\text { (coesão) }\end{array}$} & \multirow[b]{2}{*}{$\begin{array}{c}\text { Classe } \\
\text { (Normal em } \\
\text { negrito) }\end{array}$} & \multicolumn{6}{|c|}{ Distribuição de classes } \\
\hline & & & & cे & 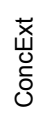 & 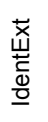 & 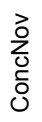 & 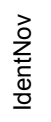 & $\stackrel{\infty}{\mathscr{0}}$ \\
\hline \multirow{9}{*}{ iris } & \multirow{9}{*}{4} & \multirow{3}{*}{ dens } & Iris-setosa & .86 & .00 & .00 & .00 & .00 & .14 \\
\hline & & & Iris-versicolor & .00 & .00 & .00 & .40 & .39 & .21 \\
\hline & & & Iris-virginica & .00 & .00 & .00 & .37 & .29 & .34 \\
\hline & & \multirow{3}{*}{ d1 } & Iris-setosa & .84 & .00 & .00 & .00 & .00 & .16 \\
\hline & & & Iris-versicolor & .00 & .00 & .00 & .43 & .23 & .33 \\
\hline & & & Iris-virginica & .00 & .00 & .00 & .40 & .18 & .42 \\
\hline & & \multirow{3}{*}{ d2 } & Iris-setosa & .84 & .00 & .00 & .00 & .00 & .16 \\
\hline & & & Iris-versicolor & .00 & .00 & .00 & .46 & .24 & .31 \\
\hline & & & Iris-virginica & .00 & .00 & .00 & .45 & .17 & .38 \\
\hline \multirow{6}{*}{ breastwisconsin } & \multirow{6}{*}{9} & \multirow{2}{*}{ dens } & benign & .98 & .00 & .00 & .00 & .00 & .01 \\
\hline & & & malignant & 19 & .02 & .02 & .33 & .31 & .13 \\
\hline & & \multirow{2}{*}{ d1 } & benign & .98 & .00 & .00 & .01 & .00 & .01 \\
\hline & & & malignant & .20 & .02 & .01 & .30 & .30 & .17 \\
\hline & & \multirow{2}{*}{ d2 } & benign & .98 & .00 & .00 & .00 & .00 & .01 \\
\hline & & & malignant & .20 & .02 & .02 & .29 & 31 & 17 \\
\hline \multirow{9}{*}{ waveform } & \multirow{9}{*}{21} & \multirow{3}{*}{ dens } & wave0 & .53 & .24 & .19 & .00 & .00 & .03 \\
\hline & & & wave1 & .21 & .16 & .61 & .01 & .00 & .01 \\
\hline & & & wave2 & .14 & .18 & .67 & .01 & .00 & .01 \\
\hline & & \multirow{3}{*}{ d1 } & wave0 & .48 & .30 & .13 & .01 & .00 & .08 \\
\hline & & & wave1 & .15 & .25 & .55 & .01 & .00 & .03 \\
\hline & & & wave2 & .15 & .25 & .53 & .02 & .01 & .03 \\
\hline & & \multirow{3}{*}{ d2 } & wave0 & .51 & .25 & .12 & .01 & .00 & .10 \\
\hline & & & wave1 & 17 & .24 & .54 & .02 & .01 & .04 \\
\hline & & & wave2 & .17 & .24 & .52 & .02 & .01 & .04 \\
\hline \multirow{9}{*}{ waveformnoise } & \multirow{9}{*}{40} & \multirow{3}{*}{ dens } & wave0 & .37 & .37 & .20 & .02 & .01 & .02 \\
\hline & & & wave1 & .13 & .25 & .58 & .03 & .01 & .01 \\
\hline & & & wave2 & .11 & .26 & .58 & .03 & .01 & .01 \\
\hline & & \multirow{3}{*}{ d1 } & wave0 & .42 & .42 & .06 & .02 & .01 & .07 \\
\hline & & & wave1 & .13 & .39 & .41 & .03 & .00 & .03 \\
\hline & & & wave2 & .16 & .39 & .37 & .05 & .01 & .03 \\
\hline & & & wave0 & .38 & .43 & .10 & .03 & .00 & .07 \\
\hline & & d2 & wave1 & .10 & .38 & .47 & .02 & .01 & .03 \\
\hline & & & wave2 & .14 & .37 & .40 & .05 & .01 & .03 \\
\hline & & dens & GC & - & - & - & - & - & - \\
\hline & & 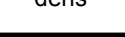 & A & - & - & - & - & - & - \\
\hline Jumnhom? & 1026 & $d 1$ & GC & .20 & .15 & .10 & .00 & .00 & .55 \\
\hline 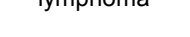 & $40<0$ & 41 & A & .05 & .23 & .04 & .00 & .00 & .68 \\
\hline & & d? & GC & .20 & .25 & .00 & .00 & .00 & .55 \\
\hline & & us & A & .05 & .24 & .03 & .00 & .00 & .68 \\
\hline
\end{tabular}

Tabela 5.13: Influência do critério de validação sobre a distribuição de classes. 


\begin{tabular}{|c|c|c|c|c|c|c|c|c|c|c|}
\hline \multirow[b]{2}{*}{$\begin{array}{l}\text { Conjunto de } \\
\text { dados }\end{array}$} & \multirow[b]{2}{*}{$\begin{array}{l}\text { Número de } \\
\text { atributos } \\
\text { (dimensões) }\end{array}$} & \multirow[b]{2}{*}{$\begin{array}{l}\text { Critério de } \\
\text { validação } \\
\text { (coesão) }\end{array}$} & \multicolumn{8}{|c|}{ Métricas obtidas ao final da aprendizagem } \\
\hline & & & 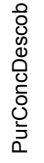 & 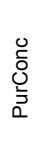 & 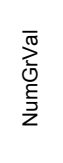 & 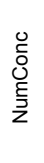 & 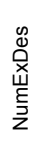 & 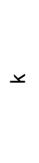 & 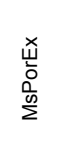 & 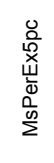 \\
\hline \multirow{3}{*}{ iris } & \multirow{3}{*}{4} & dens & .96 & .64 & 5.9 & 2.3 & 28 & 5 & 22 & 20 \\
\hline & & d1 & .99 & .74 & 7.2 & 4.7 & 38 & 7 & 28 & 27 \\
\hline & & d2 & .96 & .77 & 7.8 & 4.7 & 35 & 7 & 27 & 22 \\
\hline \multirow{3}{*}{ breastwisconsin } & \multirow{3}{*}{9} & dens & .98 & .98 & 14.5 & 1.7 & 31 & 6 & 23 & 22 \\
\hline & & d1 & .98 & .98 & 13.9 & 2.0 & 40 & 8 & 25 & 28 \\
\hline & & d2 & .98 & .99 & 13.3 & 1.7 & 41 & 8 & 24 & 25 \\
\hline \multirow{3}{*}{ waveform } & \multirow{3}{*}{21} & dens & .87 & .65 & 117.1 & 3.9 & 45 & 9 & 38 & 43 \\
\hline & & d1 & .91 & .68 & 183.5 & 6.9 & 127 & 26 & 74 & 94 \\
\hline & & d2 & .88 & .66 & 177.0 & 5.4 & 134 & 27 & 73 & 93 \\
\hline \multirow{3}{*}{ waveformnoise } & \multirow{3}{*}{40} & dens & .90 & .62 & 185.4 & 1.9 & 33 & 6 & 75 & 98 \\
\hline & & d1 & .93 & .67 & 295.3 & 2.1 & 106 & 21 & 162 & 238 \\
\hline & & d2 & .89 & .62 & 279.6 & 3.1 & 106 & 21 & 155 & 229 \\
\hline \multirow{3}{*}{ lymphoma } & \multirow{3}{*}{4026} & dens & - & - & - & - & - & - & - & - \\
\hline & & d1 & .94 & .93 & 0.9 & 0.8 & 17 & 3 & 4015 & 6962 \\
\hline & & d2 & .91 & .92 & 0.9 & 0.9 & 17 & 3 & 4065 & 6531 \\
\hline
\end{tabular}

Tabela 5.14: Influência do critério de validação sobre diversas métricas.

vol $\left(c_{i}, n\right)$ e, portanto, de dens. Os resultados confirmam o aspecto apresentado por Stibor et al. (2006, Figura 2), que mostra como vol $\left(c_{i}, n\right)$ tende a zero à medida que a dimensão ultrapassa valores em torno de 20 para $r=1.2$, por exemplo.

\subsubsection{Influência da adaptação automática do número de grupos}

OLINDDA adapta automaticamente o valor de $k$, utilizando informação sobre a avaliação dos grupos candidatos, para gerar grupos cada vez mais adequados às restrições impostas pelos critérios de validação (Seção 4.6.5). Para avaliar o impacto dessa estratégia, ela foi comparada com uma outra, implementada em uma versão anterior de OLINDDA, em que o valor de $k$ era calculado de uma maneira mais simples. Naquela versão, o cálculo do valor de $k$ considerava simplesmente o número de exemplos disponíveis para agrupamento na memória temporária de perfis desconhecidos. Tendo o número médio de exemplos por grupo como um parâmetro fixo, $k$ era calculado dividindo-se o número de exemplos disponíveis por esse parâmetro.

Os resultados (Spinosa et al., 2007a mostraram que a adaptação automática do parâmetro número de grupos foi responsável por um aumento substancial na quantidade de grupos válidos (conceitos) descobertos. Esse efeito é ilustrado na Figura 5.18 para o conjunto de dados breastwisconsin, tendo a classe benign como conceito normal. Os gráficos à esquerda referem-se à versão anterior de OLINDDA, e os à direita mostram o resultado da versão atual, com a adaptação automática de $k$. Observa-se que a adaptação automática de $k$ incrementou tanto o número de exemplos que formaram conceitos de novidade $(\backslash \backslash \backslash)$ quanto o dos que foram identificados por esses novos conceitos (cinza claro), confirmando sua importância no contexto da abordagem proposta. 

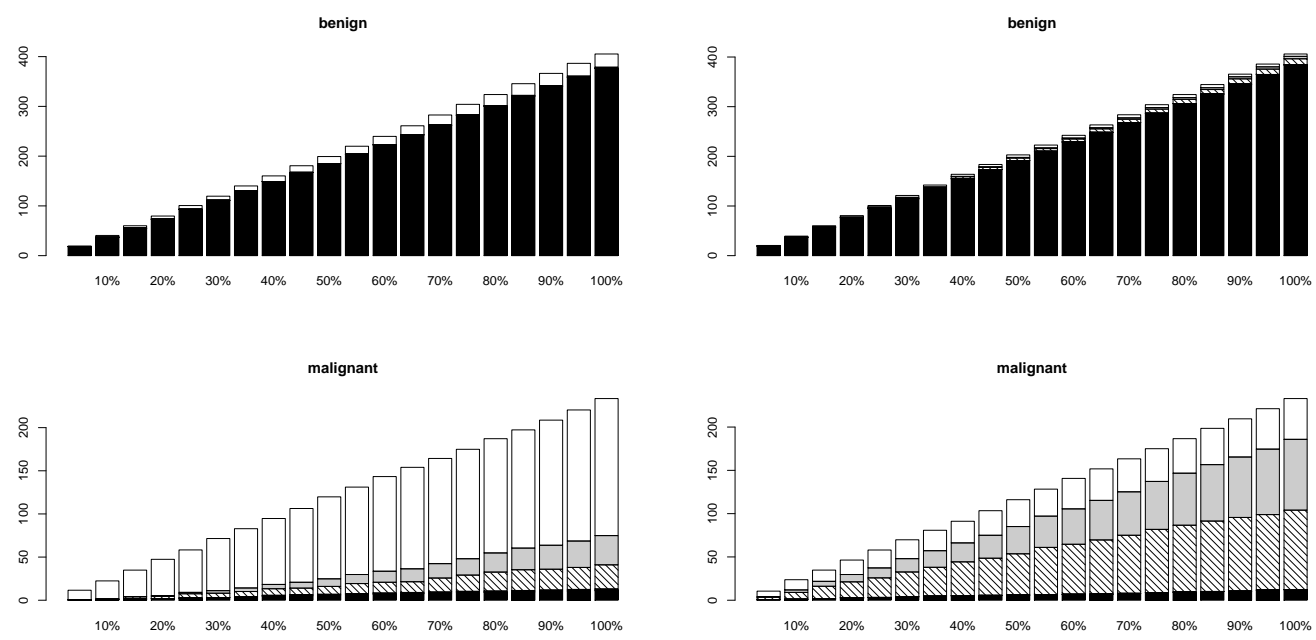

Figura 5.18: Influência da adaptação automática do parâmetro número de grupos.

\subsection{Considerações finais}

Com base na análise da evolução de uma série de métricas, a avaliação experimental de OLINDDA apresentada neste capítulo procurou ser abrangente e proporcionar uma visão clara dos pontos positivos e negativos de cada aspecto da abordagem proposta, considerando que ambos podem contribuir igualmente para o avanço das pesquisas na área.

O próximo capítulo resume as principais conclusões e contribuições deste trabalho, assim como as suas limitações e desafios futuros. 


\section{Capítulo 6}

\section{Conclusão}

Este capítulo sintetiza as principais conclusões, contribuições e limitações deste trabalho, e estabelece alguns dos pontos a serem estudados no futuro.

\subsection{Aspectos gerais da abordagem proposta}

A abordagem proposta neste trabalho, em que se destacam o uso da memória temporária de perfis desconhecidos, dos algoritmos de agrupamento e dos critérios de validação, é capaz de encontrar novos conceitos de maneira não-supervisionada em dados que podem assumir a forma de um fluxo contínuo.

Na maior parte das vezes, a composição dos conceitos descobertos apresenta alto grau de pureza em termos das classes reais do problema, demonstrando sua capacidade de descobrir conceitos cuja composição é semelhante à das classes.

A fusão de conceitos ao longo do tempo contribui para produzir um número menor de rótulos, ampliando a capacidade de descrevê-los mais detalhadamente por meio de um conjunto de hiperesferas.

A abordagem proposta neste trabalho, OLINDDA, mostrou-se robusta à presença de outliers entre os conceitos a serem descobertos, o que é uma característica importante dada a natureza não-supervisionada da fase de aprendizado contínuo. Sua sensibilidade a outliers no conjunto de dados inicial, que define o conceito normal, pode ser facilmente reduzida com o tratamento prévio destes exemplos.

Observou-se ainda, nos experimentos realizados, que a adaptação automática do número de grupos contribui para a geração de grupos que melhor atendam aos critérios de validação, a qualquer momento (Spinosa et al., 2007a).

Mesmo em problemas envolvendo uma grande quantidade de dados, OLINDDA foi capaz de manter o tempo médio de processamento por exemplo praticamente constante, confirmando a viabilidade de sua aplicação a FCD (Spinosa et al., 2008). 


\subsection{Contribuições}

As principais contribuições deste trabalho são:

- Propor uma nova abordagem para o problema da DN. Na literatura, a DN tem sido tratada muitas vezes como uma das abordagens para detecção de outliers, em que um novo exemplo que não seja identificado como membro de um conceito-alvo é simplesmente denominado novidade. Um dos principais objetivos deste trabalho foi o de tratar novidade como um novo conceito, isto é, uma abstração de instâncias ou exemplos que compartilham um conjunto de características e que realmente apresente-se como algo substancialmente novo. Para encontrar esses novos conceitos, foram usadas técnicas de agrupamento e critérios de validação associados a uma fase de $\mathrm{C} 1 \mathrm{C}$, em uma abordagem que pretende ser capaz de construir conhecimento relevante de maneira automática e não-supervisionada (Spinosa et al., 2008, 2007a c b d, 2006; Spinosa, 2005).

- Fortalecer a DN como parte de um processo de aprendizado contínuo. A visão do aprendizado como um processo contínuo que depende intrinsecamente da descoberta de algo novo orientou o desenvolvimento deste trabalho. Grande parte das técnicas de DN propostas na literatura não se preocupam com o aspecto temporal que, neste trabalho, é considerado fundamental para o tratamento do problema. Para isso, a abordagem proposta mantém modelos capazes de representar o conhecimento a qualquer momento, e beneficia-se dessa informação na análise de novos exemplos.

- Explorar a DN em FCD. Os desafios impostos por uma série de problemas reais demandam um novo paradigma em que uma grande quantidade de dados gerados continuamente passam a ser tratados sob a forma de um fluxo. A detecção de novos conceitos em FCD é um importante tópico de pesquisa nesse contexto. Acredita-se que este trabalho tenha contribuído para o avanço das pesquisas nessa área (Spinosa et al., 2008, 2007d, 2006).

- Propor uma metodologia e um conjunto de métricas para a avaliação de técnicas de DN. Para a análise do desempenho de OLINDDA em diversos conjuntos de dados artificiais e reais, foram propostos uma metodologia e um conjunto de métricas que procuram demonstrar como a abordagem se comporta sob diversos pontos de vista, em diferentes cenários. Como todas essas métricas são armazenadas ao longo do tempo, é possível avaliar detalhadamente a evolução do processo de aprendizado. Esse conjunto de metodologia e métricas pode ser utilizado para avaliar outras técnicas de DN, proporcionando uma análise bastante mais detalhada do que a normalmente encontrada na literatura. 
- Introduzir o uso de técnicas de DN em bioinformática. Estudos iniciais realizados neste doutoramento introduziram o uso de técnicas de DN em bioinformática, no problema da análise de expressão gênica, com o objetivo de detectar novos perfis de expressão cujas características possam estar relacionados a uma determinada manifestação fisiológica até então desconhecida. Mostrou-se que esse tipo de técnica pode contribuir para a identificação de perfis de expressão que apresentem características novas, e que a combinação de técnicas de DN produz um resultado mais robusto (Spinosa, 2005; Spinosa and de Carvalho, 2005ba, 2004).

\subsection{Limitações e trabalho futuro}

Algumas limitações são descritas a seguir, acompanhadas do trabalho futuro por elas motivado.

- Modelos baseados em hiperesferas. Mesmo considerando a fusão de conceitos, fronteiras de decisão hiperesféricas têm limitações, e podem não conseguir descrever adequadamente certas distribuições. Como a abordagem proposta independe da estrutura utilizada para descrever os dados, é possível incorporar outros tipos de modelos. A possibilidade de uso de outras técnicas de $\mathrm{C} 1 \mathrm{C}$ na fase de distinção entre o conceito normal e perfis desconhecidos, já incorporada a OLINDDA, permite que isso seja feito para o modelo normal. A alteração na estrutura dos demais modelos, considerando a possibilidade de atualizações incrementais, permitiria a utilização de outras técnicas em todo o processo, possivelmente melhorando os resultados nos casos em que o modelo baseado em hiperesferas falha. Vale notar, entretanto, que fronteiras de decisão mais complexas podem implicar um maior custo computacional, podendo eventualmente limitar sua aplicação em alguns casos.

- Transição de novidade para normal e eliminação de conceitos obsoletos. À medida que o tempo passa, conceitos que vão sendo descobertos como novidade podem tornar-se comuns ao ponto de que, talvez, devessem passar a integrar a definição do conceito normal. Uma outra possibilidade a ser considerada é a de conceitos que deixem de existir nos dados com o passar do tempo. Estratégias envolvendo os conceitos de utilidade e habituação, como as utilizadas em diversas ANN auto-organizáveis e construtivas, podem oferecer alternativas promissoras para promover avanços nesse sentido.

- Mudanças em conceitos (concept drift). A possibilidade de estender o conceito normal por meio do modelo extensão pretende tratar parcialmente eventuais mudanças ocorridas nas características do conceito normal. Essa é, entretanto, uma estratégia limitada para lidar com alguns tipos de mudanças em conceitos (concept 
drift), pois permite apenas atualizações incrementais. Faz parte do trabalho futuro estudar maneiras de identificar pequenas mudanças em todos os conceitos existentes, alterando suas descrições para refleti-las. Considerando, por exemplo, a posição dos exemplos explicados por um conceito, pode ser possível identificar que ele esteja movendo-se ( $d r i f t)$ em uma determinada direção, o que permitiria ao algoritmo fazer pequenas correções na posição das fronteiras de decisão desse conceito ao longo do tempo.

- Limiar do grau de coesão. OLINDDA estabelece que novos conceitos devem ser coesos e representativos. Os critérios de validação propostos mostraram-se adequados, ignorando grupos esparsos ou com poucos exemplos. Uma limitação da estratégia utilizada está no fato de que o limiar do grau de coesão é definido com base no modelo normal, sem que se possa garantir que o grau de coesão de um novo conceito será semelhante ou superior ao do conceito normal. Por outro lado, o uso de um limiar definido manualmente parece uma opção mais inadequada. Essa situação motiva o estudo tanto de formas alternativas para a escolha do limiar de coesão quanto de outros critérios de validação.

- Eliminação de exemplos antigos da memória temporária. A memória temporária de perfis desconhecidos apenas elimina exemplos à medida que sua capacidade tenha se esgotado. Pode ser interessante eliminar também exemplos que já estejam na memória há um determinado tempo, considerando que, dependendo da aplicação, as características por eles representadas podem não ser mais relevantes.

- Estabilidade do algoritmo k-médias. O algoritmo de agrupamento k-médias, opção padrão utilizada por OLINDDA, foi escolhido por apresentar como principais vantagens, além da simplicidade, a rápida convergência e o baixo custo computacional, fatores importantes nas aplicações envolvendo FCD. Como desvantagem, entretanto, está a dependência da qualidade dos centróides iniciais. Quando utilizado no contexto de OLINDDA, k-médias apresentou bons resultados, melhores inclusive do que os obtidos com os algoritmos PAM e CLARA. Não foram detectados efeitos negativos que indicassem algum tipo de instabilidade. É possível que o número de vezes em que grupos candidatos são gerados tenha suprido alguma instabilidade natural de k-médias, decorrente da escolha inicial dos centróides. Entretanto, dada a importância do tema (Ben-David et al., 2006; Kuncheva and Vetrov, 2006), considera-se como trabalho futuro um estudo mais profundo acerca da estabilidade do algoritmo k-médias no contexto de seu uso em OLINDDA.

O aprendizado contínuo não-supervisionado de novos conceitos apresenta uma série de desafios. Por outro lado, as aplicações envolvendo FCD impõem restrições adicionais. O problema da DN e o aprendizado em FCD possuem uma ligação estreita e pouco 
explorada. Neste trabalho apresentou-se uma nova abordagem para detecção de novos conceitos que pode ser aplicada a FCD. Ao enfrentar os diversos desafios relacionados com esse problema, espera-se ter produzindo resultados que contribuam para um melhor entendimento dos fatores envolvidos, conduzindo ao aprimoramento das técnicas de AM. 


\section{Referências bibliográficas}

Abeni, P., Baltatu, M., and D'Alessandro, R. (2006). User authentication based on face recognition with support vector machines. In Proceedings of the 3rd Canadian Conference on Computer and Robot Vision (CRV 2006), page 42. IEEE. (Citado na página 21.)

Alberts, B., Bray, D., Lewis, J., Raff, M., Roberts, K., and Watson, J. D. (1997). Biologia Molecular da Célula. Artmed, 3a edition. (Citado na página 12.)

Albrecht, S., Busch, J., Kloppenburg, M., Metze, F., and Tavan, P. (2000). Generalized radial basis function networks for classification and novelty detection: Self-organization of optimal bayesian decision. Neural Networks, 13(10):1075-1093. (Citado na página 17.)

Alizadeh, A. A., Eisen, M. B., Davisintegral, R. E., Maintegral, C., Lossos, I. S., Rosenwaldintegral, A., Boldrick, J. C., Sabetintegral, H., Tranintegral, T., Yuintegral, X., Powell, J. I., Yang, L., Marti, G. E., Moore, T., Jr, J. H., Lu, L., Lewis, D. B., Tibshirani, R., Sherlock, G., Chan, W. C., Greiner, T. C., Weisenburger, D. D., Armitage, J. O., Warnke, R., Levy, R., Wilson, W., Grever, M. R., Byrd, J. C., Botstein, D., Brown, P. O., and Staudt, L. M. (2000). Distinct types of diffuse large b-cell lymphoma identified by gene expression profiling. Nature, 403:503-511. (Citado nas páginas 30 e 33.)

Alon, U., Barkai, N., Notterman, D. A., Gish, K., Ybarra, S., Mack, D., and Levine, A. J. (1999). Broad patterns of gene expression revealed by clustering analysis of tumor and normal colon tissues probed by oligonucleotide arrays. Proceedings of National Academy of Sciences USA, 96:6745-6750. (Citado na página 33.)

Arthur, D. and Vassilvitskii, S. (2006). How slow is the k-means method? In Proceedings of the 22nd Annual ACM Symposium on Computational Geometry (SCG 2006), pages 144-153. ACM. (Citado na página 52 .)

Asuncion, A. and Newman, D. J. (2007). UCI machine learning repository. http://www. ics.uci.edu/ mlearn/MLRepository.html. (Citado na página 21.) 
Babcock, B., Babu, S., Datar, M., Motwani, R., and Widom, J. (2002). Models and issues in data stream systems. In Proceedings of the 21st ACM SIGMOD-SIGACTSIGART Symposium on Principles of Database Systems (PODS 2002), pages 1-16. ACM. (Citado na página 13.)

Baldi, P. and Brunak, S. (2001). Bioinformatics: the Machine Learning approach. MIT Press, 2nd edition. (Citado na página 11.)

Barnett, V. and Lewis, T. (1995). Outliers in Statistical Data. John Wiley \& Sons, 3rd edition. (Citado na página 10 .)

Beatty, P. C. W., Hoare, S. W., and Asbridge, D. (2000). A real-time novelty detector for artefact identification in physiological measurements. In Proceedings of the Annual International Conference of the IEEE Engineering in Medicine and Biology, volume 1, pages 616-618. (Citado na página 22.)

Ben-David, S., Luxburg, U., and Pál, D. (2006). A sober look at clustering stability. In 19th Annual Conference on Learning Theory (COLT 2006), Lecture Notes in Computer Science, volume 4005, pages 5-19. (Citado na página 96.)

Ben-Hur, A., Horn, D., Siegelmann, H. T., and Vapnik, V. (2001). Support vector clustering. Journal of Machine Learning Research, 2:125-137. (Citado na página 22.)

Bennett, K. P. and Campbell, C. (2000). Support vector machines: Hype or hallelujah? SIGKDD Explorations, 2(2):1-13. (Citado na página 20.)

Brenner, S., Johnson, M., Bridgham, J., Golda, G., Lloyd, D. H., Johnson, D., Luo, S., McCurdy, S., Foy, M., Ewan, M., Roth, R., George, D., Eletr, S., Albrecht, G., Vermaas, E., Williams, S. R., Moon, K., Burcham, T., Pallas, M., DuBridge, R. B., Kirchner, J., Fearon, K., Mao, J., and Corcoran, K. (2000). Gene expression analysis by massively parallel signature sequencing (MPSS) on microbead arrays. Nature Biotechnology, 18(6):630-634. (Citado na página 12.)

Brotherton, T. and Johnson, T. (2001). Anomaly detection for advanced military aircraft using neural networks. In Proceedings of the IEEE Aerospace Conference, volume 6, pages 3113-3123. (Citado na página 17.)

Brotherton, T., Johnson, T., and Chadderdon, G. (1998). Classification and novelty detection using linear models and a class dependent - elliptical basis function neural network. In Proceedings of the IEEE International Conference on Neural Networks, volume 2, pages 876-879. (Citado na página 17.)

Brown, M. P. S., Grundy, W. N., Lin, D., Cristianini, N., Sugnet, C., Furey, T. S., Ares Jr., M., and Haussler, D. (2000). Knowledge-based analysis of microarray gene 
expression data using support vector machines. Proceedings of National Academy of Sciences USA, 97(1):262-267. (Citado na página 12.)

Bruske, J. and Sommer, G. (1995). Dynamic cell structures. In Advances in Neural Information Processing Systems, volume 7, pages 497-504. (Citado na página 18.)

Campbell, C. and Bennett, K. P. (2001). A linear programming approach to novelty detection. In Neural Information Processing Systems, volume 14, pages 395-401. MIT Press. (Citado nas páginas 21 e 22.)

Casimir, R., Boutleux, E., Clerc, G., and Yahoui, A. (2006). The use of features selection and nearest neighbors rule for faults diagnostic in induction motors. Engineering Applications of Artificial Intelligence, 19:169-177. (Citado na página 16.)

Castaño, R., Judd, M., Estlin, T., Anderson, R. C., Scharenbroich, L., Song, L., Gaines, D., Fisher, F., Mazzoni, D., and Castaño, A. (2004). Autonomous onboard traverse science system. In 2004 IEEE Aerospace Conference, volume 1, pages 159-167. (Citado na página 22.)

Chang, C. and Lin, C. (2004). LIBSVM: a Library for Support Vector Machines. National Taiwan University, Department of Computer Science and Information Engineering. (Citado na página 30.)

Clifton, D. A., Bannister, P. R., and Tarassenko, L. (2006). Learning shape for jet engine novelty detection. In International Symposium on Neural Networks (ISSN 2006), Lecture Notes in Computer Science, volume 3973, pages 828-835. (Citado na página 22.)

Cover, T. M. and Hart, P. E. (1967). Nearest neighbor pattern classification. IEEE Transactions on Information Theory, 13(1):21-27. (Citado na página 15.)

Dasgupta, D. and Forrest, S. (1996). Novelty detection in time series data using ideas from immunology. In Proceedings of the $5^{\text {th }}$ International Conference on Intelligent Systems (IS 1996). (Citado na página 24.)

Davy, M. and Godsill, S. (2002). Detection of abrupt spectral changes using support vector machines. an application to audio signal segmentation. In Proceedings of the International Conference on Acoustics, Speech and Signal Processing, volume 2, pages 1313-1316. (Citado na página 22.)

Davy, M., Gretton, A., Doucet, A., and Rayner, P. J. W. (2002). Optimised support vector machines for nonstationary signal classification. IEEE Signal Processing Letters, 9(12):442-445. (Citado nas páginas 21 e 22.) 
Desobry, F. and Davy, M. (2003). Support vector-based online detection of abrupt changes. In Proceedings of the International Conference on Acoustics, Speech and Signal Processing, volume 4, pages 872-875. (Citado nas páginas 21 e22.)

Diehl, C. P. and Hampshire II, J. B. (2002). Real-time object classification and novelty detection for collaborative video surveillance. In Proceedings of the International Joint Conference on Neural Networks, volume 3, pages 2620-2625. (Citado na página 22.)

Drake, J. M., Randin, C., and Guisan, A. (2006). Modelling ecological niches with support vector machines. Journal of Applied Ecology, 43:424-432. (Citado na página 21.)

Duda, R. O. and Hart, P. E. (2001). Pattern Classification. Wiley Interscience, 2nd edition. (Citado nas páginas 15,17 e 52 .)

Elkan, C. (2000). Results of the KDD'99 classifier learning. ACM SIGKDD Explorations, 1(2):63-64. (Citado nas páginas 55, 62 e 70.)

Fan, W., Huang, Y., Wang, H., and Yu, P. S. (2004). Active mining of data streams. In Proceedings of the 2004 SIAM International Conference on Data Mining (SDM 2004). (Citado na página 25.)

Fawcett, T. (2006). An introduction to roc analysis. Pattern Recognition Letters, 27:861874. (Citado na página 59.)

Fisher, D. H. (1987). Knowledge acquisition via incremental conceptual clustering. Machine Learning, 2(2):139-172. (Citado na página 26.)

Freeman, W. M., Walker, S. J., and Vrana, K. E. (1999). Quantitative RT-PCR: pitfalls and pontential. Biotechniques, 26:112-122. (Citado na página 12.)

Fritzke, B. (1994). Growing cell structures - a self-organizing network for unsupervised and supervised learning. Neural Networks, 7:1441-1460. (Citado na página 18.)

Fritzke, B. (1995). A growing neural gas network learns topologies. In Advances in Neural Information Processing Systems, volume 7, pages 625-632. (Citado na página 18.)

Fritzke, B. (1997). A self-organizing network that can follow non-stationary distributions. In Proceedings of the International Conference on Artificial Neural Networks, pages 613-618. (Citado na página 18.)

Furey, T. S., Christianini, N., Duffy, N., Bednarski, D. W., Schummer, M., and Hauessler, D. (2000). Support vector machine classification and validation of cancer tissue samples using microarray expression data. Bioinformatics, 16(10):906-914. (Citado na página 12.) 
Gama, J. and Gaber, M. M. (2007). Learning from Data Streams: Processing Techniques in Sensor Networks. Springer. (Citado na página 3.)

Gazen, C., Carbonell, J., and Hayes, P. (2005). Novelty detection in data streams: A small step towards anticipating strategic surprise. In Novel Intelligence from Massive Data (NIMD) PI Meeting. (Citado na página 25.)

Golub, T. R., Slonim, D. K., Tamayo, P., Huard, C., Gaasenbeek, M., Mesirov, J. P., Coller, H., Loh, M., Downing, J. R., Caligiuri, M. A., Bloomfield, C. D., and Lander, E. S. (1999). Molecular classification of cancer: Class discovery and class prediction by gene expression. Science, 286:531-537. (Citado nas páginas 30 e 33.)

Guha, S., Rastogi, R., and Shim, K. (1998). Cure: an efficient clustering algorithm for large databases. In Proceedings of the 1998 ACM SIGMOD International Conference on Management of Data (SIGMOD 1998), pages 73-84. ACM. (Citado na página 26.)

Harrington, C. A., Rosenow, C., and Retief, J. (2000). Monitoring gene expression using DNA microarrays. Current Opinion in Microbiology, 3:285-291. (Citado na página 12.)

Haykin, S. (1998). Neural Networks: A Comprehensive Foundation. Prentice Hall, 2nd edition. (Citado na página 16.)

Hayton, P., Schölkopf, B., Tarassenko, L., and Anuzis, P. (2000). Support vector novelty detection applied to jet engine vibration spectra. In Advances in Neural Information Processing Systems, volume 13, pages 946-952. MIT Press. (Citado na página 21.)

Hebb, D. O. (1949). The organization of behavior. Wiley. (Citado na página 19.)

Hoare, S. W., Asbridge, D., and Beatty, P. C. W. (2002). On-line novelty detection for artefact identification in automatic anaesthesia record keeping. Medical Engineering \& Physics, 24:673-681. (Citado na página 22.)

Hodge, V. J. and Austin, J. (2004). A survey of outlier detection methodologies. Artificial Intelligence Review, 22:85-126. (Citado na página 10.)

Hoffmann, H. (2007). Kernel pca for novelty detection. Pattern Recognition, 40:863-874. (Citado na página 57.)

Jain, A. K., Murty, M. N., and Flynn, P. J. (1999). Data clustering: a review. ACM Computing Surveys, 31(3):264-323. (Citado nas páginas 26 e 50.)

Jakubek, S. and Strasser, T. (2002). Fault-diagnosis using neural networks with ellipsoidal basis function. In Proceedings of the American Control Conference, volume 5, pages 3846-3851. (Citado na página 17.) 
Jia, H., Murphey, Y. L., Gutchess, D., and Chang, T. S. (2005). Identifying knowledge domain and incremental new class learning in svm. In Perceedings of the 2005 IEEE International Joint Conference on Neural Networks (IJCNN 2005), volume 5, pages 2742-2747. IEEE. (Citado na página 21.)

Kaufman, L. and Rousseeuw, P. J. (1990). Finding Groups in Data: An Introduction to Cluster Analysis. Wiley-Interscience. (Citado nas páginas 27 e 45.)

Keogh, E., Lonardi, S., and Chiu, B. Y. (2002). Finding surprising patterns in a time series database in linear time and space. In Proceedings of the $8^{\text {th }} A C M$ SIGKDD International Conference on Knowledge Discovery and Data Mining (KDD 2002), pages 550-556. (Citado na página 24.)

Khan, J., Wei, J. S., Ringnér, M., Saal, L. H., Ladanyi, M., Westermann, F., Berthold, F., Schwab, M., Antonescu, C. R., Peterson, C., and Meltzer, P. S. (2001). Classification and diagnostic prediction of cancers using gene expression profiling and artificial neural networks. Nature Medicine, 7(6):673-679. (Citado na página 12,)

Klinkenberg, R. (2004). Learning drifting concepts: Example selection vs. example weighting. Intelligent Data Analysis, Special Issue on Incremental Learning Systems Capable of Dealing with Concept Drift, 8(3):281-300. (Citado nas páginas 8 e 20.)

Kohonen, T. (2001). Self-Organizing Maps. Springer, 3rd edition. (Citado na página 18.)

Kuncheva, L. I. and Vetrov, D. P. (2006). Evaluation of stability of k-means cluster ensembles with respect to random initialization. Transactions on Pattern Analysis and Machine Intelligence, 28(11):1798-1808. (Citado na página 96.)

Landgrebe, T. C. W., Tax, D. M. J., Paclík, P., and Duin, R. P. W. (2006). The interaction between classification and reject performance for distance-based reject-option classifiers. Pattern Recognition Letters, 27:908-917. (Citado na página 8.)

Lee, K., Kim, D., Lee, K. H., and Lee, D. (2007). Density-induced support vector data description. IEEE Transactions on Neural Networks, 18(1):284-289. (Citado na página 21.)

Li, M., Holmes, G., and Pfahringer, B. (2004). Clustering large datasets using cobweb and k-means in tandem. In Proceedings of the 17th Australian Joint Conference on Artificial Intelligence (AI 2004), Lecture Notes in Computer Science, volume 3339, pages 368-379. Springer. (Citado na página 26.)

Li, Y., Pont, M. J., and Jones, N. B. (2002). Improving the performance of the radial basis function classifiers in condition monitoring and fault diagnosis applications where 
"unknown" faults may occur. Pattern Recognition Letters, 23:569-577. (Citado na página 17.)

Lin, J., Keogh, E., and Lonardi, S. (2004). Visualizing and discovering non-trivial patterns in large time series databases. Information Visualization, 4(2):61-82. (Citado na página 24.)

Lin, J., Keogh, E., Lonardi, S., and Chiu, B. (2003). A symbolic representation of time series, with implications for streaming algorithms. In Proceedings of the $8^{\text {th }} A C M S I G$ MOD Workshop on Research Issues in Data Mining and Knowledge Discovery (DMKD 2003), pages 2-11. (Citado na página 24.)

Manevitz, L. M. and Yousef, M. (2001). One-class SVMs for document classification. Journal of Machine Learning Research, 2:139-154. (Citado nas páginas 21 e 22.)

Markou, M. and Singh, S. (2003a). Novelty detection: a review - part 1: statistical approaches. Signal Processing, 83:2481-2497. (Citado nas páginas 7 e 14.)

Markou, M. and Singh, S. (2003b). Novelty detection: a review - part 2: neural network based approaches. Signal Processing, 83:2499-2521. (Citado nas páginas 7, 14 e 16.)

Marsland, S. (2001). On-line Novelty Detection through Self-Organisation, with Applications to Inspection Robotics. PhD thesis, The University of Manchester, Department of Computer Science. (Citado na página 19.)

Marsland, S. (2003). Novelty detection in learning systems. Neural Computing Surveys, 3:157-195. (Citado nas páginas 9 e 10.)

Marsland, S., Shapiro, J., and Nehmzow, U. (2002). A self-organising network that grows when required. Neural Networks, 15:1041-1058. (Citado nas páginas 19 e 20.)

McCulloch, W. S. and Pitts, W. (1943). A logical calculus of ideas immanent in nervous activity. Bulletin of Mathematical Biophysics, 5:115-133. (Citado na página 16.)

Meidanis, J. and Setúbal, J. C. (1994). Uma Introdução à Biologia Computacional. Universidade Federal de Pernambuco (UFPE), IX Escola de Computação. (Citado na página 11.)

Michalski, R. S., Carbonell, J. G., and Mitchell, T. M. (1986). Machine Learning: An Artificial Intelligence Approach, Volume II. Morgan Kaufmann. (Citado nas páginas 1 e 44.)

Munroe, D. T. and Madden, M. G. (2005). Multi-class and single-class classification approaches to vehicle model recognition from images. In Proceedings of the 16th Irish 
conference on Artificial Intelligence and Cognitive Science (AICS 2005), pages 93-102. (Citado na página 16.)

Ng, R. T. and Han, J. (2002). Clarans: a method for clustering objects for spatial data mining. IEEE Transactions on Knowledge and Data Engineering, 14(5):1003-1016. (Citado na página 27.)

Parzen, E. (1962). On the estimation of a probability density function and mode. Annals of Mathematical Statistics, 33:1065-1076. (Citado na página 15.)

Pietraszek, T. (2007). On the use of roc analysis for the optimization of abstaining classifiers. Machine Learning, 68(2):137-169. (Citado na página 8.)

Roberts, S. J. and Penny, W. (1996). Novelty, confidence and errors in connectionist systems. In Proceedings of the IEE Colloquium on Intelligent Sensors and Fault Detection, volume 1996/261. (Citado na página 16.)

Rätsch, G., Mika, S., Schölkopf, B., and Müller, K. R. (2002). Constructing boosting algorithms from SVMs: an application to one-class classification. IEEE Transactions on Pattern Analysis and Machine Intelligence, 24(9):1184-1199. (Citado na página 21.)

Salvador, S. and Chan, P. (2004). Determining the number of clusters/segments in hierarchical clustering/segmentation algorithms. In 16th IEEE International Conference on Tools with Artificial Intelligence (ICTAI 2004), pages 576-584. (Citado na página 26.)

Salvador, S. and Chan, P. (2005). Learning states and rules for detecting anomalies in time series. Applied Intelligence, 23(3):241-255. (Citado na página 26.)

Sanchez-Hernandez, C., Boyd, D. S., and Foody, G. M. (2007). Mapping specific habitats from remotely sensed imagery: Support vector machine and support vector data description based classification of coastal saltmarsh habitats. Ecological Informatics, 2:83-88. (Citado na página 21.)

Schölkopf, B., Platt, J. C., Shawe-Taylor, J., Smola, A. J., and Williamson, R. C. (1999). Estimating the support of a high-dimensional distribution. Technical Report 87, Microsoft Research. (Citado nas páginas 21 e 29.)

Schölkopf, B., Platt, J. C., Shawe-Taylor, J., Smola, A. J., and Williamson, R. C. (2001). Estimating the support of a high-dimensional distribution. Neural Computation, 13(7):1443-1471. (Citado na página 21.)

Schölkopf, B., Smola, A. J., Williamson, R. C., and Bartlett, P. L. (2000). New support vector algorithms. Neural Computation, 12(5):1207-1245. (Citado na página 21.) 
Shahabi, C., Tian, X., and Zhao, W. (2000). Tsa-tree: a wavelet-based approach to improve the efficiency of multi-level surprise and trend queries on time-series data. In Proceedings of the $12^{\text {th }}$ International Conference on Scientific and Statistical Database Management (SSDBM 2000), pages 55-68. (Citado na página 24.)

Shipp, M. A., Ross, K. N., Tamayo, P., Weng, A. P., Kutok, J. L., Aguiar, R. C. T., Gaasenbeek, M., Angelo, M., Reich, M., Pinkus, G. S., Ray, T. S., Koval, M. A., Last, K. W., Norton, A., Lister, T. A., Mesirov, J., Neuberg, D. S., Lander, E. S., Aster, J. C., and Golub, T. R. (2002). Diffuse large B-cell lymphoma outcome prediction by gene-expression profiling and supervised machine learning. Nature Medicine, 8(1):6874. (Citado na página 12.)

Souza, B. F. (2005). Seleção de características em SVMs aplicadas a dados de expressão gênica. Master's thesis, Universidade de São Paulo (USP), Instituto de Ciências Matemáticas e de Computação (ICMC). (Citado na página 35.)

Spinosa, E. J. (2005). Detecção de novidade em bioinformática. Monografia do exame de qualificação de doutoramento, Universidade de São Paulo (USP), Instituto de Ciências Matemáticas e de Computação (ICMC). (Citado nas páginas 53,94 e 95.)

Spinosa, E. J. and de Carvalho, A. C. P. L. F. (2004). SVMs for novel class detection in bioinformatics. In III Brazilian Workshop on Bioinformatics (WOB 2004). SBC. 8 pages. (Citado nas páginas 32 e 95 .)

Spinosa, E. J. and de Carvalho, A. C. P. L. F. (2005a). Combining one-class classifiers for robust novelty detection in gene expression data. In IV Brazilian Symposium on Bioinformatics (BSB 2005), Lecture Notes in Computer Science, volume 3594, pages 54-64. Springer-Verlag. (Citado nas páginas 41 e 95.)

Spinosa, E. J. and de Carvalho, A. C. P. L. F. (2005b). Support vector machines for novel class detection in bioinformatics. Genetics and Molecular Research, 4(3):608615. (Citado nas páginas 32 e 95.)

Spinosa, E. J., de Carvalho, A. P. L. F., and Gama, J. (2006). An online learning technique for coping with novelty detection and concept drift in data streams. In $3^{\text {rd }}$ International Workshop on Knowledge Discovery from Data Streams (IWKDDS 2006), during the 23 $3^{\text {rd }}$ International Conference on Machine Learning (ICML 2006). 10 pages. (Citado nas páginas 53 e 94 .)

Spinosa, E. J., de Carvalho, A. P. L. F., and Gama, J. (2007a). Cluster-based novelty detection with dynamic adaptation of the number of clusters. In $13^{\text {th }}$ Portuguese Conference on Artificial Intelligence (EPIA 2007). (Citado nas páginas 51, 53, 91, 93, e 94.) 
Spinosa, E. J., de Carvalho, A. P. L. F., and Gama, J. (2007b). Detecção de novidade com o algoritmo de agrupamento k-médias. In XIV Jornadas de Classificação e Análise de Dados (JOCLAD 2007), pages 83-87. ISEP. (Citado nas páginas 53 e 94.)

Spinosa, E. J., de Carvalho, A. P. L. F., and Gama, J. (2007c). Learning novel concepts: beyond one-class classification with OLINDDA. In International Workshop on Knowledge Discovery from Ubiquitous Data Streams (IWKDUDS 2007), during the $18^{\text {th }}$ European Conference on Machine Learning (ECML 2007) and the $11^{\text {th }}$ European Conference on Principles and Practice of Knowledge Discovery in Databases (PKDD 2007). 12 pages. (Citado nas páginas 53 e 94.)

Spinosa, E. J., de Carvalho, A. P. L. F., and Gama, J. (2007d). OLINDDA: A clusterbased approach for detecting novelty and concept drift in data streams. In $22^{\text {nd }}$ Annual ACM Symposium on Applied Computing (SAC 2007), pages 448-452. ACM. (Citado nas páginas 53 e 94 .)

Spinosa, E. J., de Carvalho, A. P. L. F., and Gama, J. (2008). Cluster-based novel concept detection in data streams applied to intrusion detection in computer networks. In $23^{\text {rd }}$ Annual ACM Symposium on Applied Computing (SAC 2008), volume 2, pages 976-980. ACM. (Citado nas páginas 70, 93 e 94.)

StatLib (2007). Statlib datasets archive. http://lib.stat.cmu.edu/datasets/. (Não citado no texto.)

Stibor, T., Timmis, J., and Eckert, C. (2006). On the use of hyperspheres in artificial immune systems as antibody recognition regions. In 5th International Conference on Artificial Immune Systems (ICARIS 2006), Lecture Notes in Computer Science, volume 4163, pages 215-228. (Citado nas páginas 48, 89 e 91.)

Tarassenko, L., Hayton, P., Cerneaz, N., and Brady, M. (1995). Novelty detection for the identification of masses in mammograms. In Proceedings of the $4^{\text {th }}$ IEE International Conference on Artificial Neural Networks, volume 4, pages 442-447. (Citado na página 15.)

Tarassenko, L., Nairac, A., Townsend, N., and Cowley, P. (1999). Novelty detection in jet engines. In IEE Colloquium on Condition Monitoring, pages 4/1-4/5. (Citado na página 22.)

Tavakkoli, A., Nicolescu, M., and Bebis, G. (2006). A novelty detection approach for foreground region detection in videos with quasi-stationary backgrounds. In Perceedings of the 2nd International Symposium (ISVC 2006), Lecture Notes in Computer Science, volume 4291, pages 40-49. (Citado na página 21.) 
Tax, D. M. J. (2001). One-class classification - Concept-learning in the absence of counterexamples. PhD thesis, Delf University of Technology, Faculty of Information Technology and Systems. (Citado nas páginas 9, 21, 22, 64, e 76.)

Tax, D. M. J. (2005). DDtools, the data description toolbox for matlab. http://www-ict.ewi.tudelft.nl/ davidt/ dd_tools.html. version 1.1.2. (Citado nas páginas $33 \mathrm{e} 64$.)

Tax, D. M. J. and Duin, R. P. W. (1999a). Data domain description using support vectors. In Proceedings of the European Symposium on Artificial Neural Networks, pages 251257. (Citado na página 21.)

Tax, D. M. J. and Duin, R. P. W. (1999b). Support vector domain description. Pattern Recognition Letters, 20:1191-1199. (Citado na página 21.)

Tax, D. M. J. and Duin, R. P. W. (2002). Uniform object generation for optimizing oneclass classifiers. Journal of Machine Learning Research, 2:155-173. (Citado na página 21.)

Tax, D. M. J., Juszczak, P., Pekalska, E., and Duin, R. P. W. (2006). Outlier detection using ball descriptions with adjustable metric. In Joint IAPR International Workshops on Structural and Syntactic Pattern Recognition (SSPR 2006) and Statistical Techniques in Pattern Recognition (SPR 2006), Lecture Notes in Computer Science, volume 4109, pages 587-595. (Citado na página 22.)

Thompson, R. F. and Spencer, W. A. (1966). Habituation: A model phenomenon for the study of neuronal substrates of behaviour. Psychological Review, 73:16-43. (Citado na página 10.)

Tsymbal, A. (2004). The problem of concept drift: definitions and related work. Technical Report TCD-CS-2004-15, The University of Dublin, Trinity College, Department of Computer Science. (Citado na página 10.)

Valiant, L. G. (1984). A theory of the learnable. Communications of the ACM, 27(11):1134-1142. (Citado na página 9.)

Vapnik, V. N. (1995). The Nature of Statistical Learning Theory. Springer-Verlag. (Citado na página 20.)

Vasconcelos, G. C., Fairhust, M. C., and Bisset, D. L. (1995). Investigating feedforward neural networks with respect to the rejection of spurious patterns. Pattern Recognition Letters, 16:207-212. (Citado na página 16.)

Velculescu, V. E., Ahang, L., Vogelstein, B., and Kinzler, K. W. (1995). Serial analysis of gene expression. Science, 270:484-487. (Citado na página 12,) 
Vlachos, M., Wu, K., Chen, S., and Yu, P. S. (2005). Fast burst correlation of financial data. In $9^{\text {th }}$ European Conference on Principles and Practice of Knowledge Discovery in Databases (PKDD 2005), Lecture Notes in Computer Science, volume 3721, pages 368-379. (Citado na página 23.)

Vlassis, N. A., Dimopoulos, A., and Papakonstantinou, G. K. (1997). The probabilistic growing cell structures algorithm. In Proceedings of the International Conference on Artificial Neural Networks, pages 649-654. (Citado na página 18.)

Wang, D., Yeung, D. S., and Tsang, E. C. C. (2006). Structured one-class classification. IEEE Transactions on Systems, Man, and Cybernetics, Part B, 36(6):1283-1295. (Citado na página 21.)

Wang, Q. H., Lopes, L. S., and Tax, D. M. J. (2004). Visual object recognition through one-class learning. In Proceedings of the International Conference on Image Analysis and Recognition (ICIAR 2004), Lecture Notes in Computer Science, volume 3211, pages 463-470. (Citado na página 21.)

West, M., Blanchette, C., Dressman, H., Huang, E., Ishida, S., Spang, R., Zuzan, H., Jr., J. A. O., Marks, J. R., and Nevins, J. R. (2001). Predicting the clinical status of human breast cancer by using gene expression profiles. Proceedings of National Academy of Sciences USA, 98(20):11462-11467. (Citado na página 33.)

Wu, K., Chen, S., and Yu, P. S. (2004). Interval query indexing for efficient stream processing. In Proceedings of the $13^{\text {th }}$ ACM International Conference on Information and Knowledge Management, pages 88-97. (Citado na página 23.)

Xu, Y., Selaru, F. M., Yin, J., Zou, T. T., Shustova, V., Mori, Y., Sato, F., Liu, T. C., Olaru, A., Wang, S., Kimos, M. C., Perry, K., Desai, K., Greenwald, B. D., Krasna, M. J., Shibata, D., Abraham, J. M., and Meltzer, S. J. (2002). Artificial neural networks and gene filtering distinguish between global gene expression profiles of barrett's esophagus and esophageal cancer. Cancer Research, 62(12):3493-3497. (Citado na página 12.)

Yang, Y., Pierce, T., and Carbonell, J. G. (1998). A study of retrospective and on-line event detection. In 21 ${ }^{\text {st }}$ Annual International ACM SIGIR Conference on Research and Development in Information Retrieval (SIGIR 1998), pages 28-36. (Citado na página 26.)

Yang, Y., Zhang, J., Carbonell, J., and Jin, C. (2002). Topic-conditioned novelty detection. In Proceedings of the $8^{\text {th }}$ International Conference on Knowledge Discovery and Data Mining, pages 688-693. (Citado na página 23.) 
Yeung, D. and Chow, C. (2002). Parzen-window network intrusion detectors. In Proceedings of the $16^{\text {th }}$ International Conference on Pattern Recognition, volume 4, pages 385-388. (Citado na página 15.)

Zeng, Z., Fu, Y., Roisman, G. I., Wen, Z., Hu, Y., and Huang, T. S. (2006). Oneclass classification for spontaneous facial expression analysis. In Proceedings of the 7th International Conference on Automatic Face and Gesture Recognition (FGR 2006), pages 281-286. IEEE. (Citado na página 21.)

Zhang, T., Ramakrishnan, R., and Livny, M. (1997). Birch: A new data clustering algorithm and its applications. Data Mining and Knowledge Discovery, 1(2):141-182. (Citado na página 26.)

Zhao, Y. G., Wang, S. P., Liu, Y. G., and He, Q. M. (2006). An on-line learning approach with support vector dormain classifier. In Proceedings of the 5th International Conference on Machine Learning and Cybernetics (ICMLC 2006), pages 3600-3604. IEEE. (Citado na página 21.) 